\title{
Low Energy Carbon Capture via Electrochemically Induced pH Swing with Electrochemical Rebalancing
}

\author{
Shijian Jin ${ }^{\dagger}$, Min Wu $\mathrm{W}^{\dagger}$, Yan Jing ${ }^{\ddagger}$, Roy G. Gordon* and Michael J. Aziz ${ }^{\dagger *}$ \\ $\dagger$ John A. Paulson School of Engineering and Applied Sciences, Harvard University, Cambridge, \\ Massachusetts, 02138, United States \\ Department of Chemistry and Chemical Biology, Harvard University, Cambridge, \\ Massachusetts 02138, United States \\ *maziz [at] harvard [dot] edu
}

\begin{abstract}
We demonstrate a carbon capture system based on $\mathrm{pH}$ swing cycles driven through proton-coupled electron transfer of sodium (3,3'-(phenazine-2,3-diylbis(oxy))bis(propane-1-sulfonate)) (DSPZ) molecules. Electrochemical reduction of DSPZ causes an increase of hydroxide concentration, which absorbs $\mathrm{CO}_{2}$; subsequent electrochemical oxidation of the reduced DSPZ consumes the hydroxide, causing $\mathrm{CO}_{2}$ outgassing. The measured electrical work of separating $\mathrm{CO}_{2}$ from a binary mixture with $\mathrm{N}_{2}$, at $\mathrm{CO}_{2}$ inlet partial pressures ranging from 0.1 to 0.5 bar, and releasing to a pure $\mathrm{CO}_{2}$ exit stream at $1.0 \mathrm{bar}$, was measured for electrical current densities of 20 to $150 \mathrm{~mA} \mathrm{~cm}$. The work for separating $\mathrm{CO}_{2}$ from a 0.1 bar inlet and concentrating into 1 bar exit is $61.3 \mathrm{~kJ}$

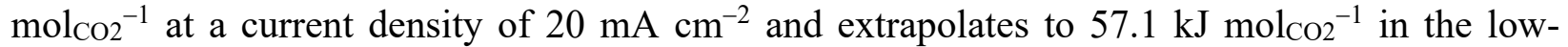
current-density limit. At this limit, the cycle work for capture from 0.4 mbar extrapolates to $108-212 \mathrm{~kJ} \mathrm{~mol}_{\mathrm{CO}_{2}}{ }^{-1}$ depending on the initial composition of the electrolyte. We also introduce an electrochemical rebalancing method that extends cell lifetime by recovering the initial electrolyte composition after it is perturbed by side reactions. We discuss the implications of these results for future low-energy electrochemical carbon capture devices.
\end{abstract}

\section{Introduction}

Accumulating $\mathrm{CO}_{2}$ emissions from anthropogenic activities constitute the major cause of global climate change. ${ }^{1,2}$ While efforts are being made in switching from fossil fuel-based energy to virtually emissions-free sources such as nuclear, solar, wind and geothermal, fossil fuel combustion will remain an important component of the world economy for a long time. ${ }^{3}$ Consequently, carbon removal - whether captured from a point source ${ }^{2,4-8}$ such as a combustion power plant or directly from the air (a.k.a. direct air capture, DAC) or the ocean ${ }^{2,9-13}$ - in order to reduce atmospheric $\mathrm{CO}_{2}$ concentrations, is gaining increasing attention.

Numerous methods for point source capture and DAC have been developed. Among the most studied is wet amine scrubbing for point source capture ${ }^{4-6}$ and strongly alkaline $(\mathrm{pH}>14)$ solution for $\mathrm{DAC}, 2,9$ both of which rely on a large temperature-swing cycle to regenerate sorbents. Although sorbent composition has been optimized to lower the energy cost for both strategies, the thermal energy requirement for heating is still $\sim 100 \mathrm{~kJ} \mathrm{~mol}_{\mathrm{CO}_{2}}{ }^{-1}$ for point source capture ${ }^{6,14,15}$ 
and $>150 \mathrm{~kJ}{\text { mol } \mathrm{CO}_{2}}^{-1}$ for DAC. ${ }^{10,16}$ In addition, sorbent volatility, toxicity and corrosivity cause 48 environmental concerns. ${ }^{2}$ Methods that remove $\mathrm{CO}_{2}$ from the ocean, which allow it to absorb more $\mathrm{CO}_{2}$, have also been studied, but the high water-handling requirement is a challenge. ${ }^{12,13}$

Electrochemically mediated separation technologies constitute an increasingly attractive alternative to traditional temperature-swing or pressure-swing methods because of the rapidly decreasing cost of intermittent renewable electricity and the mild operating conditions of ambient temperature and pressure. ${ }^{7,8,13,17-20}$ However, most existing methods operate at low current density $\left(<5 \mathrm{~mA} \mathrm{~cm}{ }^{-2}\right)$ because of large overpotentials and the corresponding energetic cost at higher current density, implying a high capital cost of electrochemical hardware. Recently, our group proposed and demonstrated a $\mathrm{pH}$ swing cycle for $\mathrm{CO}_{2}$ separation electrochemically driven through proton-coupled electron transfer (PCET) of redox active organic molecules ("Q"). ${ }^{18} \mathrm{In}$ this scheme, proton-coupled electrochemical reduction of these molecules $\left(\mathrm{Q}+2 \mathrm{H}_{2} \mathrm{O}+2 \mathrm{e}^{-} \rightarrow \mathrm{QH}_{2}+2 \mathrm{OH}^{-}\right)$ raises the electrolyte $\mathrm{pH}$ and total alkalinity (TA), leading to $\mathrm{CO}_{2}$ capture from point source or air and conversion to dissolved inorganic carbon (DIC); subsequent electrochemical oxidation of the reduced molecules $\left(\mathrm{QH}_{2}+2 \mathrm{OH}^{-} \rightarrow \mathrm{Q}+2 \mathrm{H}_{2} \mathrm{O}+2 \mathrm{e}^{-}\right)$acidifies the electrolyte and lowers TA, resulting in the conversion of DIC to $\mathrm{CO}_{2}$ gas and its release.

Here, we report a proof-of-concept point source $(10 \%) \mathrm{CO}_{2}$ separation system that uses a sodium (3,3'-(phenazine-2,3-diylbis(oxy))bis(propane-1-sulfonate)), i.e. DSPZ, based electrochemical $\mathrm{pH}$-swing cell with an energy cost of only $61.3 \mathrm{~kJ} \mathrm{~mol}_{\mathrm{CO}_{2}}{ }^{-1}$ at $20 \mathrm{~mA} \mathrm{~cm}^{-2}$. Through analyzing the cycle work obtained under systematically varied inlet partial pressure and current density, we estimate that the cost for capturing from a $0.4 \mathrm{mbar} \mathrm{CO}_{2}$ inlet using this system extrapolates to $108-212 \mathrm{~kJ} \mathrm{~mol}_{\mathrm{CO}_{2}}{ }^{-1}$ in the low-current-density limit, and that it can be further lowered if a higher concentration of DSPZ, or other PCET-active molecules, is used. Recognizing the sensitivity of the reduced form of DSPZ, i.e. $\mathrm{DSPZH}_{2}$, to chemical oxidation by atmospheric or dissolved $\mathrm{O}_{2}$, we introduce and demonstrate an electrochemical rebalancing method that expels oxygen from solution and restores the initial composition of the electrolytes. 


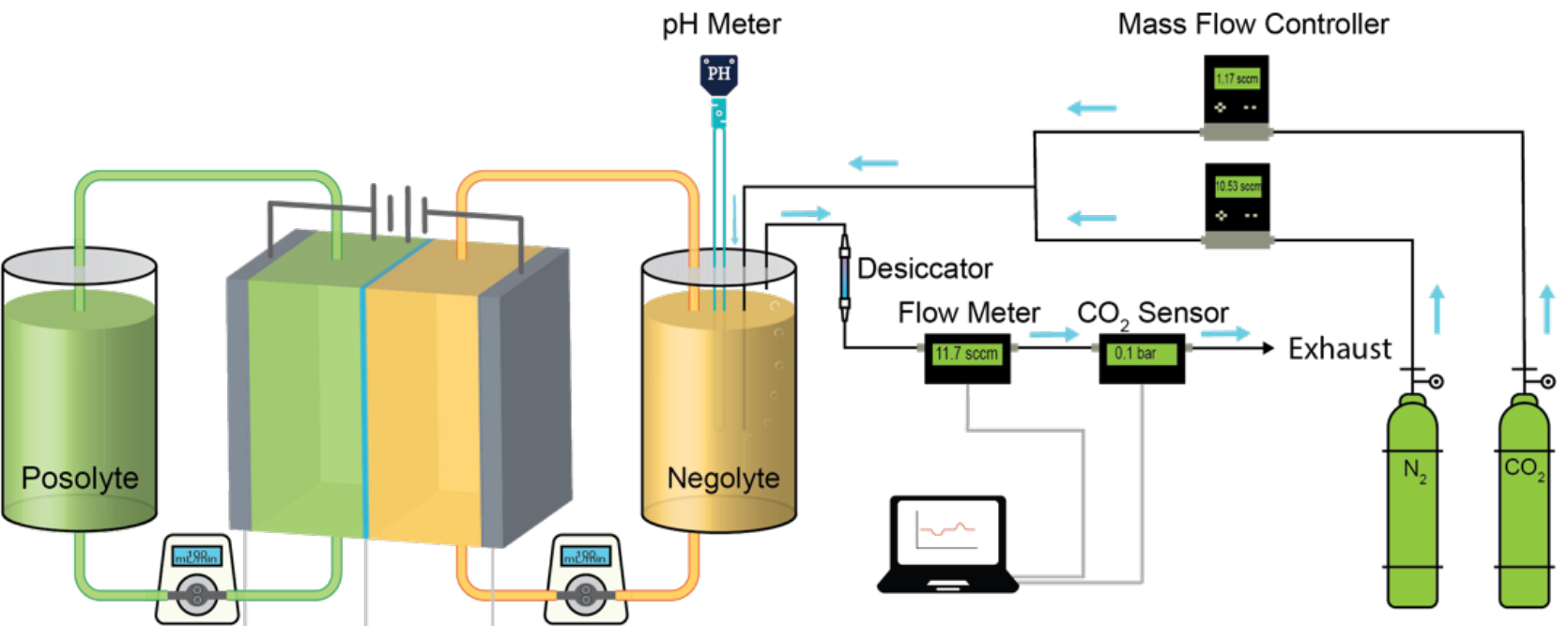

Porous Carbon Electrode-

Cation Exchange Membrane

Porous Carbon Electrode

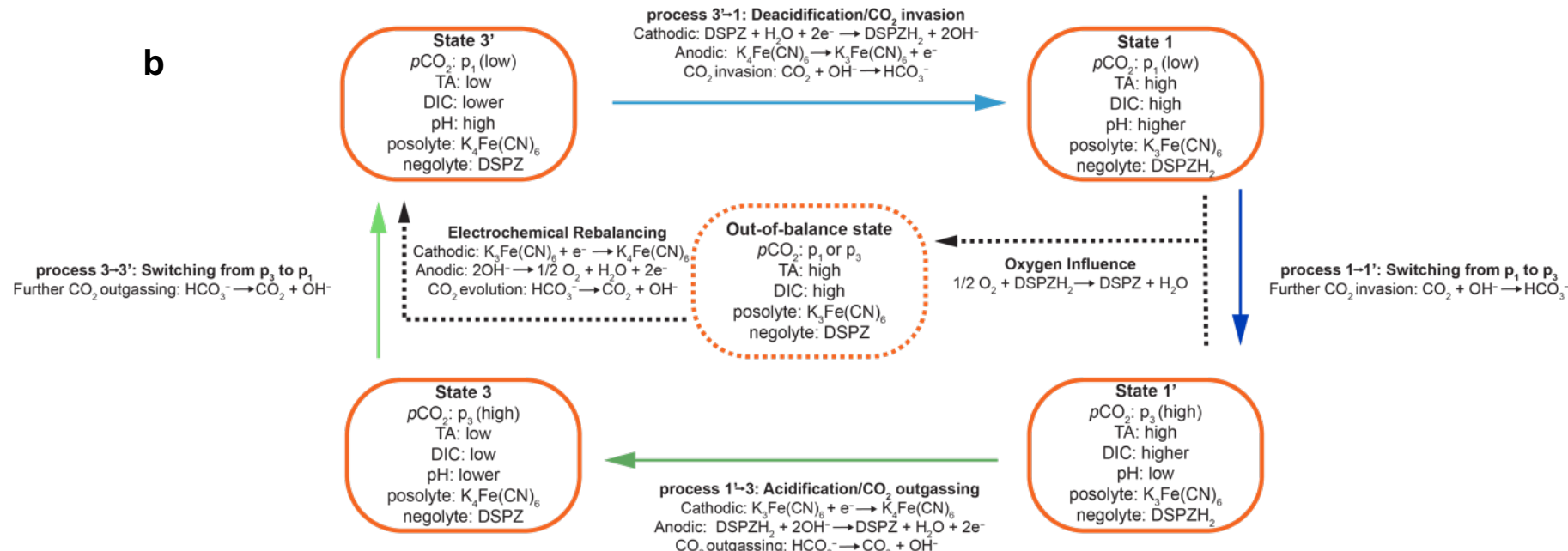

Fig. 1| Scheme of the pH swing carbon capture flow system. a, Schematic of the $\mathrm{Fe}(\mathrm{CN})_{6}$ (posolyte) | DSPZ (negolyte) flow cell and full system. Blue arrows indicate gas flow direction. Adapted from Jin et al. ${ }^{18} \mathbf{b}$, Process flow. The solid arrows refer to desired reactions in a complete carbon capture/release cycle. The carbonate formation and decomposition reactions are neglected for simplicity. The dashed arrow on the right side refers to the side reaction caused by oxygen and the dashed arrow on the left refers to reactions in the electrochemical rebalancing step.

\section{Device Setup and Process Flow}

Fig. 1a shows the schematic of the $\mathrm{Fe}(\mathrm{CN})_{6} \mid \mathrm{DSPZ}$ carbon capture flow cell and the hardware for providing the gas mixture and analyzing the exhaust. The upstream gas composition in the negolyte headspace was controlled by $\mathrm{CO}_{2}$ and $\mathrm{N}_{2}$ mass flow controllers (MFCs). Downstream of the desiccator, the total gas flow rate and $\mathrm{CO}_{2}$ partial pressure were measured using a digital flow meter and a $\mathrm{CO}_{2}$ sensor, respectively. A pH probe immersed in the negolyte solution reported the temporal evolution of its $\mathrm{pH}$, which enabled the tracking of TA and DIC in real time. ${ }^{18}$ Fig. 1b illustrates the electrolyte composition in the four states of the $\mathrm{pH}$ swing carbon capture cycle and the processes connecting the states. We denote the $\mathrm{CO}_{2}$ partial pressure during the $\mathrm{CO}_{2}$ capture process as the inlet pressure or $p_{1}$, and that during the $\mathrm{CO}_{2}$ outgassing process as the exit pressure 
93 or $p_{3}$. Similarly, the subscripts following TA or DIC refer to the TA and DIC of the corresponding 94 states. The naming convention for the states is adopted from previous work, ${ }^{18}$ where the 95 equilibrium and constraints governing $\mathrm{pH}$, TA, DIC and $p \mathrm{CO}_{2}$ are explained in detail. The four 96 sequential processes are 3 ' $\rightarrow 1$ : two-stage deacidification $+\mathrm{CO}_{2}$ invasion (inlet); $1 \rightarrow 1$ ': change of 97 the headspace atmosphere from inlet to exit pressure, i.e. switching from $p_{1}$ to $p_{3} ; 1^{\prime} \rightarrow 3$ : two-stage 98 acidification $+\mathrm{CO}_{2}$ outgassing (exit) and $3 \rightarrow 3^{\prime} \mathrm{f}$ : change of the headspace atmosphere from exit to 99 inlet pressure, i.e. switching from $p_{3}$ to $p_{1}$ (Fig. 1b, four arrows). Note that, as $\mathrm{DSPZH}_{2}$ is reversibly 100 chemically oxidized by atmospheric $\mathrm{O}_{2}$ to DSPZ, the posolyte supplies extra charge to 101 electrochemically reduce the extra oxidized DSPZ; this is reflected in the low Coulombic 102 efficiency of the cell and an accumulation of TA and DIC in the negolyte. This process also 103 transforms more of the posolyte to its oxidized form, i.e. $\left[\mathrm{K}^{+}\right]_{4}\left[\mathrm{Fe}^{\mathrm{II}}(\mathrm{CN})_{6}\right]^{4-} \rightarrow$ $104\left[\mathrm{~K}^{+}\right]_{3}\left[\mathrm{Fe}^{\mathrm{III}}(\mathrm{CN})_{6}\right]^{3-}+\mathrm{e}^{-}$, than at a similar point in the previous deacidification-acidification cycle. 105 During cell operation reduction on one side must be accompanied by oxidation on the other side 106 but, as the available fraction of reduced species on the posolyte side, i.e. $\left[\mathrm{K}^{+}\right]_{4}\left[\mathrm{Fe}^{\mathrm{II}}(\mathrm{CN})_{6}\right]^{4-}$, 107 decreases, the cell can access less and less of its theoretical capacity during its oxidation-reduction 108 oscillations; this is reflected in the decaying capacity of the cell. Eventually both sides become $109100 \%$ oxidized and cell operation ceases. Our remedy for such situation is the electrochemical 110 rebalancing method explained later in the text. 


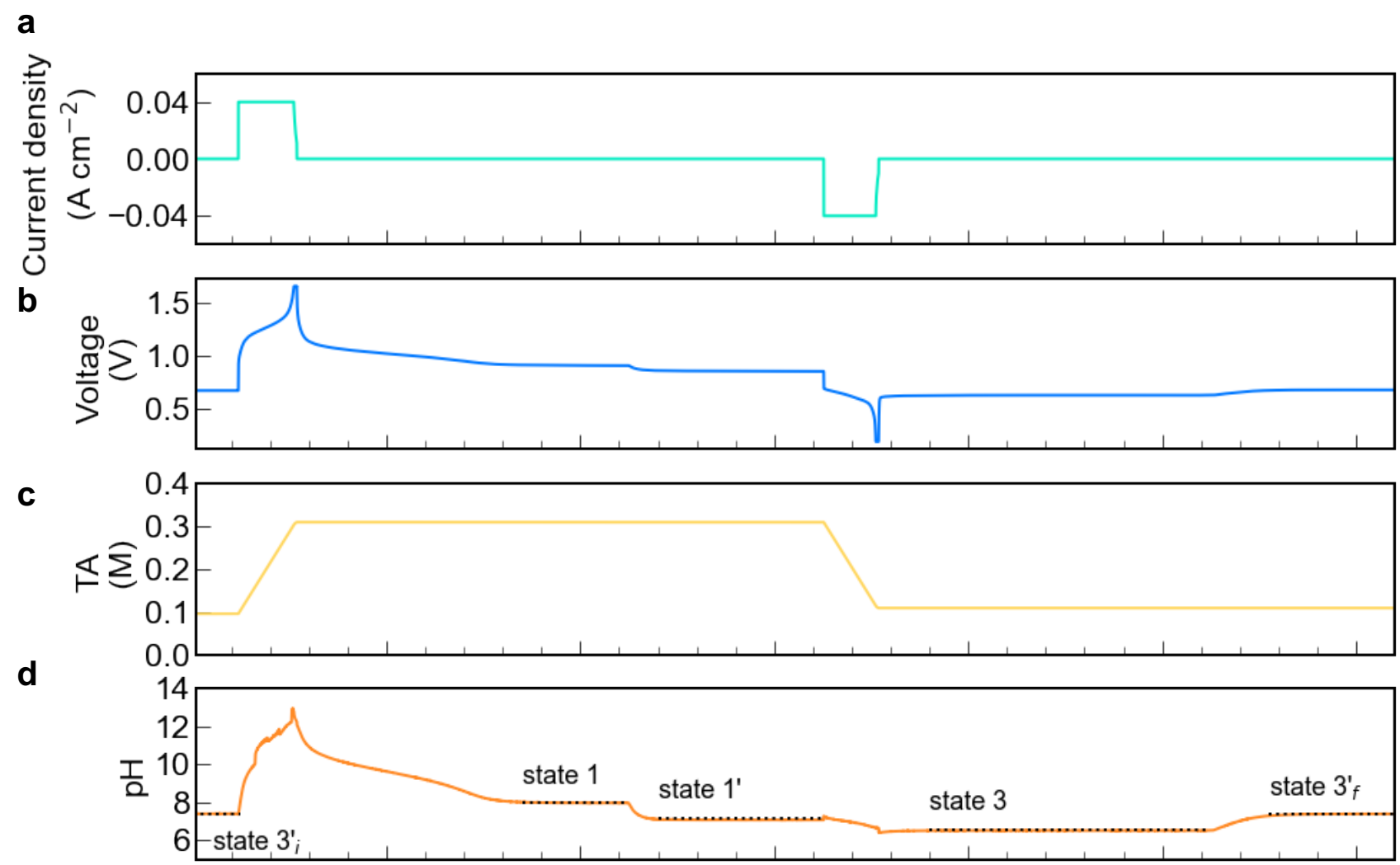

e

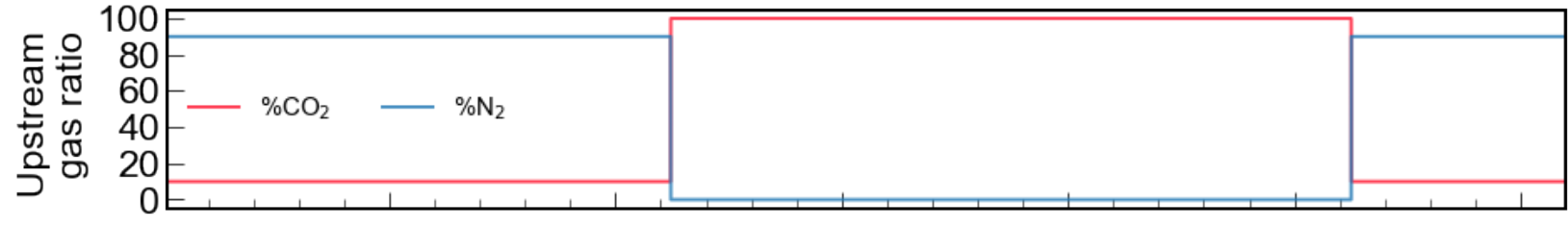

f

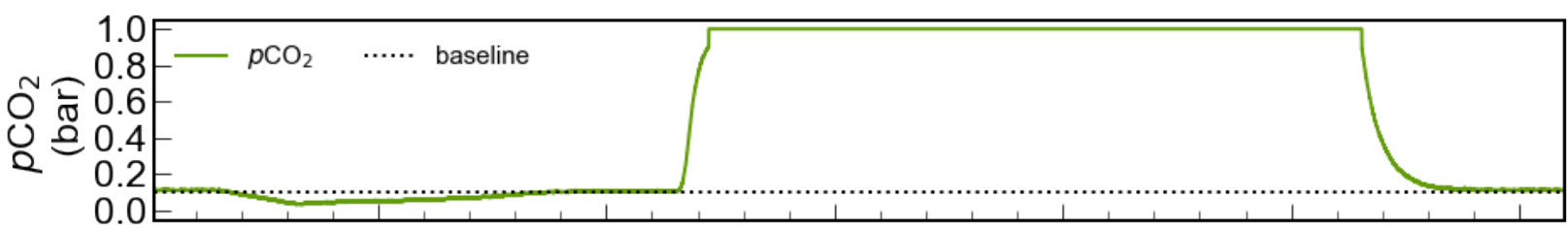

g

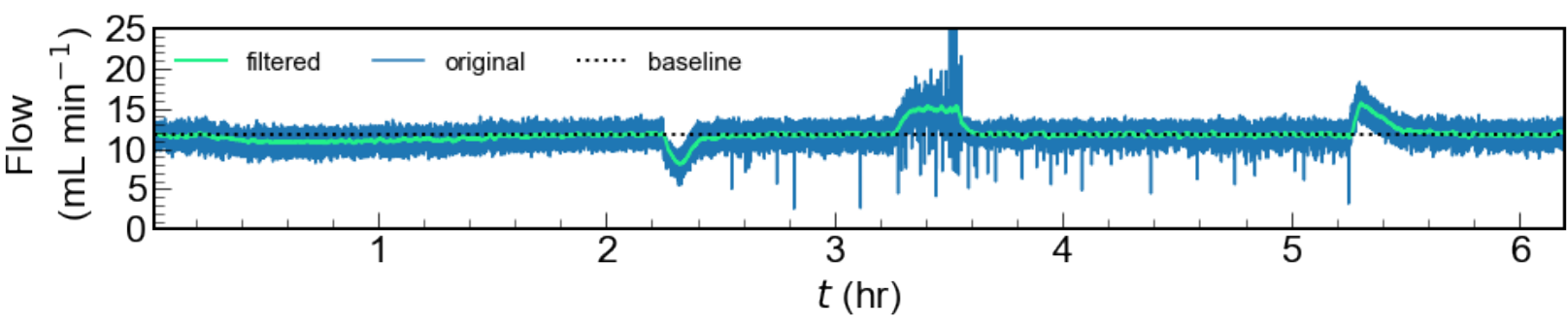

Fig. 2| $\mathrm{A} \mathrm{CO} 2$ concentrating cycle with inlet pressure $p_{1}=0.1$ bar and exit pressure $p_{3}=1$ bar using a DSPZbased flow cell at $40 \mathrm{~mA} \mathrm{~cm}$. Electrolytes comprised $10 \mathrm{~mL} 0.11 \mathrm{M} \mathrm{DSPZ}$ in $1 \mathrm{M} \mathrm{KCl}$ (negolyte, capacity limiting) and $35 \mathrm{~mL} 0.1 \mathrm{M} \mathrm{K}_{4} \mathrm{Fe}(\mathrm{CN})_{6}$ and $0.04 \mathrm{M} \mathrm{K}_{3} \mathrm{Fe}(\mathrm{CN})_{6}$ in $1 \mathrm{M} \mathrm{KCl}$ (posolyte, non-capacity limiting). a, Current density. b, Voltage. c, Total alkalinity. d, pH of the negolyte. States $3^{\prime}{ }_{i}, 1,1$ ', 3 and $3_{f}^{\prime}$ represent $\mathrm{pH}$ values before deacidification under 0.1 bar $p \mathrm{CO}_{2}$, after deacidification+absorption under 0.1 bar $p \mathrm{CO}_{2}$, after changing $p \mathrm{CO}_{2}$ from 0.1 bar to 1 bar, after acidification+desorption under 1 bar and after changing $p \mathrm{CO}_{2}$ from 1 bar to 0.1 bar, respectively. The detailed composition of these states is elaborated in Table 1. e $\mathrm{N}_{2}$ and $\mathrm{CO}_{2}$ percentage in the upstream source gas, controlled by mass flow controllers. $\mathbf{f}$, downstream $\mathrm{CO}_{2}$ partial pressure. The baseline indicates $p \mathrm{CO}_{2}=0.1$ bar. $\mathbf{g}$, downstream total gas flow rate; the baseline is $11.8 \mathrm{~mL} \mathrm{~min}^{-1}$. 


\section{One Carbon Capture Cycle with $p_{1}=0.1$ bar and $p_{3}=1$ bar at $40 \mathrm{~mA} \mathrm{~cm}^{-2}$}

In previous work we demonstrated a series of non-concentrating cycles, in which both exit and inlet $p \mathrm{CO}_{2}$ were 0.47 bar, utilizing a DSPZ-based flow cell at $40-150 \mathrm{~mA} \mathrm{~cm}^{-2} .{ }^{18}$ In the present work we show the use of this setup for $\mathrm{CO}_{2}$ separation from low partial pressure in a mixture with nitrogen and release into a pure $\mathrm{CO}_{2}$ exit stream at 1.0 bar. Fig. 2 demonstrates one such cycle with $p \mathrm{CO}_{2}=1.0$ and 0.1 bar at the exit and inlet, respectively. Beginning at state $3{ }^{\prime}{ }_{i}$, the upstream $\mathrm{CO}_{2}$ partial pressure was set to $0.1 \mathrm{bar}$, which is close to its value in the flue gas from either coal or natural gas fired power plants. ${ }^{7}$ We define $t$ as the time elapsed. As deacidification began (Fig. $2 \mathbf{a}$ and $\mathbf{b}, t=0.2 \mathrm{hr}$ ), the TA went up at a linear rate because only $\mathrm{K}^{+}$ions crossed the cation exchange membrane (CEM) when a constant $40 \mathrm{~mA} \mathrm{~cm}^{-2}$ current density was applied (Fig. 2 c). ${ }^{18}$ As a result of the PCET reactions during the reduction of DSPZ, the negolyte pH (Fig. 2 d) increased from near neutral to $\sim 13.5$ at the end of the deacidification process, indicated by the steep increase of voltage until reaching the preset voltage cutoff of $1.65 \mathrm{~V}$ (Fig. $2 \mathbf{~ b , ~} t=0.6 \mathrm{hr}$ ). $\mathrm{CO}_{2}$ invasion began when deacidification began but continued beyond the end of deacidification: invasion lasted until $t=1.8 \mathrm{hr}$, as indicated by the $p \mathrm{CO}_{2}$ signal returning to the 0.1 bar baseline, because of the limited reaction rate between dilute $\mathrm{OH}^{-}$and $\mathrm{CO}_{2}$. The deviation in the gas flow rate (Fig. 2 g) from the baseline starting at $t=0.2 \mathrm{hr}$ and returning at $1.8 \mathrm{hr}$ also documents the complete capture process. As $\mathrm{CO}_{2}$ reacted with hydroxide and water to form $\mathrm{CO}_{3}{ }^{2-}$ and $\mathrm{HCO}_{3}{ }^{-}$, the $\mathrm{pH}$ (Fig. 2 d) dropped from $\sim 13.5$ at $t=0.5 \mathrm{hr}$ to 8.1 at $1.8 \mathrm{hr}$ and then plateaued, once again indicating the completion of the capture process. The absorbed volume of $\mathrm{CO}_{2}$ is $47 \mathrm{~mL}$ (eq. 1 in Methods). Assuming $T=293 \mathrm{~K}, p=1$ bar and ideal gas behavior, this absorption causes a change in DIC of $0.20 \mathrm{M}\left(2.0 \mathrm{mmol} \mathrm{CO}_{2}\right.$ in $10 \mathrm{~mL}$ negolyte volume). We denote this change as

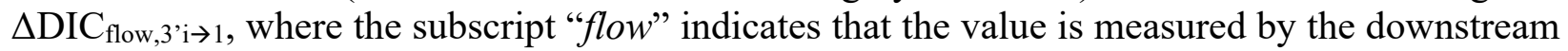
flowmeter and $\mathrm{CO}_{2}$ sensor and " 3 ' $i \rightarrow 1$ " indicates that this value corresponds to the change in process $3{ }^{\prime} \rightarrow 1$ (Table 1). The same naming convention is used for both $\Delta \mathrm{TA}$ and $\triangle \mathrm{DIC}$ throughout the rest of this text. Unlike the flowmeter and $\mathrm{CO}_{2}$ sensor, which quantify $\triangle \mathrm{DIC}$, the $\mathrm{pH}$ probe, in addition to providing a measured value $\left(\mathrm{pH}_{\text {meas }}\right)$, provides a direct measurement of DIC, because given two values from TA, DIC, $p \mathrm{CO}_{2}$ and $\mathrm{pH}$, the others can be derived. ${ }^{18,21}$ At state 3 ' $\mathrm{i}$, the DIC (regardless of subscripts) and TA values are calculated using $\mathrm{pH}_{\text {meas }}$ and assumed gas-solution equilibrium, i.e. $\mathrm{CO}_{2}(a q)=0.035 \times p \mathrm{CO}_{2}$, where 0.035 comes from Henry's law constant of $35 \mathrm{mM}$ $\operatorname{bar}^{-1}$ for $\mathrm{CO}_{2}$ at room temperature. Because $\Delta \mathrm{TA}_{3}{ }^{\prime} \mathrm{i} \rightarrow 1$ is known from Fig. 2 c, $\mathrm{TA}_{1}$ can be evaluated, and so can the TA values at other states. One way of obtaining DIC in all states except $3{ }^{\prime}{ }_{i}$ and of obtaining $\triangle \mathrm{DIC}$ values between all states is to use the known TA and $\mathrm{CO}_{2}(\mathrm{aq})$, and we denote these values with subscript "TA_eq" (Table 1). This method is also used to construct the ideal cycles [ESI, Fig. S1]. Another way to calculate DIC is to use the TA and $\mathrm{pH}_{\text {meas }}$ without assuming gas-solution equilibrium. We denote DIC and $\triangle \mathrm{DIC}$ calculated this way with subscript "TA-pH". The $\triangle \mathrm{DIC}$ between state $3^{\prime}{ }_{\mathrm{i}}$ and 1, i.e. $0.20 \mathrm{M}$, determined by flow meter and $\mathrm{CO}_{2}$ sensor, i.e. $\Delta \mathrm{DIC}_{\text {flow, } 3^{\prime} \mathrm{i} \rightarrow 1}$, is corroborated by $\Delta \mathrm{DIC}_{\mathrm{TA}-\mathrm{pH}, 3^{\prime} \mathrm{i} \rightarrow 1}$ and $\Delta \mathrm{DIC}_{\mathrm{TA}-\mathrm{eq}, 3^{\prime} \mathrm{i} \rightarrow 1}$ (Table 1).

Table 1/ Summary of TA, $p \mathrm{CO}_{2}, \mathbf{p H}$, DIC and $\triangle \mathrm{DIC}$. TA is calculated by counting charges and assuming $\mathrm{K}^{+}$is the only ion passing through the $\mathrm{CEM} ; p \mathrm{CO}_{2}$ is the $\mathrm{CO}_{2}$ partial pressure at each state; $\mathrm{pH}_{\text {meas }}$ refers to the negolyte $\mathrm{pH}$ measured by the $\mathrm{pH}$ probe. All DIC and TA values at state $3_{i}{ }_{i}$ are calculated using the measured $\mathrm{pH}$ and assuming gas-solution equilibrium. In all other states, $\mathrm{pH}_{\mathrm{TA}-\text { eq }}$ and $\mathrm{DIC}_{\mathrm{TA}-\text {-eq }}$ are calculated using TA and assuming gas-solution equilibrium. DIC $\mathrm{TA}_{\mathrm{TAH}}$ is calculated using $\mathrm{TA}$ and $\mathrm{pH}_{\text {meas }} ; \triangle \mathrm{DIC}_{\mathrm{TA}-\mathrm{pH}}$ and $\triangle \mathrm{DIC}_{\mathrm{TA}-\mathrm{eq}}$ are the difference in $\mathrm{DIC}_{\mathrm{TA}-\mathrm{pH}}$ and $\mathrm{DIC}_{\mathrm{TA}-\mathrm{eq}}$ values, respectively, between two consecutive states; $\triangle \mathrm{DIC}_{\text {flow }}$ is converted from the volume of $\mathrm{CO}_{2}$ captured or released, measured by the downstream flow meter and $\mathrm{CO}_{2}$ sensor and $\mathrm{DIC}_{\text {flow }}$ is calculated by adding $\triangle \mathrm{DIC}$ flow at the current state to $\mathrm{DIC}_{\text {flow }}$ at the state one row above. Because $\Delta \mathrm{DIC}$ flow is not measurable between states 1 and 1 ' 
and states 3 and $3_{f}^{\prime}, D_{\text {flow }}$ at states $1^{\prime}$ and $3_{f}^{\prime}$ is calculated by adding $D C_{\text {flow }}$ with $\Delta D I C_{T A-p H}$ values between the corresponding states.

\begin{tabular}{|c|c|c|c|c|c|c|c|c|c|c|}
\hline State & $\begin{array}{l}\text { TA } \\
\text { (M) }\end{array}$ & $\begin{array}{c}\mathbf{p}_{1}, \mathrm{pCO}_{2} \\
\text { (bar) }\end{array}$ & $\mathrm{pH}_{\text {meas }}$ & $\mathrm{pH}_{\text {TA-eq }}$ & $\begin{array}{l}\text { DIC }_{\text {flow }} \\
\text { (M) }\end{array}$ & $\begin{array}{l}\text { DIC }_{\text {TA-pH }} \\
\text { (M) }\end{array}$ & $\begin{array}{l}\text { DIC }_{\text {TA-eq }} \\
\text { (M) }\end{array}$ & $\begin{array}{c}\Delta \text { DIC }_{\text {flow }} \\
\text { (M) }\end{array}$ & $\begin{array}{l}\Delta \mathrm{DI} \mathrm{C}_{\mathrm{TA}-\mathrm{pH}} \\
\text { (M) }\end{array}$ & $\begin{array}{l}\Delta \mathrm{DIC} \mathrm{C}_{\text {TA-eq }} \\
\text { (M) }\end{array}$ \\
\hline $3_{i}^{\prime}$ & $0.11^{a}$ & 0.1 & 7.4 & $7.4^{\mathrm{a}}$ & $0.11^{\mathrm{a}}$ & $0.11^{\mathrm{a}}$ & $0.11^{\mathrm{a}}$ & \multirow{2}{*}{0.20} & \multirow{2}{*}{0.20} & \multirow{2}{*}{0.20} \\
\hline 1 & 0.32 & 0.1 & 8.1 & 7.9 & 0.31 & 0.31 & 0.31 & & & \\
\hline \multirow{2}{*}{$1^{\prime}$} & \multirow{2}{*}{0.32} & \multirow{2}{*}{1.0} & \multirow{2}{*}{7.1} & \multirow{2}{*}{6.9} & \multirow{2}{*}{$0.34^{b}$} & \multirow{2}{*}{0.34} & \multirow{2}{*}{0.34} & $\mathrm{~N} / \mathrm{A}$ & 0.03 & 0.03 \\
\hline & & & & & & & & 0.20 & -0.20 & -0.20 \\
\hline 3 & 0.12 & 1.0 & 6.6 & 6.5 & 0.14 & 0.14 & 0.14 & N/A & -0.03 & -0.03 \\
\hline $3_{f}^{\prime}$ & 0.12 & 0.1 & 7.5 & 7.5 & $0.12^{\mathrm{c}}$ & 0.12 & 0.12 & & & \\
\hline $\begin{array}{l}{ }^{a} \text { All va } \\
{ }^{\circ} \text { Calcu } \\
\text { 'Calcu }\end{array}$ & $\begin{array}{l}\text { s deriv } \\
\text { ed by } \\
\text { ed by s }\end{array}$ & $\begin{array}{l}\text { from } \mathrm{pH} \\
\text { רming DI } \\
\text { רming DI }\end{array}$ & $\begin{array}{l}\mathrm{s}, \text { assul } \\
\mathrm{w}, 1 \text { and } \\
\mathrm{w}, 3 \text { and }\end{array}$ & $\begin{array}{l}\text { ing gas-s } \\
\mathrm{D}^{\mathrm{DIC}} \mathrm{C}_{\mathrm{TA}-\mathrm{p}}, \\
\mathrm{DII}_{\mathrm{TA}-\mathrm{H}},\end{array}$ & ion e & & & & & \\
\hline
\end{tabular}

171

172

173

174

175

176

177

178

179

180

181

182

183

184

185

186

187

188

189

190

191

192

193

194

195

196

197

198

199

200

201

202

After $\mathrm{CO}_{2}$ capture at 0.1 bar $\left(p_{1}\right)$ was completed, the headspace of the negolyte was switched to a pure $\mathrm{CO}_{2}$ environment $\left(p_{3}\right)$ to prepare for $\mathrm{CO}_{2}$ outgassing, i.e. going through process $1 \rightarrow 1^{\prime}$ ' (Fig. $2 \mathrm{e}, t=2.2 \mathrm{hr}$ ). The drop in flow rate at $t=2.2 \mathrm{hr}$ and its return to the baseline at $2.5 \mathrm{hr}$ is caused by the combined effect of mismatched valve response rate in the MFCs (the $\mathrm{N}_{2}$ MFC valve closes faster than the $\mathrm{CO}_{2} \mathrm{MFC}$ valve opens) and a small increase in DIC due to increased $p \mathrm{CO}_{2}$ in the headspace. This increase in DIC, corresponding to $\Delta \mathrm{DIC}_{1 \rightarrow 1}$, is difficult to quantify via the flowmeter and $\mathrm{CO}_{2}$ sensor, but can be determined using $\mathrm{pH}_{\text {meas }}\left(\Delta \mathrm{DIC}_{\mathrm{TA}-\mathrm{pH}, 1 \rightarrow 1^{\prime}}\right)$ or assuming gassolution equilibrium $\left(\triangle \mathrm{DIC} \mathrm{TA}_{\mathrm{TA}} \mathrm{eq}, 1 \rightarrow 1^{\prime}\right)$, which both give $0.03 \mathrm{M}$ (Table 1). The acidification $+\mathrm{CO}_{2}$ outgassing (process $1^{\prime} \rightarrow 3$ ) started at $t=3.2 \mathrm{hr}$ and ended at a little over $3.6 \mathrm{hr}$ (Fig. 2 a-d and g). Note that, unlike in process $3{ }^{\prime} \rightarrow 1$, the $\mathrm{CO}_{2}$ outgassing, which is observable from $\mathrm{pH}$ change and an increase in flow rate, (Fig. $\mathbf{2} \mathbf{d}$ and $\mathbf{g}$ ) lasted for no more than ten minutes after the acidification process (Fig. 2 a and b) finished. The outgassed $\mathrm{CO}_{2}$ volume was $49 \mathrm{~mL}$ (eq. 1), which is equivalent to $\Delta \mathrm{DIC}_{\text {flow, } 1^{\prime} \rightarrow 3}=-0.20 \mathrm{M}$. Once again, $\Delta \mathrm{DIC}_{\mathrm{TA}-\mathrm{pH}}$ and $\Delta \mathrm{DIC}_{\mathrm{TA}-\mathrm{eq}}$ agree with $\Delta \mathrm{DIC}_{\text {flow }}$ for the changes between states $1^{\prime}$ ' and 3 . Starting from a little over $t=5.2 \mathrm{hr}$, the headspace was filled with 0.1 bar $\mathrm{CO}_{2}+0.9$ bar $\mathrm{N}_{2}$ to recover the state 3 ' for the next cycle (process $3 \rightarrow 3{ }^{\prime}$ f). Like process $1 \rightarrow 1^{\prime}$, there was a combined effect of valve response and additional $\mathrm{CO}_{2}$ outgassing during process $3 \rightarrow 3$ 'f, causing an increase in flow rate (Fig. $2 \mathbf{g}, t=5.2 \mathrm{hr}$ to $5.6 \mathrm{hr}$ ). Note that state $3{ }^{\prime} \mathrm{f}$ has slightly higher $\mathrm{pH}$ and $0.01 \mathrm{M}$ more of TA and DIC than state $3{ }^{\prime} \mathrm{i}$ because of the influence of oxygen (Fig. 1 b).

\section{Calculation of $\Delta \mathrm{DIC}_{\mathrm{flow}, 3 \rightarrow 1}$ and Molar Cycle Work}

The discussion above shows how $\Delta \mathrm{DIC}_{\text {flow, } 3^{\prime} \mathrm{i} \rightarrow 1}$ and $\Delta \mathrm{DIC}_{\text {flow, } 1^{\prime} \rightarrow 3}$ are obtained by gas flow measurement, but neither of these two quantities reflect the actual amount captured at 0.1 bar and released at 1.0 bar, because both states $3^{\prime}{ }_{i}$ and 1 are at $p_{1}=0.1$ bar while both states 1 ' and 3 are at $p_{3}=1$ bar. The important quantity is the difference in DIC between states 3 and 1 . With help of $\mathrm{TA}$ and $\mathrm{pH}$ measurements, $\Delta \mathrm{DIC}_{\text {flow }, 1 \rightarrow 3}$ is evaluated as $\Delta \mathrm{DIC}_{\mathrm{TA}-\mathrm{pH}, 1 \rightarrow 1^{\prime}}+\Delta \mathrm{DIC}_{\text {flow }, 1^{\prime} \rightarrow 3}=-0.17 \mathrm{M}$; equivalently, but with opposite sign, $\Delta \mathrm{DIC}_{\text {flow }, 3 \rightarrow 1}=\Delta \mathrm{DIC}_{\text {flow }, 3^{\prime} \rightarrow 1}+\Delta \mathrm{DIC}_{\mathrm{TA}-\mathrm{pH}, 3 \rightarrow 3^{\prime} \mathrm{f}}=0.17 \mathrm{M}$, i.e., $1.7 \mathrm{mmol} \mathrm{CO}_{2}$ in a $10 \mathrm{~mL}$ negolyte volume. Because sufficient gas-solution equilibrium is approached (Fig. 2 f and g), $\Delta \mathrm{DIC}_{\mathrm{TA}-\mathrm{eq}}$ may also be used in place of $\Delta \mathrm{DIC}_{\mathrm{TA}-\mathrm{pH}}$ in such calculations, resulting in the same values of $\Delta \mathrm{DIC}_{\text {flow }, 1 \rightarrow 3}$ and $\Delta \mathrm{DIC}_{\text {flow }, 3 \rightarrow 1}$. 
In this cycle, the deacidification work into the system, $w_{\text {deacidification, }}$ is $0.267 \mathrm{~kJ}$ and the acidification work, $w_{\text {acidification, }}$ is $-0.119 \mathrm{~kJ}$ (eq. 3 ). Dividing the cycle work, $w_{\text {cycle }}$ (eq. 2), by $1.7 \mathrm{mmol} \mathrm{CO}$

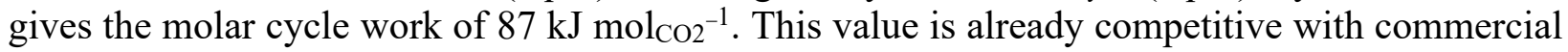
amine scrubbing processes, ${ }^{4,6}$ and it can be further decreased by using membranes with lower 208 ohmic resistance or molecules with lower electron transfer overpotential. ${ }^{22}$

a

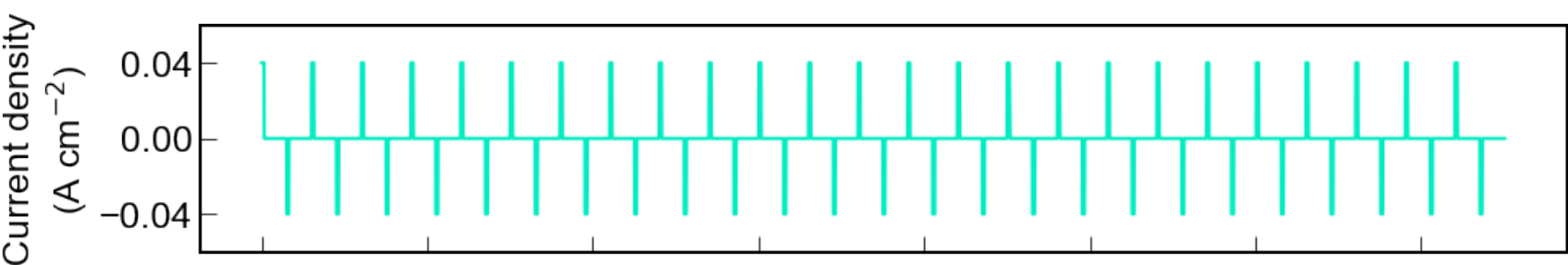

b

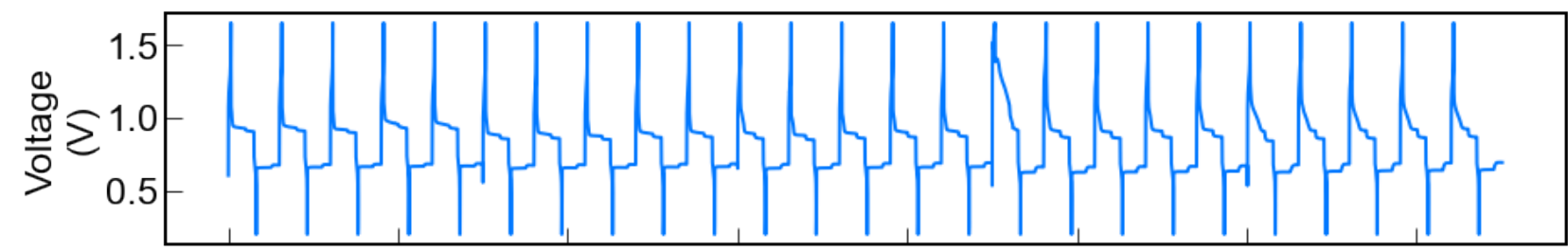

C

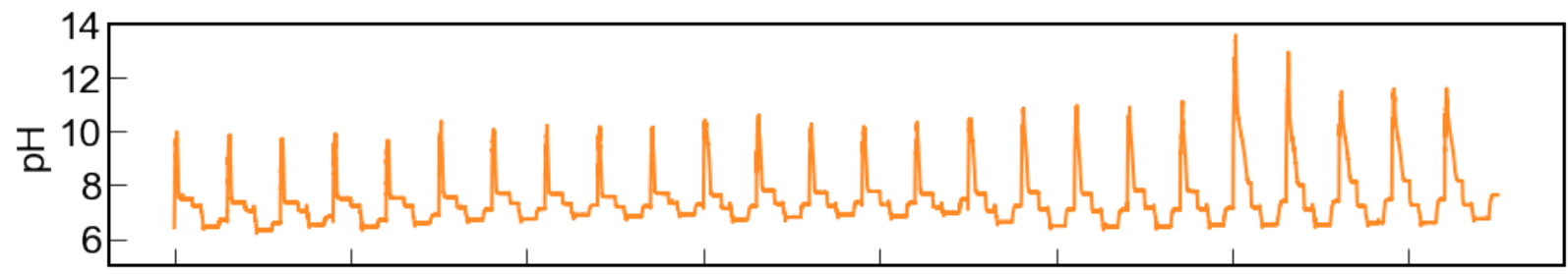

d

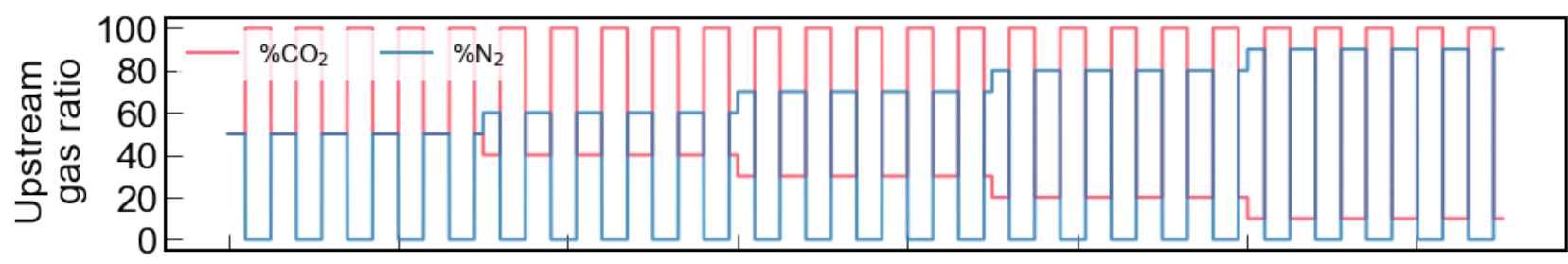

e
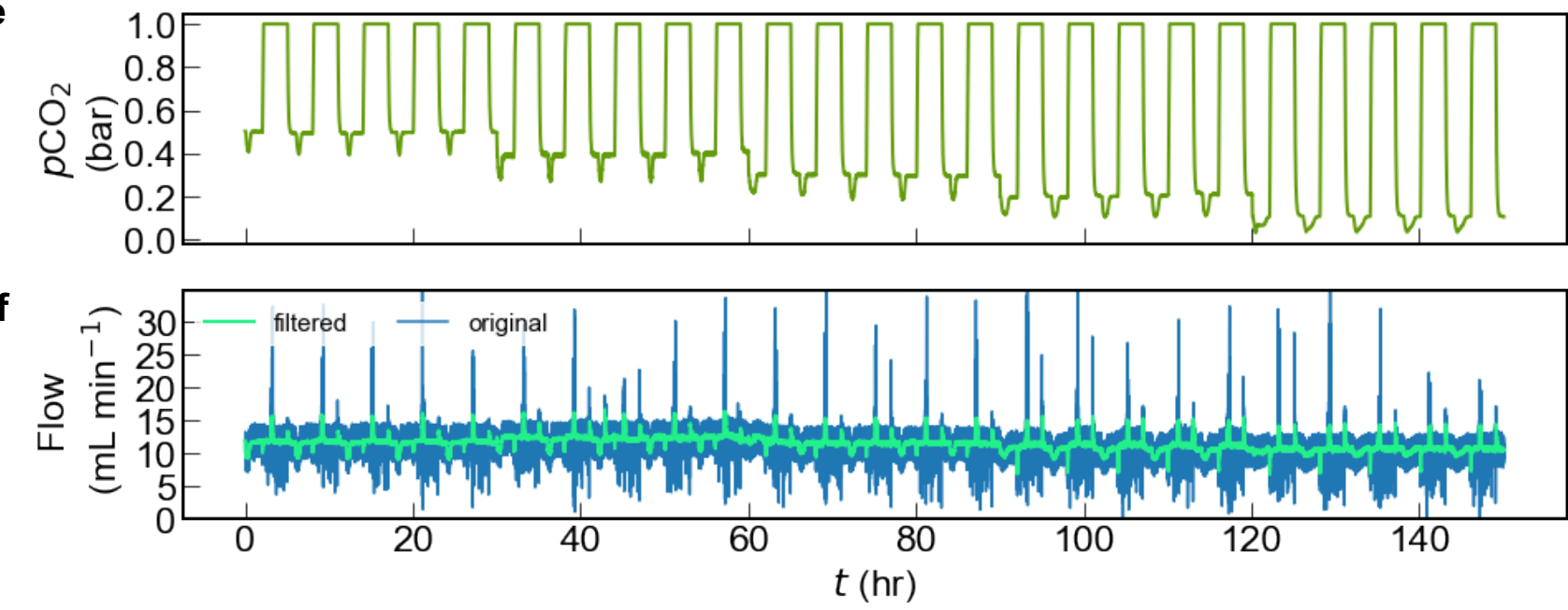
Fig. 3| Twenty five $\mathrm{CO}_{2}$ concentrating cycles with $0.5,0.4,0.3,0.2$, and 0.1 bar inlet $p \mathrm{CO}_{2}$ and 1 bar exit $p \mathrm{CO}_{2}$ at $40 \mathrm{~mA} \mathrm{~cm}^{-2}$. Same cell and negolyte as in Fig. 2 were employed. a, Current density. b, Voltage. c, pH of the negolyte. d, $\mathrm{N}_{2}$ and $\mathrm{CO}_{2}$ percentage in the upstream source gas, controlled by mass flow controllers; total pressure 1.0 bar. e, downstream $\mathrm{CO}_{2}$ partial pressure. f, downstream total gas flow rate.

Carbon Capture Cycles with $p_{1}=0.1-0.5$ bar at $40 \mathrm{~mA} \mathrm{~cm}^{-2}$

In order to understand how the electrical work depends on the inlet $p \mathrm{CO}_{2}$, we performed five cycles each at $p_{1}=0.1$ to 0.5 bar with $p_{3}=1.0$ bar (Fig. 3). The same cell components and negolyte as in Fig. 2 were used, and the posolyte was replaced with a fresh solution for each inlet condition to avoid oxygen-induced long-term cell imbalance (Fig. 1b). ${ }^{23}$ Fig S5b shows that the $\mathrm{CO}_{2}$ outgassing period is identical regardless of inlet $p \mathrm{CO}_{2}$ because the exit $p \mathrm{CO}_{2}$ is always 1 bar and the current density is always $40 \mathrm{~mA} \mathrm{~cm}{ }^{-2}$. In contrast, the capture period increases as inlet $p \mathrm{CO}_{2}$ decreases (ESI, Fig S5a) because of the expected trend of reaction rate with decreasing reactant concentration. $\Delta \mathrm{DIC}$ flow, $3 \rightarrow 1$ values decrease as $p_{1}$ decreases (Fig. 4a) because of greater $\Delta \mathrm{DIC}$ during processes $1 \rightarrow 1$ ' and $3 \rightarrow 3$ ' (vertical arrows in Fig. 4c) at smaller $p_{1}$. The measured values closely align with the theoretical $\Delta \mathrm{DIC}_{\mathrm{TA}-\mathrm{eq}, 3 \rightarrow 1}$ vs. $p_{1}$ curve $(\mathbf{F i g} . \mathbf{4 a})$.

This alignment permits us to estimate $\Delta \mathrm{DIC}$ flow, $3 \rightarrow 1$ for $p_{1}=0.4 \mathrm{mbar}$ and $p_{3}=1 \mathrm{bar}$, i.e. similar to DAC conditions, by following the $\Delta \mathrm{DIC}_{\mathrm{TA}-\mathrm{eq}, 3 \rightarrow 1}$ vs. $p_{1}$ curve to obtain a value of $0.049 \mathrm{M}$. Note that the $\Delta \mathrm{DIC}_{\mathrm{TA}-\mathrm{eq}, 3 \rightarrow 1}$ vs. $p_{1}$ curve shifts downward as TA ${ }_{3}$ 'i increases (ESI, Fig. S3b). This has relatively small impacts on $\Delta \mathrm{DIC}_{\mathrm{TA}-\mathrm{eq}, 3 \rightarrow 1}$ with high $p_{1}$, but it causes significant differences for small $p_{1}$ values. For example, when $p_{1}=0.4 \mathrm{mbar}, \Delta \mathrm{DIC}_{\mathrm{TA}-\mathrm{eq}, 3 \rightarrow 1}$ for $\mathrm{TA}_{3}{ }^{\prime} \mathrm{i}=0,0.11$ and $0.21 \mathrm{M}$ is $0.096,0.049$ and $0.005 \mathrm{M}$, respectively (ESI, Fig. S1-3). Because $\Delta \mathrm{DIC}_{3 \rightarrow 1}$ is in the denominator when $\mathrm{CO}_{2}$ molar cycle work is calculated, lowering $\triangle \mathrm{DIC}_{3 \rightarrow 1}$ increases the molar energy cost accordingly (ESI, Fig. S2b and c). High $\mathrm{TA}_{3}{ }^{\prime}$ i should therefore be avoided, and a necessary step to achieve this goal is to limit the impact of oxidation of $\mathrm{DSPZH}_{2}$ by oxygen (Fig. 1b). 

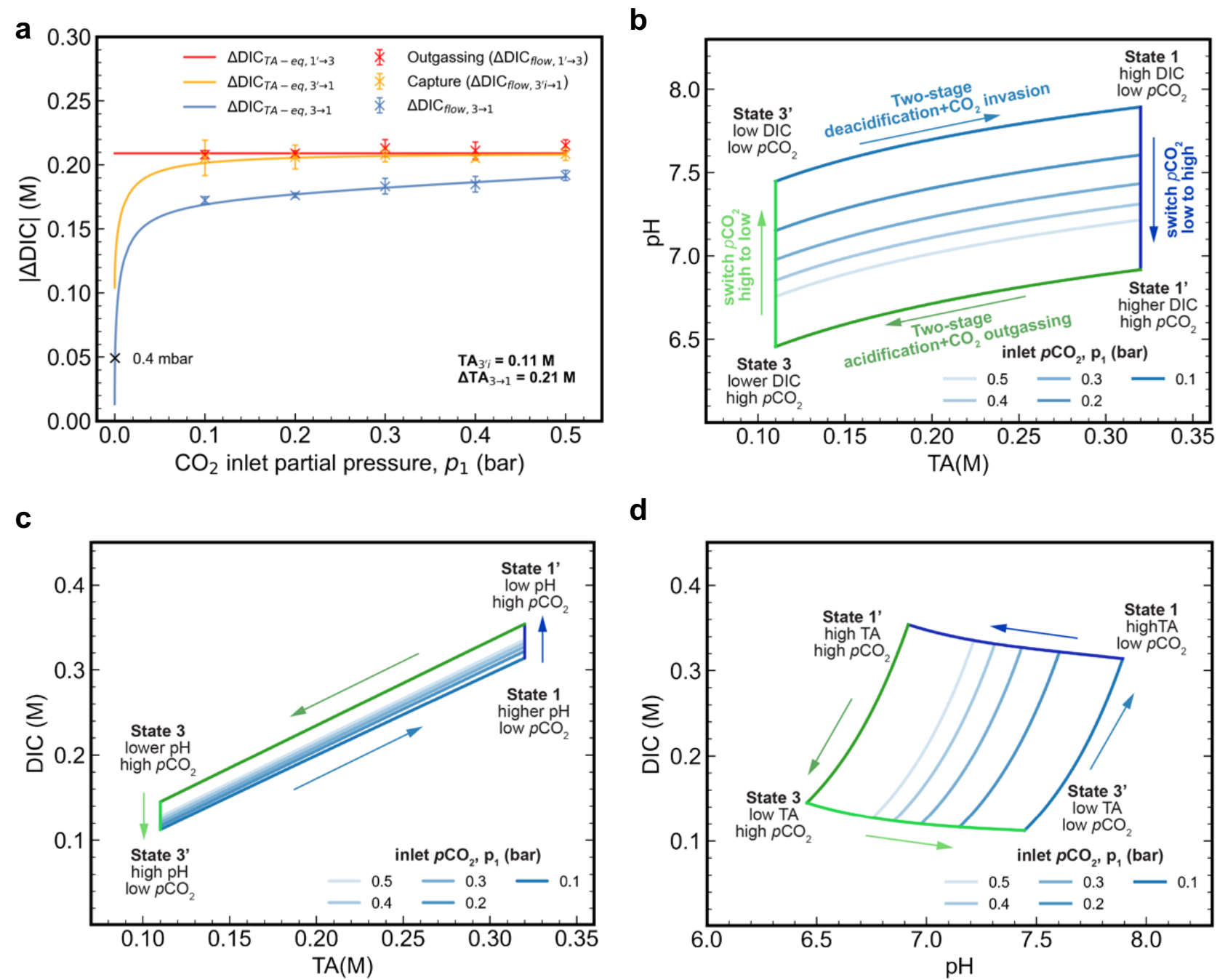

Fig. 4| Summary of the experimental concentrating cycles with different inlet $p \mathrm{CO}_{2}$ in Fig. 3 and the TA/pH/DIC relations of the ideal cycles with corresponding experimental conditions. $a, \triangle D I C_{\text {flow }}$ extracted from Fig. 3 e and $\mathbf{f}$ (colored " $x$ " markers) and calculated $\triangle \mathrm{DIC}_{\mathrm{TA} \text {-eq }}$ given $\mathrm{TA}_{3^{\prime} \mathrm{i}}=0.11 \mathrm{M}$ and $\Delta \mathrm{TA}_{3 \rightarrow 1}=0.21 \mathrm{M}$ (lines). The black " $\mathrm{x}$ " marker refers to the result that $\triangle \mathrm{DIC}$ for the ideal cycle equals $0.049 \mathrm{M}$ when $p \mathrm{CO}_{2}=0.4 \mathrm{mbar} . \mathbf{b}, \mathrm{pH} v \mathrm{~s}$. TA in the ideal cycles, assuming $\mathrm{TA}_{3^{\prime} \mathrm{i}}=0.11 \mathrm{M}, \Delta \mathrm{TA}_{3 \rightarrow 1}=0.21 \mathrm{M}$ and gas-solution equilibrium. $p_{1}$ in the legends represents $p \mathrm{CO}_{2}$ during the two-stage deacidification $+\mathrm{CO}_{2}$ invasion process. The arrows indicate the direction of the processes in the experiments. c, DIC vs. TA in the ideal cycles. d, DIC vs. pH in the ideal cycles.

\section{Carbon Capture Cycles with $p_{1}=0.1-0.5$ bar at $20-150 \mathrm{~mA} \mathrm{~cm}^{-2}$} $-150 \mathrm{~mA} \mathrm{~cm}^{-2}$ (Fig. 5 a and ESI, Fig. S7). As current density increases at a fixed $p_{1}$, the net cycle work increases as the required deacidification work increases and the acidification work returned decreases in magnitude; these trends are caused by increased ohmic, electron-transfer and masstransport overpotentials at higher current density. ${ }^{22}$ It is noteworthy that we achieve $61.3 \mathrm{~kJ}$ molco2 $^{-1}$ cycle work for $p_{1}=0.1$ bar and $p_{3}=1$ bar using a current density of $20 \mathrm{~mA} \mathrm{~cm}{ }^{-2}$, which is a competitive energy cost at a much higher current density compared to other electrochemical $\mathrm{CO}_{2}$ separation methods for flue gas capture. ${ }^{24,25} \mathrm{~A}$ linear extrapolation of the cycle work shows $57.1 \mathrm{~kJ} \mathrm{~mol}_{\mathrm{CO}^{2}}{ }^{-1}$ at the low-current-density limit (Fig. 5e). 
256 It is evident from Fig. $\mathbf{5 b}$ that $\Delta \mathrm{DIC}_{\text {flow }, 3 \rightarrow 1}$ is independent of current density for a given value of $257 p_{1}$. This occurs because varying current density changes only the rate of change in TA and not the 258 value of $\Delta \mathrm{TA}_{3 \rightarrow 1}$, and sufficient reaction time was allowed to approach gas-solution equilibrium, 259 whether the current density was low (Fig. 2f and g) or high (ESI, Fig. S8). The slight variations 260 in $\triangle \mathrm{TA}$ and $\triangle \mathrm{DIC}$ were caused by occasional foaming or negolyte droplets clinging to the wall of 261 the reservoir, both of which cause small amounts of charge capacity to be instantaneously 262 inaccessible from time to time. In contrast, increasing $p \mathrm{CO}_{2}$ at the inlet raises $\Delta \mathrm{DIC}$ flow, $3 \rightarrow 1$ (Fig. $263 \mathbf{5 b}$ ), for the reason explained in the discussion of Fig. 4d. In addition to the cycle results presented 264 in Fig. 5, five cycles with $p_{1}=0.05$ bar and $p_{3}=1$ bar and current density being $40 \mathrm{~mA} \mathrm{~cm}^{-1}$ were 265 tested under faster negolyte pumping to enhance mass transport rates, yielding an average cycle 266 work of $92.6 \mathrm{~kJ}$ mol $_{\mathrm{CO} 2}{ }^{-1}$ (ESI, Fig. S9). 


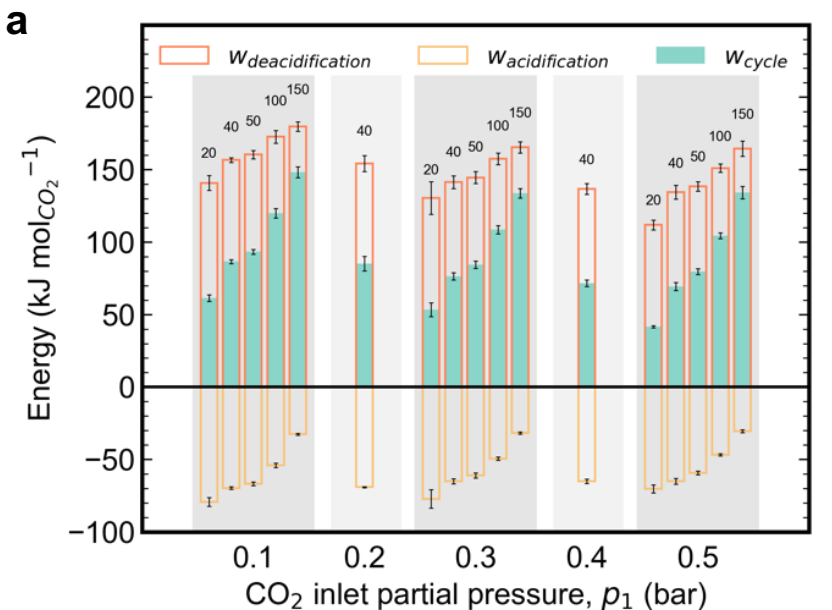

C
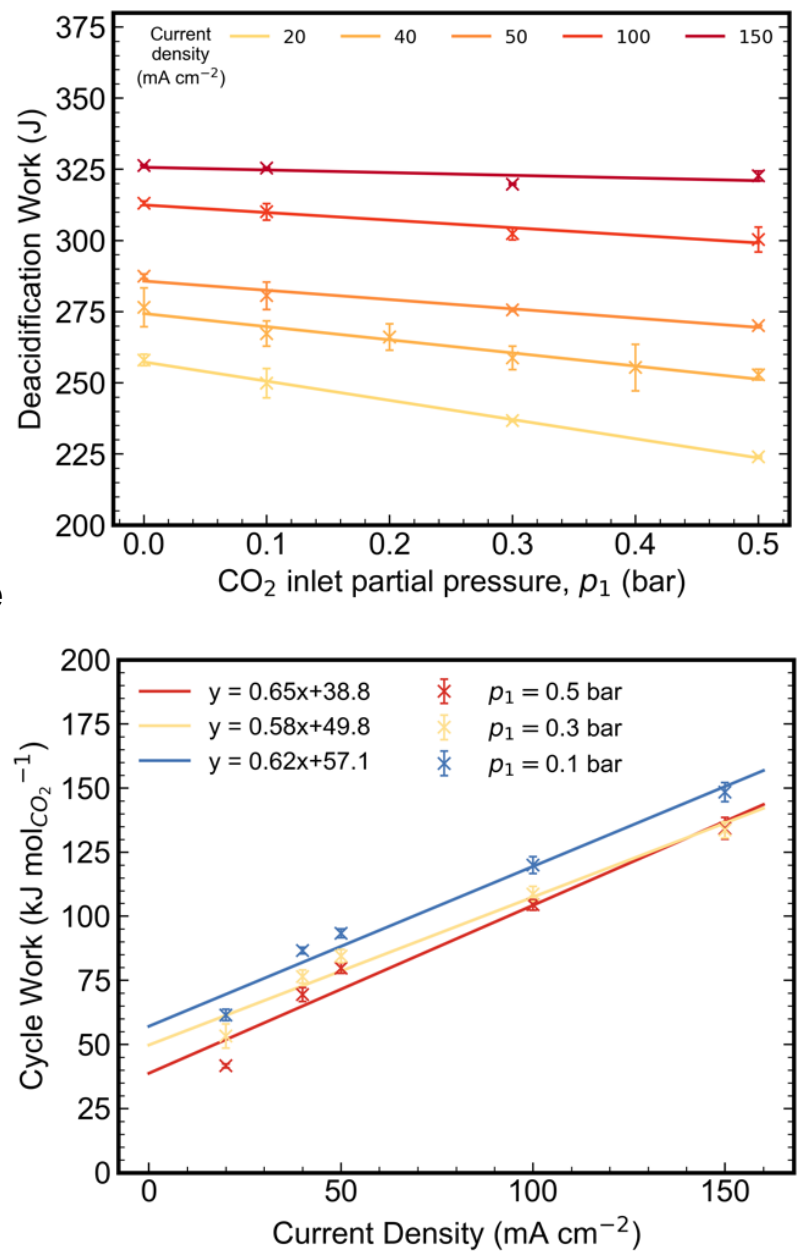

b

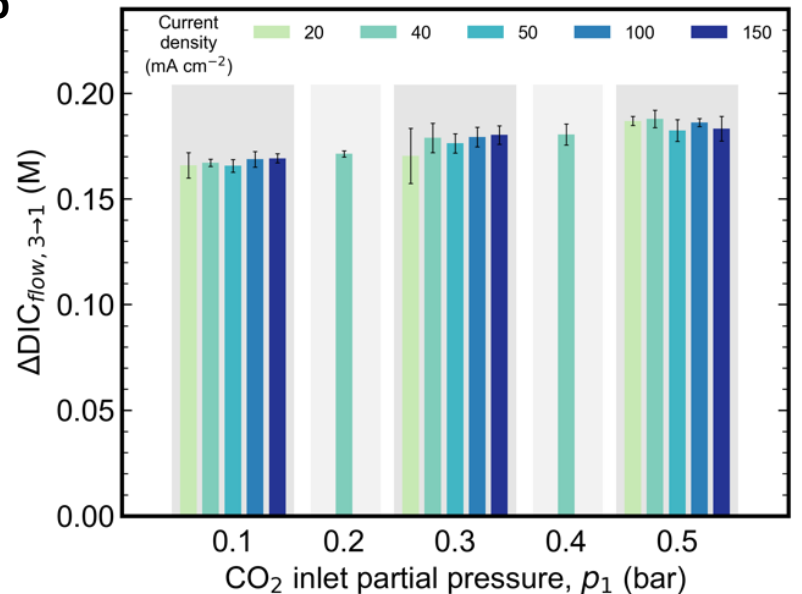

d
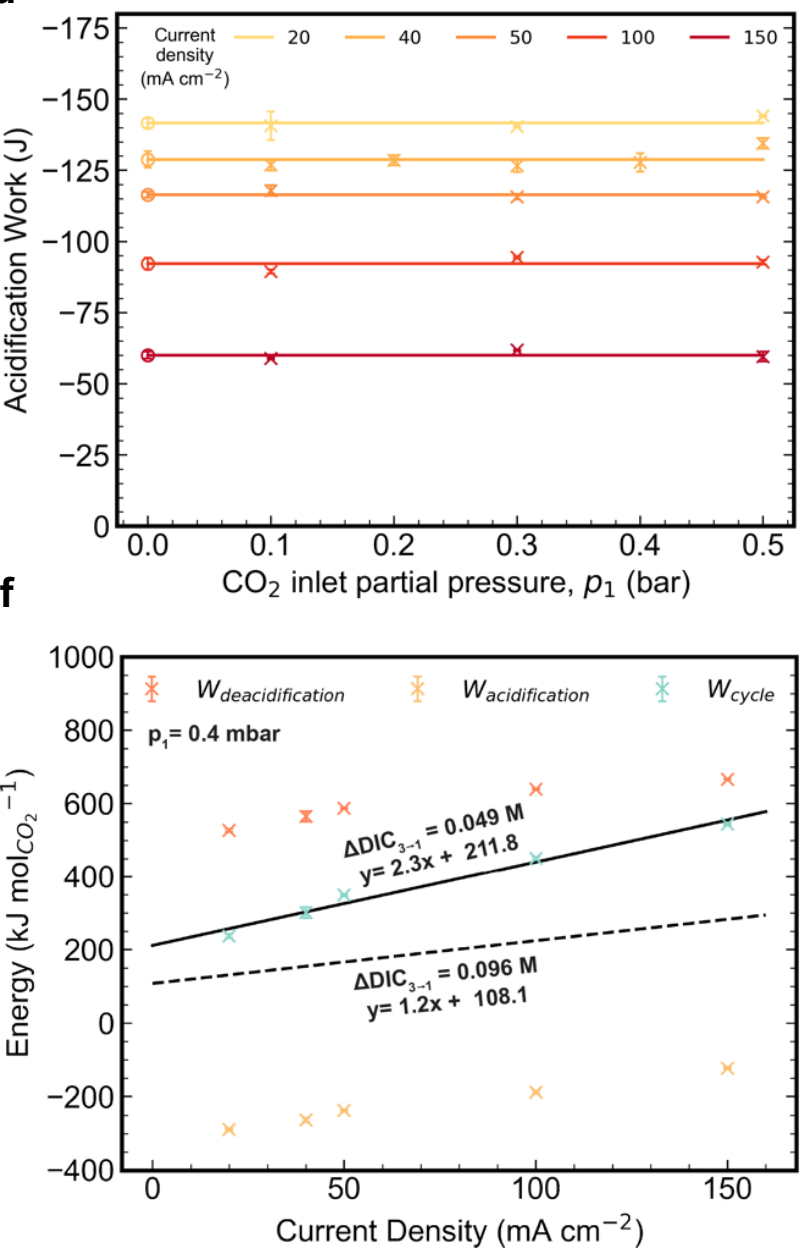

Fig. 5| Summary of the experimental concentrating cycles performed under $20,40,50,100$ and $150 \mathrm{~mA} \mathrm{~cm}^{-2}$ current densities and $p_{1}=0.5,0.4,0.3,0.2$ and 0.1 bar. a, $\mathrm{CO}_{2}$ molar deacidification, acidification and cycle work vs. $p_{1}$ for current densities indicated above the bars, in $\mathrm{mA} \mathrm{cm}^{-2}$. In both $\mathbf{a}$ and $\mathbf{b}$ the horizontal axis is categorical, and each shadowed region refers to a single $p_{1}$ value. $\mathbf{b}, \Delta \mathrm{DIC} \mathrm{C}_{\text {flow }, 3 \rightarrow 1} v s p_{1}$ for various current densities. c, Deacidification work vs. $p_{1}$ for various current densities. The " $x$ " markers refer to measured data. The deacidification work of the cycles under pure $\mathrm{N}_{2}$ is used for $p_{1}=0.0$ bar. $\mathbf{d}$, Acidification work vs. $p_{1}$ for various current densities. The "x" markers refer to measured data. For each current density, the acidification work at $p_{1}=0.0$ bar ("o" markers) is chosen to be the average value of the work obtained at other $p_{1}$ values at the same current density. e, $\mathrm{CO}_{2}$ molar deacidification, 
acidification and cycle work vs. current density for $p_{1}=0.1,0.3$ and 0.5 bar. f, Estimated $\mathrm{CO}_{2}$ molar deacidification, acidification and cycle work for $p_{1}=0.4$ mbar. Extrapolation is performed using deacidification and acidification work at 0.0 bar $p_{1}$ in $\mathbf{c}$ and $\mathbf{d}$, and divided by expected $\Delta \mathrm{DIC}_{3 \rightarrow 1}$ at $p_{1}=0.4$ mbar obtained from Fig. $\mathbf{4 d}$. The solid line refers to a linear fit of $\mathrm{CO}_{2}$ molar cycle work vs. current density assuming $\mathrm{TA}_{3^{\prime} \mathrm{i}}=0.11 \mathrm{M}\left(\Delta \mathrm{DIC}_{3 \rightarrow 1}=0.049 \mathrm{M}\right)$ and the dashed line refers to the same information but assuming $\mathrm{TA}_{3^{\prime} \mathrm{i}}=0.0 \mathrm{M}\left(\Delta \mathrm{DIC}_{3 \rightarrow 1}=0.096 \mathrm{M}\right)$.

\section{Estimate of Molar Cycle Work at $p_{1}=0.4$ mbar and $p_{3}=1$ bar}

Using the results obtained from $p_{1}=0.1-0.5$ bar, we estimate the $\mathrm{CO}_{2}$ molar cycle work for $p_{1}=$ $0.4 \mathrm{mbar}$ and $p_{3}=1$ bar, i.e. similar to DAC conditions. However, a simple regression of the molar cycle work from higher $p_{1}$ values to $p_{1}=0.4 \mathrm{mbar}$ does not guarantee accurate extrapolation because both deacidification work (Fig. 5c) and $\Delta \mathrm{DIC}_{\text {flow }, 3 \rightarrow 1}$ vary as $p_{1}$ varies $(\mathbf{F i g} . \mathbf{4 d})$. Instead, we evaluate the molar cycle work at $p_{1}=0.4 \mathrm{mbar}$ using cycle work (Fig. 5c and d) and ideal cycle $\Delta \mathrm{DIC}_{\mathrm{TA}-\mathrm{eq}, 3 \rightarrow 1}$, which we show corresponds closely to $\Delta \mathrm{DIC}_{\text {flow }, 3 \rightarrow 1}$ at various $p_{1}$. The deacidification work at $p_{1}=0.4 \mathrm{mbar}$ is simply the deacidification work under a pure $\mathrm{N}_{2}$ atmosphere, i.e. 0.0 bar $p \mathrm{CO}_{2}$ (Fig. 5c), and the reason that deacidification work decreases with higher $p_{1}$ is that higher $p_{1}$ lowers the average negolyte $\mathrm{pH}$, which in turn decreases the cell voltage and thereby decreases the work (eq. 3). The acidification work is always the same because $p_{3}$ is always 1 bar and $\Delta \mathrm{TA}_{3 \rightarrow 1}$ is always the same (hence the flat lines in Fig. 5d); therefore for $p_{1}=0.0$ bar we use the average work from higher $p_{1}$ values. With $\mathrm{TA}^{\prime}{ }^{\prime} \mathrm{i}=0.11 \mathrm{M}$ and $\Delta \mathrm{TA}_{3 \rightarrow 1}=0.21 \mathrm{M}$, $\Delta \mathrm{DIC}_{3 \rightarrow 1}$ at $p_{1}=0.4 \mathrm{mbar}$ and $p_{3}=1$ bar is $0.049 \mathrm{M}$ (Fig. 4d). The molar cycle work for various current densities, evaluated by dividing the sum of deacidification and acidification work at $p_{1}=$ 0.0 bar by $0.049 \mathrm{M}$, is shown in Fig. 5f. A linear extrapolation through these values projects a minimum cycle work of $211.8 \mathrm{~kJ} \mathrm{~mol} \mathrm{CO}^{-1}$ at the small-current-density limit (Fig. 5f). This is about $10 \%$ less energetic cost comparing with the concentrated $\mathrm{KOH}$ process. ${ }^{9}$ As shown by the dashed curve, however, with $\mathrm{TA}_{3^{\prime}} \mathrm{i}=0.0 \mathrm{M}$ and the same $\Delta \mathrm{TA}_{3 \rightarrow 1}$, the cycle work may be cut in half to $108.1 \mathrm{~kJ} \mathrm{~mol} \mathrm{CO}^{-1}$; this occurs because of the nearly doubled $\Delta \mathrm{DIC}_{\text {flow }, 3 \rightarrow 1}$ of $0.096 \mathrm{M}$ despite similar cycle work (ESI, Fig. S2 and S3). In addition, due to its solubility of $0.7 \mathrm{M}$ in aqueous solution, ${ }^{18} \mathrm{DSPZ}$ can induce a $\Delta \mathrm{TA}_{3 \rightarrow 1}$ or $\Delta\left[\mathrm{OH}^{-}\right]$of $1.4 \mathrm{M}$ and thereby potentially yield even lower molar cycle work (ESI, Fig. S4)

\section{Comparison with Existing Technologies}

Table 2 summarizes some of the emerging technologies for point source capture, DAC, and direct ocean capture (DOC), where $\mathrm{CO}_{2}$ is removed from seawater, allowing more $\mathrm{CO}_{2}$ uptake by the ocean. Many approaches to DAC have used aqueous alkaline solutions ${ }^{2,9}$ or solid amine-based adsorption methods, ${ }^{2,}{ }^{24}$ which require thermal excursions to release captured $\mathrm{CO}_{2}$. One of the state-of-the-art DAC approaches relies on concentrated (2-5 Molar) alkaline solutions on a higharea contactor to absorb $\mathrm{CO}_{2}$ and transform it into aqueous $\mathrm{K}_{2} \mathrm{CO}_{3}$ and $\mathrm{KHCO}_{3}$. These are then converted into solid $\mathrm{CaCO}_{3}$ in a pellet reactor by mixing the aqueous carbonates with $\mathrm{Ca}(\mathrm{OH})_{2}$. Releasing the $\mathrm{CO}_{2}$ requires heating the $\mathrm{CaCO}_{3}$ to $900{ }^{\circ} \mathrm{C}$ in an oxygen-fired calciner, which costs $264-296 \mathrm{~kJ} / \mathrm{molCO}_{2}{ }^{2,}{ }^{2}$ Another, less mature, aqueous approach uses amino acids for the carbon capture step and undergoes a subsequent sorbent regeneration cycle employing solid bisiminoguanidine carbonate precipitation and $\mathrm{CO}_{2}$ release through heating to $>100{ }^{\circ} \mathrm{C}$; this cycle requires $152-422 \mathrm{~kJ} / \mathrm{molCO}_{2}$, depending on the type of guanidine, because a significant portion of the energy contributes to removing the undesirable hydrate from guanidine carbonate crystal. ${ }^{10,16}$ Solid sorbent DAC, mostly based on solid amine absorption and release through thermal and/or 
pressure swing, allows reduced heating requirements $\left(\sim 100^{\circ} \mathrm{C}\right)$, but the amines may decompose to volatile species that may damage the environment. ${ }^{2}$

Electrochemical carbon capture methods may offer solutions to overcome the high sorbent regeneration energy penalty and sorbent decomposition issues. Electrochemically mediated point source carbon capture methods ${ }^{7,24,26}$, at low current densities, have exhibited lower energetic costs than amine-scrubbing methods. In addition, $\mathrm{CO}_{2}$ removal from ocean water, which restores the $\mathrm{CO}_{2}$ capture capability of oceans, via electrochemical methods such as bipolar membrane electrodialysis (BPMED), have shown promisingly low energetic cost. ${ }^{12,}{ }^{13}$ However, the demonstrated works exhibited either low current density (slow kinetics) or low voltage efficiency. In addition, the high water-handling requirement of direct ocean capture adds significantly to the energetic cost.

The performance of our $\mathrm{pH}$-swing flow cell, demonstrated for capture at 0.1 bar and projected for 0.4 mbar appears competitive compared with existing technologies, not only in terms of energetic cost with cheap electricity from renewable sources, but also because of much larger applicable current density (Table 2). ${ }^{27}$ Additionally, the all-liquid configuration obviates the need for the precipitation and heating of solid carbonates. Furthermore, the compatibility with an aqueous electrolyte of non-volatile, non-corrosive and potentially low-cost organic molecules implies that a carbon capture technology based on this concept has the potential for wide scale practical implementation.

Table 2| Comparison of this work and emerging technologies for DAC, DOC and point source capture. $\mathrm{CO}_{2}$ separation work with "th" subscript denote thermal energy inputs, whereas " $e$ " subscript denotes electrical work input.

\begin{tabular}{|c|c|c|c|}
\hline Method & Purpose & $\begin{array}{c}\mathrm{CO}_{2} \text { separation } \\
\text { work inputs } \\
\left(\mathrm{kJ} \text { mol }_{\mathrm{CO}_{2}}^{-1}\right)\end{array}$ & $\begin{array}{l}\text { Current Density } \\
\qquad\left(\mathrm{mA} \mathrm{cm}^{-2}\right)\end{array}$ \\
\hline Alkaline solvent ${ }^{2,9}$ & DAC & $264-396_{t h}{ }^{a}$ & $\mathrm{~N} / \mathrm{A}$ \\
\hline Solid amine sorbents ${ }^{2}$ & DAC & $150-211_{\mathrm{th}}{ }^{\mathrm{b}}$ & $\mathrm{N} / \mathrm{A}$ \\
\hline $\begin{array}{l}\text { Amino acid solvents and solid bis- } \\
\text { iminoguanidines }{ }^{10}\end{array}$ & DAC & $152-422_{\mathrm{th}^{\mathrm{C}}}^{\mathrm{c}}$ & N/A \\
\hline Fuel cell concentrator ${ }^{17}$ & DAC & $350_{e}^{d}$ & 0.5 \\
\hline $\begin{array}{l}\text { Processing seawater within a } \\
\text { BPMED reactor }{ }^{13}\end{array}$ & DOC & $155_{\mathrm{e}}^{\mathrm{f}}$ & 3.3 \\
\hline $\begin{array}{l}\text { Titrating seawater with BPMED } \\
\text { acid/base }{ }^{12}\end{array}$ & DOC & $39 \mathrm{e}^{\mathrm{g}}$ & 100 \\
\hline Traditional amine ab-/desorption ${ }^{4}$ & $\begin{array}{l}\text { Point source } \\
\text { capture }\end{array}$ & $132-150_{\text {th }}$ & $N / A$ \\
\hline Shell Cansolv ${ }^{6}$ & $\begin{array}{l}\text { Point source } \\
\text { capture }\end{array}$ & $103_{\text {th }}$ & N/A \\
\hline Quinone Direct binding $^{7}$ & $\begin{array}{l}\text { Point source } \\
\text { capture }\end{array}$ & $56 e^{h}$ & 0.5 \\
\hline EMAR $^{8}$ & $\begin{array}{l}\text { Point source } \\
\text { capture }\end{array}$ & $30-113_{e}^{i}$ & $2.7-11.8$ \\
\hline This work & $\begin{array}{l}0.1 \text { bar } \\
\text { capture }\end{array}$ & $61-145_{e}$ & $20-150$ \\
\hline
\end{tabular}




\begin{tabular}{|l|c|c|c|}
\hline & $\begin{array}{c}0.4 \text { mbar } \\
\text { capture }\end{array}$ & $108-212_{e}$ & Small-current-density limit \\
\hline
\end{tabular}

aWork input excludes electrical work required to operate air-liquid contactor, pellet reactor and auxiliary equipment. bDesorption energy for mid-range scenario; work input excludes electrical work required to operate air contactor fans and desorption vacuum pump.

'Energy required for bis(iminoguanidine) regeneration.

dHydrogen gas is the energy source; Energy required to operate water cooling system is excluded.

fWork input excludes costs for ocean water intake, pre-treatment and pumping.

gEnergy consumption for the best-case acid process; Work input excludes electrical work required to operate pumps and chiller.

hThe inlet gas source was simulated flue gas with $15 \% \mathrm{CO}_{2}$ and $3 \% \mathrm{O}_{2}$ in $\mathrm{N}_{2}$, but exit partial pressure was $\sim 0$ bar. Note that the energy cost was calculated based on the amount of $\mathrm{CO}_{2}$ absorbed, yet it is not clear that all absorbed $\mathrm{CO}_{2}$ was released.

iEnergy and current density values adopted from Fig.8(a) of ref. ${ }^{8}$ Simulated flue gas is $15 \% \mathrm{CO}_{2}$ in $\mathrm{N}_{2}$.

\section{Electrochemical Rebalancing}

It is clearly difficult to avoid $\mathrm{O}_{2}$ in either DAC or flue gas capture because the source gas contains $20 \%$ and $3-5 \% \mathrm{O}_{2}$, respectively. In the short term, the oxidation of $\mathrm{DSPZH}_{2}$ by $\mathrm{O}_{2}$ incurs an instantaneous loss in Coulombic efficiency. In the long term the cell will go out of balance, accumulating oxidized species in both electrolytes and $\mathrm{TA}_{3^{\prime}} \mathrm{i}, \mathrm{KOH}$ and $\mathrm{DIC}_{3^{\prime}}$ i in the negolyte (Fig. 1b). ${ }^{23}$ As a result, $\triangle \mathrm{DIC}_{3 \rightarrow 1}$ will shrink without a concomitant decrease in cycle work (ESI, Fig. S2b), leading to an increase in $\mathrm{CO}_{2}$ molar cycle work (ESI, Fig. S2c). Eventually the cell will no longer operate because both electrolytes are completely oxidized. As shown in Fig. 6a and b, as soon as the headspace was opened to air the Coulombic efficiency decreased to $\sim 65 \%$, and by the $20^{\text {th }}$ subsequent cycle the cell lost all capacity due to depletion of reduced species, i.e. $\left[\mathrm{K}^{+}\right]_{4}\left[\mathrm{Fe}^{\mathrm{II}}(\mathrm{CN})_{6}\right]^{4-}$, in the posolyte side. The negolyte $\mathrm{pH}$ also increased from near neutral to almost 14 during air exposure (ESI, Fig. S11b). Development of oxygen-insensitive molecules may alleviate the problem caused by oxygen, but even if a tiny amount of Coulombic efficiency loss, e.g. $0.1 \%$, took place every cycle, the effect is cumulative and will eventually lead to an out-ofbalance cell problem (Fig. 1b). 
a

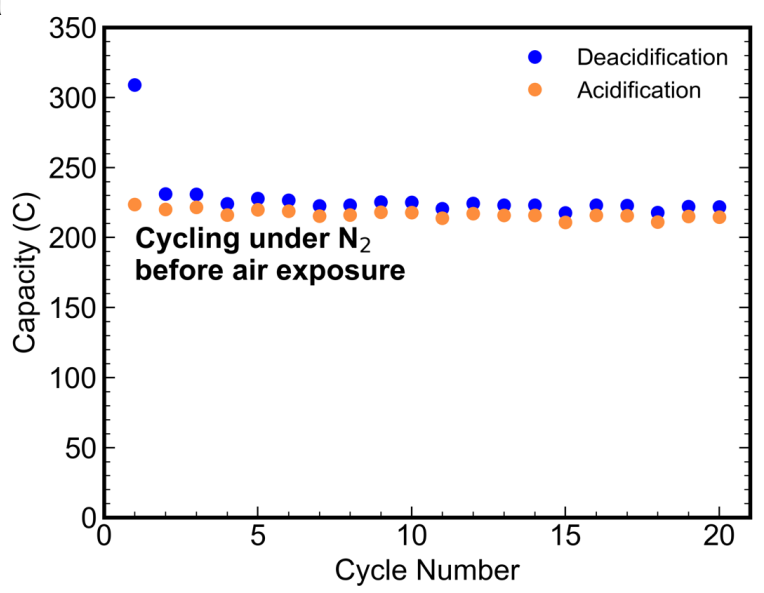

b

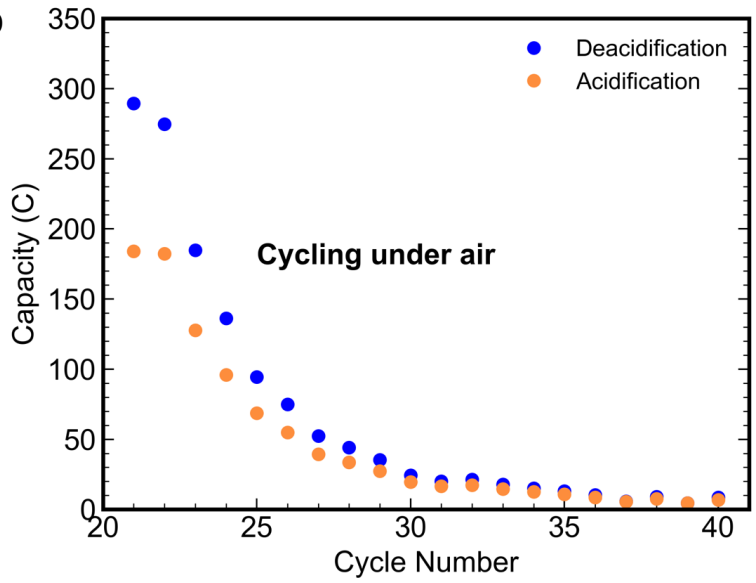

C

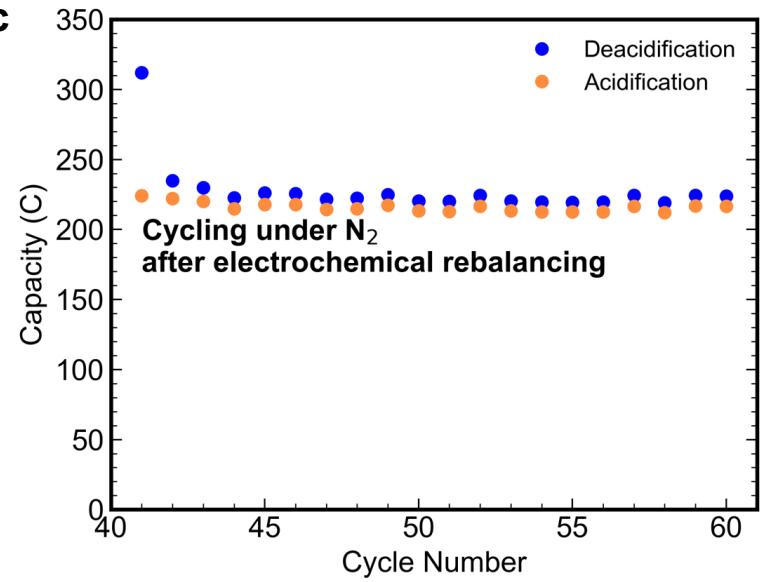

d

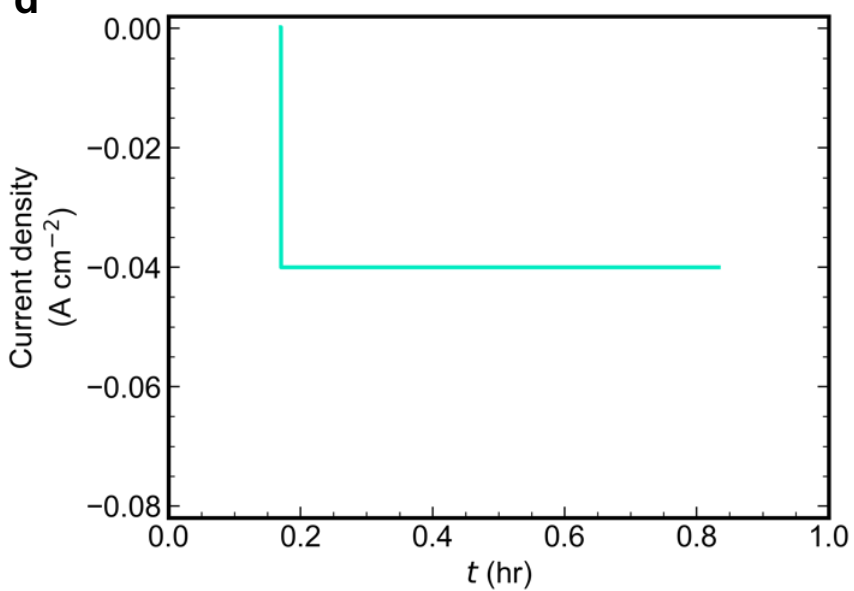

e

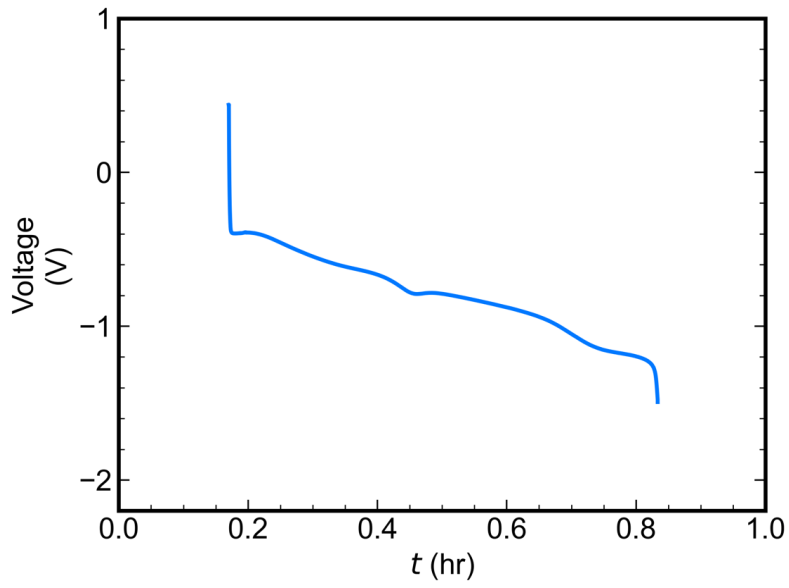

f

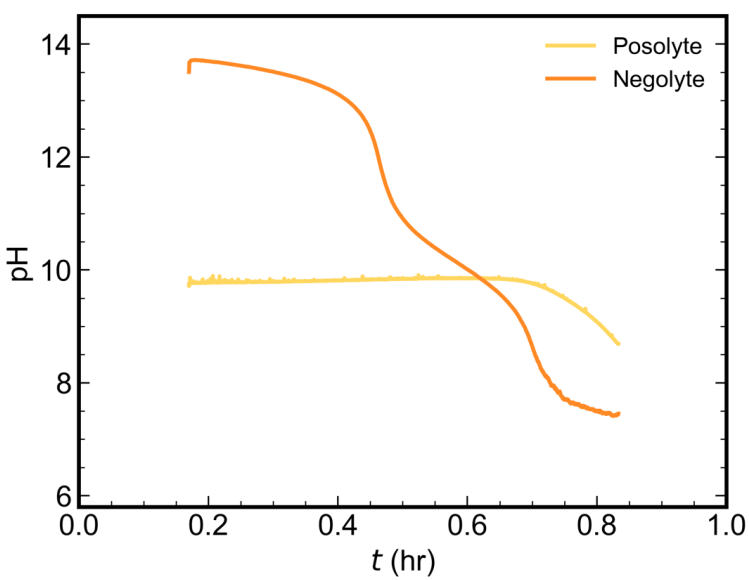

Fig. 6| The capacity fade caused by $\mathrm{O}_{2}$ on $\mathrm{Fe}(\mathrm{CN})_{6} \mid \mathrm{DSPZ}$ cell cycling $(a, b, c)$ and its mitigation by the electrochemical rebalancing method (d,e,f). a, Charge capacity vs. cycle number of the cell under pure $\mathrm{N}_{2}$ atmosphere. The first cycle has much higher deacidification capacity due to residual oxygen $\mathbf{b}$, Charge capacity vs. cycle number of the same cell from a under air. Capacity fades quickly because of the depletion of $\mathrm{K}_{4} \mathrm{Fe}(\mathrm{CN})_{6}$ in the posolyte. c, Charge capacity vs. cycle number of the cell from $\mathbf{b}$ under pure $\mathrm{N}_{2}$ atmosphere, after the electrochemical rebalancing step. The first cycle has much higher deacidification capacity due to residual oxygen. d, Current density, e, voltage, f, Posolyte and negolyte $\mathrm{pH}$ during the electrochemical rebalancing step 
Here we demonstrate the efficacy of the electrochemical rebalancing method. The method successfully recovers the $\mathrm{pH}$ of the negolyte and the capacity of the cell, which is thrown out-ofbalance by $\mathrm{O}_{2}$-induced side reactions. The electrochemical rebalancing process comprises the cathodic reaction $\left[\mathrm{K}^{+}\right]_{3}\left[\mathrm{Fe}^{\mathrm{III}}(\mathrm{CN})_{6}\right]^{3-}+\mathrm{e}^{-} \rightarrow\left[\mathrm{K}^{+}\right]_{4}\left[\mathrm{Fe}^{\mathrm{II}}(\mathrm{CN})_{6}\right]^{4-}$ in the posolyte and the anodic oxygen evolution reaction, $\mathrm{OH}^{-} \rightarrow 2 \mathrm{e}^{-}+1 / 2 \mathrm{O}_{2}$, in the negolyte. Fig. 6d,e and $\mathbf{f}$ show the cell behavior when the electrochemical rebalancing process is applied to the completely out-of-balance cell (Fig. 6b). The process starts when a constant current of $-40 \mathrm{~mA} \mathrm{~cm}^{-2}$ is applied (Fig. 6d). The voltage immediately drops from $0.2 \mathrm{~V}$ to negative values because both the cathodic and anodic half reactions are at $\sim 0.4 \mathrm{~V}$ vs. SHE at $\mathrm{pH} 14$, and there is high activation overpotential for the oxygen evolution reaction (Fig. 6e). As the rebalancing process progresses, the $\mathrm{pH}$ of the negolyte side decreases (Fig. 6f), causing the anodic half reaction to shift to higher potential, thereby further decreasing the cell potential (Fig. 6e). The sharp drop in voltage to a plateau near 0.8 hours indicates the completion of the electrochemical rebalancing process. Fig. 6c shows the postrebalancing cell capacity, which is almost identical to that prior to air exposure (Fig. 6a), indicating that essentially all lost capacity due to imbalance has been restored. The capacity accounting for all the electrons passed in the electrochemical rebalancing step is $476.8 \mathrm{C}$, which is within $1 \%$ of the theoretical capacity $(473 \mathrm{C})$ of the posolyte side, suggesting a complete recovery of the $\mathrm{K}_{4} \mathrm{Fe}(\mathrm{CN})_{6}$ and minimal side reactions other than oxygen evolution. The posolyte $\mathrm{pH}$ did not change much during the process because the cathodic half-reaction is not proton-coupled (Fig. 6f). The neutral $\mathrm{pH}$ of the negolyte at the end of the process indicates that virtually all of the accumulated hydroxide has been removed (Fig. 6f). The undiminished capacity also suggests that this method is not detrimental to DSPZ. Fig. S10 shows that the electrolytes, after electrochemical rebalancing, have the same carbon-capture capability as the original electrolytes. Hence, the electrochemical rebalancing process is a very effective method to remove the adverse effect of oxygen in DSPZ-based carbon capture flow cells. This method has potentially broad application beyond DSPZ and carbon capture, e.g. mitigating the oxygen effect in flow batteries with air or $\mathrm{pH}$ sensitive electrolytes (ESI, More on Electrochemical Rebalancing). ${ }^{23},{ }^{28-35}$ The overall energy cost is $378 \mathrm{~J}$, which is approximately 1.4 times of the cost of one deacidification half cycle at $40 \mathrm{~mA} \mathrm{~cm}^{-2}$ (Fig. 5c). This will be a significant cost if the electrochemical rebalancing is applied every few cycles, which may be necessary for a DSPZ-based system for DAC, but if the negolyte molecule is much less air sensitive or the source gas has lower oxygen content, requiring electrochemical rebalancing less frequently than once every few tens of carbon capture/release cycles, the cost will be negligible. The development of oxygen-insensitive molecules for this purpose is the subject of active research.

\section{Conclusion}

In this work, we have performed a series of $\mathrm{CO}_{2}$ concentrating cycles using a DSPZ-based flow cell with electrochemically induced $\mathrm{pH}$ swings, and the cycle work under different inlet partial pressures and current densities was analyzed and compared. We demonstrated a $61.3 \mathrm{~kJ} \mathrm{~mol}_{\mathrm{CO}_{2}}{ }^{-1}$ cycle work for $\mathrm{CO}_{2}$ separation for capture at $p_{1}=0.1$ bar and release at $p_{3}=1 \mathrm{bar}$, at a current density of $20 \mathrm{~mA} \mathrm{~cm}^{-2}$. If $\mathrm{TA}_{3}{ }^{\prime} \mathrm{i}$ is carefully maintained at a low level the projected separation work for $p_{1}=0.4 \mathrm{mbar}$ and $p_{3}=1 \mathrm{bar}$, in the low current limit, is $108.1 \mathrm{~kJ} \mathrm{~mol}_{\mathrm{CO} 2}{ }^{-1}$, and this figure can be further lowered if a higher concentration of DSPZ or another PCET-active molecule is used. Recognizing the inevitable $\mathrm{O}_{2}$-induced imbalance and capacity fade in both point source capture and DAC, we report an electrochemical rebalancing method that recovers the initially healthy cell 
composition. This method can serve as a convenient tool for mitigating oxygen-related problems in many electrochemical applications. We anticipate that the low energetic cost of the $\mathrm{pH}$ swing cycles and the effectiveness of the oxygen mitigation method demonstrated here will accelerate the techno-economic competitiveness of electrochemically-driven carbon capture systems.

\section{Methods}

\section{Materials and characterization}

All chemicals were purchased from Sigma-Aldrich or Acros Organics and were used as received. The synthetic method for DSPZ is adapted from previous work. ${ }^{18}$ In this work, sodium hydride was used to deprotonate the reaction intermediate phenazine-2,3-diol (DHPZ) instead of sodium methoxide.

\section{Flow cell experiments}

Flow cell experiments were constructed with cell hardware from Fuel Cell Tech. (Albuquerque, NM), assembled into a zero-gap flow cell configuration, similar to a previous report. ${ }^{18}$ Pyrosealed POCO graphite flow plates with serpentine flow patterns were used for both electrodes. Each electrode comprised a $5 \mathrm{~cm}^{2}$ geometric surface area covered by a stack of four sheets of Sigracet SGL 39AA porous carbon paper pre-baked in air for $24 \mathrm{~h}$ at $400{ }^{\circ} \mathrm{C}$. The outer portion of the space between the electrodes was gasketed by Viton sheets with the area over the electrodes cut out. Torque applied during cell assembly was $80 \mathrm{lb}$-in on each of eight 1/4-28 bolts. The membrane used is a Fumasep E620(K) cation exchange membrane. Cell electrolytes comprised $10 \mathrm{~mL} 0.11 \mathrm{M} \mathrm{DSPZ}$ in $1 \mathrm{M} \mathrm{KCl}$ (negolyte, capacity limiting, theoretical capacity $212 \mathrm{C}$ ) and $35 \mathrm{~mL} 0.1 \mathrm{M} \mathrm{K}_{4} \mathrm{Fe}(\mathrm{CN})_{6}$ and $0.04 \mathrm{M} \mathrm{K}_{3} \mathrm{Fe}(\mathrm{CN})_{6}$ in $1 \mathrm{M} \mathrm{KCl}$ (posolyte, noncapacity limiting, theoretical capacity $473 \mathrm{C}$ ). For every new $\mathrm{CO}_{2}$ capture cycle condition (changing current density or inlet $p \mathrm{CO}_{2}$ ), the posolyte was replaced with a fresh solution and the negolyte was acidified by adding drops of $1 \mathrm{M}$ $\mathrm{HCl}$ to remove the accumulating effect of oxygen side reactions. $10 \mu \mathrm{L}$ of antifoam B emulsion purchased from SigmaAldrich was added into the negolyte solution before cell cycling to suppress foam formation. Posolytes were fed into the cell through fluorinated ethylene propylene (FEP) tubing at a rate of $100 \mathrm{~mL} \mathrm{~min}^{-1}$ controlled by a Cole-Parmer 6 Masterflex L/S peristaltic pump, and the negolytes were circulated at the same rate controlled by a Cole-Parmer Masterflex digital benchtop gear pump system. Both posolyte and negolyte upstream gas was controlled by Sierra Smart Trak 50 Mass Flow Controllers. The flowmeter used in the downstream of negolyte headspace was a Servoflo FS4001-100-V-A. The $\mathrm{CO}_{2}$ sensor was an ExplorIR-W 100\% $\mathrm{CO}_{2}$ sensor purchased from co2meter.com. A Mettler Toledo pH electrode LE422 was used to monitor electrolyte pH. As shown in Fig. 1 a, a drierite drying tube (Cole Parmer) was placed in between the sensors and the negolyte chamber to reduce humidity level of the gas.

Glassy carbon (BASi MF-2012, 3.0mm diameter) was used as the working electrode for all three-electrode CV tests. $\mathrm{A} \mathrm{Ag} / \mathrm{AgCl}$ reference electrode (BASi MF-2052, pre-soaked in $3 \mathrm{M} \mathrm{NaCl}$ solution), and a graphite counter electrode were used for CV tests. CV tests and cell cycling were performed using a Gamry Reference 3000 potentiostat. All cycles were galvanostatic until the $1.65 \mathrm{~V}$ and $0.2 \mathrm{~V}$ voltage cutoff for deacidification and acidification, respectively, were reached, and then went through a potentiostatic process until the current reached $10 \mathrm{~mA} \mathrm{~cm}^{-2}$. In the $\mathrm{CO}_{2}$ cycles with $p_{1}=0.1,0.2,0.3,0.4$, and 0.5 bar, the MFCs set the initial negolyte headspace atmosphere to be $p_{1}$, which was then switched back and forth between $p_{1}$ and $p_{3}$ every three hours. In the cycles with $p_{1}=0.05$ bar, the switching period was five hours.

\section{Calculation of absorbed or released $\mathrm{CO}_{2}$ amount}

Because the deviation from baseline in Fig. $2 \mathbf{g}$ is solely caused by $\mathrm{CO}_{2}$ absorption, the amount of $\mathrm{CO}_{2}$ captured is calculated by integrating over the difference between the recorded flow rate and the baseline in between 0.2 and 1.8 hours, i.e.

$$
Q_{\mathrm{CO}_{2}}=\sum_{n=t_{i}}^{t_{f}}\left(\dot{V}^{\text {base }}-\dot{V}^{n}\right) \Delta t
$$


where $Q_{\mathrm{CO}}$ is the volume of $\mathrm{CO}_{2}, t_{\mathrm{i}}$ is the start time, $t_{\mathrm{f}}$ is the final time, $\dot{V}^{\mathrm{n}}$ is the instantaneous volumetric flow rate at $n^{\text {th }}$ data recording time $t_{\mathrm{n}}$, $V^{\text {base }}$ is the baseline flow rate of $11.6 \mathrm{~mL} \mathrm{~min}{ }^{-1}$, and $\Delta t$ is the time difference between successive measurements.

\section{Calculation of deacidification, acidification and cycle work}

The net cycle work is calculated by combining the work required for deacidification in process $3{ }^{\prime} i \rightarrow 1$ and the work returned by acidification in process $1^{\prime} \rightarrow 3$, i.e.

$$
w_{\text {cycle }}=w_{\text {deacidification }}+w_{\text {acidification }}
$$

The work in a process is calculated by summing over the product of voltage (Fig. 2 a) and current (Fig. 2 b), i.e.

$$
w_{\text {deacidification/acidification }}=\sum_{n=t_{i}}^{t_{f}} V^{n} j^{n} A \Delta t
$$

where $V^{\mathrm{n}}$ is the cell voltage at the $n^{\text {th }}$ data recording time $t^{\mathrm{n}}, j^{\mathrm{n}}$ is the current density at $t^{\mathrm{n}}$ and $A$ is the active geometric area of $5 \mathrm{~cm}^{2}$.

The molar cycle work $\bar{w}$ is calculated by dividing $w_{\text {cycle }}$ by $-\Delta \mathrm{DIC}$ flow, $1 \rightarrow 3$ or $\Delta \mathrm{DIC}_{\text {flow }, 3 \rightarrow 1}$ :

$$
\bar{w}=\frac{w_{\text {cycle }}}{\Delta D I C_{\text {flow }, 3 \rightarrow 1}}
$$

where $\Delta \mathrm{DIC}_{\text {flow }, 1 \rightarrow 3}=\Delta \mathrm{DIC}_{\mathrm{TA}-\mathrm{pH}, 1 \rightarrow 1^{\prime}}+\Delta \mathrm{DIC}_{\text {flow }, 1^{\prime} \rightarrow 3}$ and $\Delta \mathrm{DIC}_{\text {flow }, 3 \rightarrow 1}=\Delta \mathrm{DIC}_{\text {flow }, 3^{\prime} \rightarrow 1}+\Delta \mathrm{DIC}_{\mathrm{TA}-\mathrm{pH}, 3 \rightarrow 3^{\prime} \text { f. For high }}$

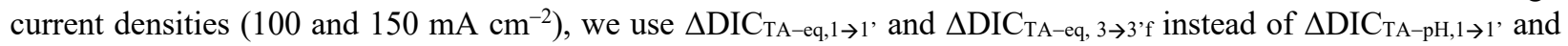

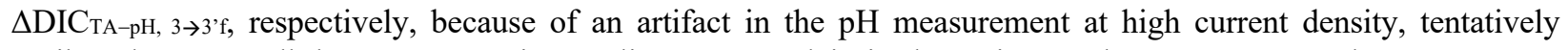
attributed to crosstalk between potentionstat lines. We explain in the main text that $\triangle \mathrm{DIC}_{\mathrm{TA}-\mathrm{pH}}$ and $\triangle \mathrm{DIC} \mathrm{C}_{\mathrm{TA}-\mathrm{eq}}$ are interchangeable when the $\mathrm{pH}$ measurement is valid.

Data availability: The data and code that support the plots and discussion of this study are available from the corresponding author upon reasonable request.

\section{Conflicts of interest}

503 None.

\section{Acknowledgments}

505 This research was supported by a grant from the Harvard University Climate Change Solutions

506 Fund. We thank Daniel Schrag, Robert Gustafson, Anatoly Rinberg, Andrew Bergman, Tommy

507 George and Eric Fell for helpful discussions. 
1. Raupach, M. R.; Marland, G.; Ciais, P.; Le Quere, C.; Canadell, J. G.; Klepper, G.; Field, C. B., Global and regional drivers of accelerating $\mathrm{CO}_{2}$ emissions. Proc Natl Acad Sci U S A 2007, 104 (24), 10288-93. 2. Negative Emissions Technologies and Reliable Sequestration: A Research Agenda (2019). The National Academies Press: 2019.

517 3. Annual Energy Outlook 2020 with projections to 2050. DOE, Ed. www.eia.gov/aeo, 2020.

518 4. Goto, K.; Kodama, S.; Higashii, T.; Kitamura, H., Evaluation of Amine-Based Solvent for Post-Combustion Capture of Carbon Dioxide. J Chem Eng Jpn 2014, 47 (8), 663-665.

5. Li, K.; Cousins, A.; Yu, H.; Feron, P.; Tade, M.; Luo, W.; Chen, J., Systematic study of aqueous monoethanolamine-based $\mathrm{CO}_{2}$ capture process: model development and process improvement. Energy Science \& Engineering 2016, 4 (1), 23-39.

6. Singh, A.; Stéphenne, K., Shell Cansolv $\mathrm{CO}_{2}$ capture technology: Achievement from First Commercial Plant. Energy Procedia 2014, 63, 1678-1685.

7. Liu, Y.; Ye, H. Z.; Diederichsen, K. M.; Van Voorhis, T.; Hatton, T. A., Electrochemically mediated carbon dioxide separation with quinone chemistry in saltconcentrated aqueous media. Nat Commun 2020, 11 (1), 2278.

8. Wang, M.; Herzog, H.; Hatton, T. A., $\mathrm{CO}_{2}$ Capture Using Electrochemically Mediated Amine Regeneration. Industrial \& Engineering Chemistry Research 2020, 59, 7087-7096.

530 9. Keith, D. W.; Holmes, G.; St. Angelo, D.; Heidel, K., A Process for Capturing $\mathrm{CO}_{2}$ from the Atmosphere. Joule 2018, 2 (8), 1573-1594.

10. Brethomé, F. M.; Williams, N. J.; Seipp, C. A.; Kidder, M. K.; Custelcean, R., Direct air capture of $\mathrm{CO}_{2}$ via aqueous-phase absorption and crystalline-phase release using concentrated solar power. Nat Energy 2018, 3 (7), 553-559.

11. Sanz-Perez, E. S.; Murdock, C. R.; Didas, S. A.; Jones, C. W., Direct Capture of $\mathrm{CO}_{2}$ from Ambient Air. Chem Rev 2016, 116 (19), 11840-11876.

12. de Lannoy, C.-F.; Eisaman, M. D.; Jose, A.; Karnitz, S. D.; DeVaul, R. W.; Hannun, K.; Rivest, J. L. B., Indirect ocean capture of atmospheric $\mathrm{CO}_{2}$ : Part I. Prototype of a negative emissions technology. Int J Greenh Gas Con 2018, 70, 243-253.

540 13. Digdaya, I. A.; Sullivan, I.; Lin, M.; Han, L.; Cheng, W. H.; Atwater, H. A.; Xiang, C., 541 A direct coupled electrochemical system for capture and conversion of $\mathrm{CO}_{2}$ from oceanwater. Nat 542 Commun 2020, 11 (1), 4412.

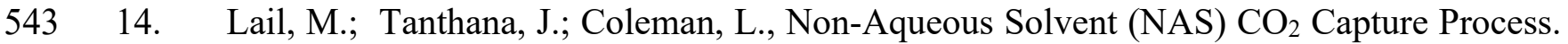
544 Energy Procedia 2014, 63, 580-594.

545 15. Heldebrant, D. J.; Koech, P. K.; Glezakou, V.-A.; Rousseau, R.; Malhotra, D.; Cantu, D. 546 C., Water-Lean Solvents for Post-Combustion $\mathrm{CO}_{2}$ Capture: Fundamentals, Uncertainties, 547 Opportunities, and Outlook. Chemical Reviews 2017, 117, 9594-9624.

548 16. Custelcean, R.; Williams, N. J.; Wang, X.; Garrabrant, K. A.; Martin, H. J.; Kidder, M. 549 K.; Ivanov, A. S.; Bryantsev, V. S., Dialing in Direct Air Capture of $\mathrm{CO}_{2}$ by Crystal Engineering of Bisiminoguanidines. ChemSusChem 2020, 13, 6381-6390.

17. Eisaman, M.; Schwartz, D.; Amic, S.; Larner, D.; Zesch, J.; Torres, F.; Littau, K. In Energy-efficient electrochemical $\mathrm{CO}_{2}$ capture from the atmosphere, Technical Proceedings of the 2009 Clean Technology Conference and Trade Show, 2009; pp 3-7. 
18. Jin, S.; Wu, M.; Gordon, R. G.; Aziz, M. J.; Kwabi, D. G., pH swing cycle for $\mathrm{CO}_{2}$ capture electrochemically driven through proton-coupled electron transfer. Energy \& Environmental Science 2020, 13 (10), 3706-3722.

19. Xie, H.; Wu, Y.; Liu, T.; Wang, F.; Chen, B.; Liang, B., Low-energy-consumption electrochemical $\mathrm{CO}_{2}$ capture driven by biomimetic phenazine derivatives redox medium. Applied Energy 2020, 259.

560 20. Xie, H.; Jiang, W.; Liu, T.; Wu, Y.; Wang, Y.; Chen, B.; Niu, D.; Liang, B., Low561 Energy Electrochemical Carbon Dioxide Capture Based on a Biological Redox Proton Carrier.

21. Zeebe, R. E.; Wolf-Gladrow, D., $\mathrm{CO}_{2}$ in Seawater: Equilibrium, Kinetics, Isotopes. Elsevier: Amsterdam, 2005; Vol. 65.

22. Chen, Q.; Gerhardt, M. R.; Aziz, M. J., Dissection of the Voltage Losses of an Acidic Quinone Redox Flow Battery. Journal of the Electrochemical Society 2017, 164 (6), A1126A1132.

23. Goulet, M.-A.; Aziz, M. J., Flow Battery Molecular Reactant Stability Determined by Symmetric Cell Cycling Methods. Journal of the Electrochemical Society 2018, 165 (7), A1466A1477.

24. Renfrew, S. E.; Starr, D. E.; Strasser, P., Electrochemical Approaches toward $\mathrm{CO}_{2}$ Capture and Concentration. ACS Catalysis 2020, 10 (21), 13058-13074.

25. Kang, J. S.; Kim, S.; Hatton, T. A., Redox-responsive sorbents and mediators for electrochemically based $\mathrm{CO}_{2}$ capture. Current Opinion in Green and Sustainable Chemistry 2021, $31,100504$.

26. Voskian, S.; Hatton, T. A., Faradaic electro-swing reactive adsorption for $\mathrm{CO}_{2}$ capture. Energy \& Environmental Science 2019.

27. Sharifian, R.; Wagterveld, R. M.; Digdaya, I. A.; Xiang, C.; Vermaas, D. A., Electrochemical carbon dioxide capture to close the carbon cycle. Energy \& Environmental Science 2021.

28. Jin, S.; Jing, Y.; Kwabi, D. G.; Ji, Y.; Tong, L.; De Porcellinis, D.; Goulet, M. A.; Pollack, D. A.; Gordon, R. G.; Aziz, M. J., A water-miscible quinone flow battery with high volumetric capacity and energy density. ACS Energy Letters 2019, 4 (6), 1342-1348.

29. Ji, Y.; Goulet, M. A.; Pollack, D. A.; Kwabi, D. G.; Jin, S.; Porcellinis, D.; Kerr, E. F.; Gordon, R. G.; Aziz, M. J., A Phosphonate-Functionalized Quinone Redox Flow Battery at NearNeutral pH with Record Capacity Retention Rate. Advanced Energy Materials 2019, 9 (12), 1900039 .

30. Beh, E. S.; De Porcellinis, D.; Gracia, R. L.; Xia, K. T.; Gordon, R. G.; Aziz, M. J., A Neutral pH Aqueous Organic-Organometallic Redox Flow Battery with Extremely High Capacity Retention. ACS Energy Letters 2017, 2 (3), 639-644.

31. Jin, S.; Fell, E. M.; Vina-Lopez, L.; Jing, Y.; Michalak, P. W.; Gordon, R. G.; Aziz, M. J., Near Neutral pH Redox Flow Battery with Low Permeability and Long-Lifetime Phosphonated Viologen Active Species. Advanced Energy Materials 2020, 10 (20), 2000100.

32. Kwabi, D. G.; Lin, K.; Ji, Y.; Kerr, E. F.; Goulet, M.-A.; De Porcellinis, D.; Tabor, D. P.; Pollack, D. A.; Aspuru-Guzik, A.; Gordon, R. G.; Aziz, M. J., Alkaline quinone flow battery with long lifetime at $\mathrm{pH}$ 12. Joule 2018, 2 (9), 1907-1908.

33. Hu, B.; DeBruler, C.; Rhodes, Z.; Liu, T. L., Long-Cycling Aqueous Organic Redox Flow Battery (AORFB) toward Sustainable and Safe Energy Storage. J Am Chem Soc 2017, 139 (3), 1207-1214. 
600 34. Huang, C. L.; Liu, C. J.; Wu, K. J.; Yue, H. R.; Tang, S. Y.; Lu, H. F.; Liang, B., CO 601 Capture from Flue Gas Using an Electrochemically Reversible Hydroquinone/Quinone Solution. 602 Energ Fuel 2019, 33 (4), 3380-3389.

603 35. Ulaganathan, M.; Aravindan, V.; Yan, Q.; Madhavi, S.; Skyllas-Kazacos, M.; Lim, T. 604 M., Recent Advancements in All-Vanadium Redox Flow Batteries. Advanced Materials Interfaces 605 2016, $3(1), 1500309$.

606 


\section{Electronic Supplementary Information}

for

4

\section{Low Energy Carbon Capture via Electrochemically Induced pH Swing with} Electrochemical Rebalancing

Shijian Jin ${ }^{\dagger}$, Min Wu $\mathrm{u}^{\dagger}$, Yan Jing ${ }^{\ddagger}$, Roy Gordon ${ }^{\ddagger}$ and Michael J. Aziz ${ }^{{ }^{*}}$

$\dagger$ John A. Paulson School of Engineering and Applied Sciences, Harvard University, Cambridge, Massachusetts, 02138, United States

17

Department of Chemistry and Chemical Biology, Harvard University, Cambridge,

Massachusetts 02138, United States

*maziz [at] harvard [dot] edu 


\section{Table of Sections}

$1 \mathrm{CO}_{2}$ Molar Ideal Cycle Work ........................................................................................ 5

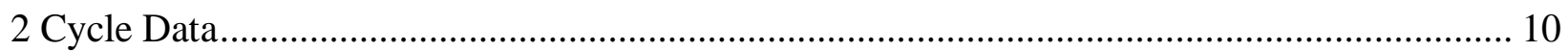

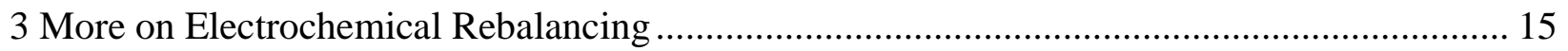

Table of Additional Figures

Fig. S 1| Ideal cycles constructed using $p_{1}=0.4$ mbar and $p_{3}=1$ bar, $\Delta \mathrm{TA} \mathrm{A}_{3 \rightarrow 1}=0.21 \mathrm{M}$ and varying $\mathrm{TA}_{3}{ }^{\prime}$. a-c, TA $3^{\prime}=0.0 \mathrm{M}$; d-f, TA $3^{\prime}=0.11 \mathrm{M}$ and g-i, TA $3^{\prime}=0.21 \mathrm{M}$; 7

Fig. S 2| Dependence of (a) $w_{\text {cycle,ideal, }}$ (b) $\Delta \mathrm{DIC}_{\mathrm{TA}-\mathrm{pH}, 3 \rightarrow 1}$ (c) and $\overline{\mathrm{w}}_{\text {ideal }}$ on $\mathrm{TA}_{3}$, in the ideal cycles

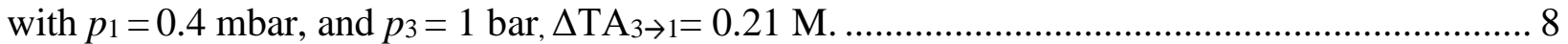

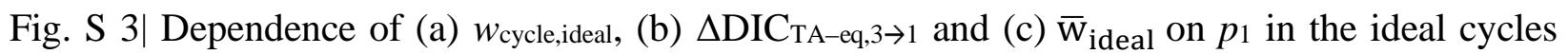
with $\Delta \mathrm{TA}_{3 \rightarrow 1}=0.21 \mathrm{M}$ and $\mathrm{TA}_{3}$ ' $=0.0,0.11$ and $0.21 \mathrm{M}$. The ' $\mathrm{x}$ ' marks indicate $p_{1}=0.4$ mbar. . 8

Fig. S $4 \mid$ Dependence of (a) $w_{\text {cycle,ideal, }}$ (b) $\Delta \mathrm{DIC}_{\mathrm{TA}-\mathrm{eq}, 3 \rightarrow 1}$ and (c) and $\overline{\mathrm{w}}_{\text {ideal }}$ on $\Delta \mathrm{TA}_{3 \rightarrow 1}$ in the ideal

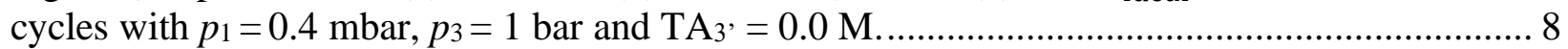

Fig. S 5| Duration of the CO2 capture and release processes in the cycles with $40 \mathrm{~mA} \mathrm{~cm} \mathrm{current}^{-2}$ density. a, Downstream $p \mathrm{CO}_{2}$ of one capture half cycle for each of the inlet $p \mathrm{CO}_{2}$ conditions. $\mathrm{b}$, Filtered total gas flow rate of one outgassing half cycle for each of the inlet $p \mathrm{CO}_{2}$ conditions. All the processes look identical because of the same exit condition, so an arbitrary offset is added to

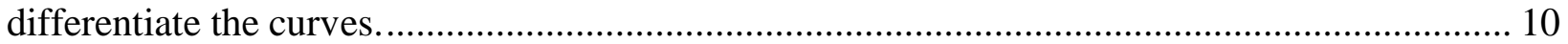

Fig. S 6| Capture and outgassing durations extracted from Fig. S 5 a and b. 10

Fig. S 7|Eighty-five $\mathrm{CO}_{2}$ concentrating cycles with varying inlet $p \mathrm{CO}_{2}$ and current densities. These are the raw data for Fig. 5. Same cell was used as in Fig 2. Liquid pumping rate is $50 \mathrm{~mL} \mathrm{~min}^{-1}$ for all the cycles. Note that, the $\mathrm{pH}$ measurements for high current densities are inaccurate, as the $\mathrm{pH}$ should never be able to reach $\mathrm{pH}>14$ for $0.11 \mathrm{M}$ DSPZ. a, Current density. b, Voltage. c, $\mathrm{N}_{2}$ and $\mathrm{CO}_{2}$ percentage in the upstream source gas, controlled by mass flow controllers. $\mathrm{d}, \mathrm{CO}_{2}$ partial pressure. e, Total gas flow rate. 11

Fig. S 8| One $\mathrm{CO}_{2}$ concentrating cycle from Fig. S 7 with 0.1 bar inlet $p \mathrm{CO}_{2}$ and 1 bar exit $p \mathrm{CO}_{2}$ at $150 \mathrm{~mA} \mathrm{~cm}^{-2}$. Note that, the $\mathrm{pH}$ measurements are not shown because of an inexplicable artifact only present at high current, so it is invalid to extract $\mathrm{DIC}_{\mathrm{TA}-\mathrm{pH}}$ for this condition. However, $\mathrm{DIC}_{\mathrm{TA}-\mathrm{eq}}$ can be extracted because sufficient gas-solution is reached, as demonstrated by fact that the $p \mathrm{CO}_{2}$ and flow curves return to their baselines after $\mathrm{CO}_{2}$ invasion and outgassing. a, Voltage profile. b, Current density. c, $\mathrm{N}_{2}$ and $\mathrm{CO}_{2}$ percentage in the upstream source gas, controlled by MFC. d, $\mathrm{CO}_{2}$ partial pressure. e, Total gas flow rate. 12 
63 Fig. S 9| Five $\mathrm{CO}_{2}$ concentrating cycles with 0.05 bar inlet $p \mathrm{CO}_{2}$ and 1 bar exit $p \mathrm{CO}_{2}$ at $40 \mathrm{~mA}$ $64 \mathrm{~cm}^{-2}$. Same cell was used as in Fig. 2. Fresh negolyte and posolyte were used. The liquid pumping 65 rate is $150 \mathrm{~mL} \mathrm{~min}^{-1}$, which is $50 \%$ faster than for capture at higher inlet pressure. a, Voltage 66 profile. b, Current density. c, $\mathrm{pH}$ of the negolyte. $\mathrm{d}, \mathrm{N}_{2}$ and $\mathrm{CO}_{2}$ percentage in the upstream source gas, controlled by mass flow controllers. e, $\mathrm{CO}_{2}$ partial pressure. f, Total gas flow rate. 13

Fig. S 10| Post-electrochemical rebalancing $\mathrm{CO}_{2}$ capture with 0.05 bar inlet $p \mathrm{CO}_{2}$ and 1 bar exit $p \mathrm{CO}_{2}$ at $40 \mathrm{~mA} \mathrm{~cm}{ }^{-2}$. Same cell was used as in Fig.2. Same posolyte and negolyte as in Fig. S 9 were used. The liquid pumping rate is $150 \mathrm{~mL} \mathrm{~min}^{-1}$. a, Voltage profile. b, Current density. c, pH of the negolyte. $\mathrm{d}, \mathrm{N}_{2}$ and $\mathrm{CO}_{2}$ percentage in the upstream source gas, controlled by mass flow controllers. e, $\mathrm{CO}_{2}$ partial pressure. f, Total gas flow rate. The system has the same carbon capture/release capability after the post-electrochemical rebalancing.

Fig. S 11| pH of the negolyte during cycles before air exposure (a), under air (b) and after

Fig. S 12| Cyclic voltammetry of DSPZ and $1 \mathrm{M} \mathrm{KOH}$ background. No additional peak was 


\begin{tabular}{|c|c|}
\hline Acronyms & Explanation \\
\hline BPMED & bipolar membrane electrodialysis \\
\hline CEM & cation exchange membrane \\
\hline DAC & direct air capture \\
\hline DIC & dissolved inorganic carbon \\
\hline $\mathrm{DIC}_{\mathrm{x}}$ & concentration of dissolved inorganic carbon in state " $\mathrm{x} "$ \\
\hline$\Delta \mathrm{DIC}_{\text {flow }, x \rightarrow y}$ & $\begin{array}{c}\text { change in DIC between states " } \mathrm{x} \text { " and " } \mathrm{y} \text { " }\left(\mathrm{DIC}_{\mathrm{y}}-\mathrm{DIC} \mathrm{D}_{\mathrm{x}}\right) \text {, measured by } \\
\text { flow meter and } \mathrm{CO}_{2} \text { sensor }\end{array}$ \\
\hline$\Delta \mathrm{DIC}_{\mathrm{TA}-\mathrm{pH}, \mathrm{x} \rightarrow \mathrm{y}}$ & $\begin{array}{c}\text { change in DIC between states " } \mathrm{x} \text { " and "y" }\left(\mathrm{DIC}_{\mathrm{y}}-\mathrm{DIC}_{\mathrm{x}}\right) \text {, measured by } \\
\text { known total alkalinity and measured } \mathrm{pH}\end{array}$ \\
\hline$\Delta \mathrm{DIC}_{\mathrm{TA}-\mathrm{eq}, \mathrm{x} \rightarrow \mathrm{y}}$ & $\begin{array}{c}\text { change in DIC between states " } \mathrm{x} \text { " and " } \mathrm{y} \text { " }\left(\mathrm{DIC}_{\mathrm{y}}-\mathrm{DIC}_{\mathrm{x}}\right) \text {, measured by by } \\
\text { known total alkalinity and assuming gas-solution equilibrium }\end{array}$ \\
\hline DOC & direct ocean capture \\
\hline DSPZ & sodium 3,3'-(phenazine-2,3-diylbis(oxy))bis(propane-1-sulfonate) \\
\hline $\mathrm{DSPZH}_{2}$ & reduced DSPZ \\
\hline EMAR & electrochemically mediated amine regeneration \\
\hline $\mathrm{K}_{3} \mathrm{Fe}(\mathrm{CN})_{6}$ & potassium ferricyanide (oxidized form of $\mathrm{Fe}(\mathrm{CN})_{6}$ ) \\
\hline $\mathrm{K}_{4} \mathrm{Fe}(\mathrm{CN})_{6}$ & potassium ferrocyanide (reduced form of $\mathrm{Fe}(\mathrm{CN})_{6}$ ) \\
\hline MFC & mass flow controller \\
\hline$p_{1}$ & $\mathrm{CO}_{2}$ partial pressure in bar during $\mathrm{CO}_{2}$ capture (inlet) \\
\hline$p_{3}$ & $\mathrm{CO}_{2}$ partial pressure in bar during $\mathrm{CO}_{2}$ outgassing (exit) \\
\hline PCET & proton-coupled electron transfer \\
\hline $\mathrm{pH}_{\mathrm{mea}}$ & $\mathrm{pH}$ measured by $\mathrm{pH}$ probe \\
\hline pHTA-eq & $\begin{array}{c}\mathrm{pH} \text { calculated using known total alkalinity and assuming gas-solution } \\
\text { equilibrium }\end{array}$ \\
\hline TA & total alkalinity \\
\hline $\mathrm{TA}_{\mathrm{x}}$ & concentration of total alkalinity in state " $\mathrm{x}$ " \\
\hline$\Delta \mathrm{TA}_{\mathrm{x} \rightarrow \mathrm{y}}$ & $\begin{array}{l}\text { change in TA between states "x" and " } y \text { " }\left(\mathrm{TA}_{\mathrm{y}}-\mathrm{TA}\right) \text {, measured by } \\
\text { counting charges during deacidification or acidification, which is } \\
\text { equivalent to twice the concentration of DSPZ. }\end{array}$ \\
\hline
\end{tabular}


87 For a system with given $\mathrm{TA}_{3^{\prime} \mathrm{i}}$ and $\Delta \mathrm{TA}_{3 \rightarrow 1}$, i.e. $\mathrm{DSPZ}$ concentration, the ideal cycle work is defined as the work input for driving the system through electrochemical deacidification at $p_{1}$ and a subsequent electrochemical acidification at $p 3$, at an infinitesimal current. In the ideal cycle, gassolution equilibrium is assumed at every point and because TA is known, $\mathrm{pH}_{\mathrm{TA}-\mathrm{eq}}$ and $\mathrm{DIC}_{\mathrm{TA}-\mathrm{eq}}$ at every point can be calculated. The $\mathrm{CO}_{2}$ molar ideal cycle work, which we denote as $\bar{w}_{\text {ideal }}$, is obtained from dividing the ideal cycle work by expected $\Delta \mathrm{DIC}_{3 \rightarrow 1}$, i.e. $\Delta \mathrm{DIC}_{\mathrm{TA}-\mathrm{eq}, 3 \rightarrow 1}$.

93

This section explains how $\bar{w}_{\text {ideal }}$ is calculated in detail. Both of the ideal cycle work and $\triangle \mathrm{DIC}_{\mathrm{TA}-\mathrm{eq}, 3 \rightarrow 1}$ are governed by these parameters: initial TA (TA ${ }^{\prime}$ ' or simply $\mathrm{TA}_{3}$ ' because $\mathrm{TA}_{3}{ }^{\prime} \mathrm{i}$ and $\mathrm{TA}_{3}$ 'f will be the same in an ideal cycle), $\Delta \mathrm{TA}_{3 \rightarrow 1}$ and $p \mathrm{CO}_{2}$ at $p_{1}$, and the following equations:

97

98

99

100

101

102

103

104

$$
\mathrm{DIC}=\left[\mathrm{CO}_{2}(\mathrm{aq})\right]+\left[\mathrm{HCO}_{3}^{-}\right]+\left[\mathrm{CO}_{3}^{2-}\right] ;
$$

$$
\mathrm{K}_{1}=\frac{\left[\mathrm{HCO}_{3}^{-}\right]\left[\mathrm{H}^{+}\right]}{\left[\mathrm{CO}_{2}(\mathrm{aq})\right]} ;
$$

$$
\mathrm{K}_{2}=\frac{\left[\mathrm{CO}_{3}^{2-}\right]\left[\mathrm{H}^{+}\right]}{\left[\mathrm{HCO}_{3}^{-}\right]} \text {; }
$$

$$
\mathrm{TA} \equiv\left[\mathrm{OH}^{-}\right]+\left[\mathrm{HCO}_{3}^{-}\right]+2\left[\mathrm{CO}_{3}^{2-}\right]-\left[\mathrm{H}^{+}\right] \text {; }
$$

$$
\left[\mathrm{S}^{+}\right]-\left[\mathrm{S}^{-}\right]=\mathrm{TA} ;
$$

$$
\left[\mathrm{H}^{+}\right]\left[\mathrm{OH}^{-}\right]=10^{-14} \text {, }
$$

where the $\mathrm{K}_{1}$ and $\mathrm{K}_{2}$ used here are $1.1 \times 10^{-6} \mathrm{M}$ and $4.1 \times 10^{-10} \mathrm{M},{ }^{1}$ resulting in the first and second $p \mathrm{Ka}$ for carbonic acid being 6.0 and 9.4, respectively. Eq. S4 is the definition of TA of the solution under consideration and eq. S5 arises from the charge neutrality constraint in solution $\left(\mathrm{S}^{+}\right.$ and $\mathrm{S}^{-}$correspond to the cationic and anionic species of the electrolyte salt). During deacidification, $\left[\mathrm{S}^{+}\right]$increases in the negolyte reservoir, so TA increases as well (eq. S5), which means an increase of hydroxide concentration or $\left[\mathrm{HCO}_{3}{ }^{-}\right]$or $\left[\mathrm{CO}_{3}{ }^{2-}\right]$ given nonzero $p \mathrm{CO}_{2}$ (eq. S4). The reverse 110 happens during acidification. The expressions for the concentration of each constituent of DIC can be derived by rearranging the above equations:

$$
\left[\mathrm{CO}_{2}(\mathrm{aq})\right]=\frac{\mathrm{DIC}}{1+\frac{\mathrm{K}_{1}}{\left[\mathrm{H}^{+}\right]}+\frac{\mathrm{K}_{1} \mathrm{~K}_{2}}{\left[\mathrm{H}^{+}\right]^{2}}} ;
$$

$$
\left[\mathrm{HCO}_{3}^{-}\right]=\frac{\mathrm{DIC}}{1+\frac{\left[\mathrm{H}^{+}\right]}{\mathrm{K}_{1}}+\frac{\mathrm{K}_{2}}{\left[\mathrm{H}^{+}\right]}} ;
$$




$$
\left[\mathrm{CO}_{3}^{2-}\right]=\frac{\mathrm{DIC}}{1+\frac{\left[\mathrm{H}^{+}\right]}{\mathrm{K}_{2}}+\frac{\left[\mathrm{H}^{+}\right]^{2}}{\mathrm{~K}_{1} \mathrm{~K}_{2}}}
$$

$\mathrm{TA}_{3}$, is calculated using eq. $\mathrm{S} 7$, measured $\mathrm{pH}$ and assumed gas-solution equilibrium, i.e.

$$
\left[\mathrm{CO}_{2}(\mathrm{aq})\right]=0.035 \times p \mathrm{CO}_{2} .
$$

where 0.035 comes from Henry's Law constant of $35 \mathrm{mM} \mathrm{bar}^{-1}$ at room temperature and the units of $\left[\mathrm{CO}_{2}(\mathrm{aq})\right]$ and $p \mathrm{CO}_{2}$ are Molar and bars, respectively. For example, in Table 1, $\mathrm{pH}_{\text {meas }}$ at state $3{ }^{\prime} \mathrm{i}$ was 7.4 , and $p \mathrm{CO}_{2}$ was 0.1 bar, so DIC can be derived from eq. $\mathrm{S} 7$ and $\mathrm{S} 10$, and subsequently $\left[\mathrm{HCO}_{3}{ }^{-}\right]$and $\left[\mathrm{CO}_{3}{ }^{2-}\right]$ from eq. $\mathrm{S} 8$ and $\mathrm{S} 9$, respectively. $\mathrm{TA}_{3}{ }^{\prime} \mathrm{i}$ is then obvious from eq. S4. Because $\Delta \mathrm{TA}_{3}{ }^{\prime} \mathrm{i} \rightarrow 1$, which is determined by the concentration of $\mathrm{DSPZ}$, is equal to $\Delta \mathrm{TA}_{3 \rightarrow 1}$, and $-\Delta \mathrm{TA}_{1}{ }^{\prime} \rightarrow 3$ (or $-\Delta \mathrm{TA}_{1 \rightarrow 3}$ ) in the ideal cycle, $\mathrm{TA}$ at states $1,1^{\prime}$ and 3 can be derived from $\mathrm{TA}_{3}{ }^{\prime} \mathrm{i}$ and $\Delta \mathrm{TA}$ values. Because TA and $p \mathrm{CO}_{2}$ is known for each state, $\mathrm{pH}_{\mathrm{TA}-\mathrm{eq}}$ and $\mathrm{DIC}_{\mathrm{TA}-\mathrm{eq}}$ can be calculated. Then $\triangle \mathrm{DIC}_{\mathrm{TA}-\mathrm{eq}, 3 \rightarrow 1}$ is simply $\mathrm{DIC}_{\mathrm{TA}-\mathrm{eq}, 1}$ minus $\mathrm{DIC}_{\mathrm{TA}-\mathrm{eq}, 3}$. In fact, we can calculate $\mathrm{TA}, \mathrm{pH}_{\mathrm{TA}-\mathrm{eq}}$ and DIC $_{\mathrm{TA}-\mathrm{eq}}$ of every point in between the states as well, and hence construct the ideal cycles. Because of the $2 \mathrm{H}^{+} / 2 \mathrm{e}^{-}$redox processes of DSPZ, ${ }^{2}$ its reduction potential, and overall cell potential decreases $59 \mathrm{mV}$ for every unit of increase in $\mathrm{pH}$. This allows us to calculate the ideal cycle work using the following equation:

$$
w_{\text {cycle }, \text { ideal }}=\sum_{n=1} 0.059 \times\left(p H_{\text {deacidification }}(T A(n))-p H_{\text {acidification }}(T A(n)) \times \Delta T A \times F\right.
$$

Where $n$ is the index, $T A$ increases by $\triangle T A$ Molar when $\mathrm{n}$ increases by $1, \mathrm{pH}$ is a function of $T A$ and the process, $0.059(\mathrm{~V} / \mathrm{pH})$ is the conversion factor between $\mathrm{pH}$ and cell voltage, $F$ is the Faraday constant $\left(96485 \mathrm{C} \mathrm{mole}_{-}{ }^{-1}\right)$ and the unit of $w_{\text {cycle,ideal }}$ is $\mathrm{J} \mathrm{L}^{-1}$. Then $\bar{w}_{\text {ideal }}$ follows naturally by dividing $w_{\text {cycle,ideal }}$ by $\Delta \mathrm{DIC}_{3 \rightarrow 1}$.

$$
\bar{w}_{\text {ideal }}=\frac{w_{\text {cycle }, \text { ideal }}}{\Delta D I C_{T A-e q, 3 \rightarrow 1}}
$$

As mentioned in the main text, $\Delta \mathrm{DIC}$ values vary as $p_{1}, \mathrm{TA}_{3}$, and $\Delta \mathrm{TA}_{3 \rightarrow 1}$ change. Fig. $4 \mathbf{e}, \mathbf{f}$ and g show the ideal cycles for various $p_{1}$ given fixed $p_{3}, \mathrm{TA}_{3}$, and $\Delta \mathrm{TA}_{3 \rightarrow 1}$. The amount of $\mathrm{CO}_{2}$ captured in process $3{ }^{\prime} i \rightarrow 1$ and monitored by the flow meter and the $\mathrm{CO}_{2}$ sensor is around $50 \mathrm{~mL}$, which translates to $0.21 \mathrm{M} \Delta \mathrm{DIC}_{\text {flow, } 3^{\prime} \mathrm{i} \rightarrow 1}$, assuming $T=293 \mathrm{~K}$ and $p=1$ bar, across all different $p_{1}$ values (Fig. 4a). This similarity is consistent with the ideal cycle behavior, illustrated in Fig. 4 c and the alignment of measured $\Delta \mathrm{DIC}_{\text {flow }, 3^{\prime} \rightarrow \rightarrow 1}$ with the theoretical $\Delta \mathrm{DIC}_{\mathrm{TA}-\mathrm{eq}, 3^{\prime} \rightarrow 1} v s . p \mathrm{CO}_{2}$ curve. The similar amount of $\mathrm{CO}_{2}$ captured and released, i.e. $\Delta \mathrm{DIC}$ flow, $3^{\prime} \rightarrow 1$ and $\Delta \mathrm{DIC}_{\text {flow, } 1^{\prime} \rightarrow 3}$, is caused by the coincidental resemblance of the slopes of the two-stage deacidification $+\mathrm{CO}_{2}$ invasion and the two-stage acidification $+\mathrm{CO}_{2}$ outgassing processes under the experimental conditions (Fig. 4 c). The agreement of $\Delta \mathrm{DIC}_{\mathrm{TA}-\mathrm{eq}, 3^{\prime} \rightarrow 1} v s . p \mathrm{CO}_{2}$ and $\Delta \mathrm{DIC}_{\mathrm{TA}-\mathrm{eq}, 1^{\prime} \rightarrow 3} \rightarrow s$. $p \mathrm{CO}_{2}$ curves at high $p_{1}$ values also corroborates the flow measurements. If the $p_{1}$ were $0.4 \mathrm{mbar}$ instead, the deacidification and acidification processes would have significantly different slopes so the amounts of $\mathrm{CO}_{2}$ captured 
149 Here we plot the ideal cycles for varying TA 3 , and fixed $p_{1}=0.4$ mbar, $p_{3}=1$ bar and $\Delta \mathrm{TA}_{3 \rightarrow 1}=$ $150 \quad 0.21 \mathrm{M}$ (Fig. S 1). The plots illustrate the effect of varying TA3' on $w_{\text {cycle,ideal, }} \Delta \mathrm{DIC}_{\mathrm{TA}-\mathrm{eq}}$, and $151 \bar{w}_{\text {ideal }}$.

152
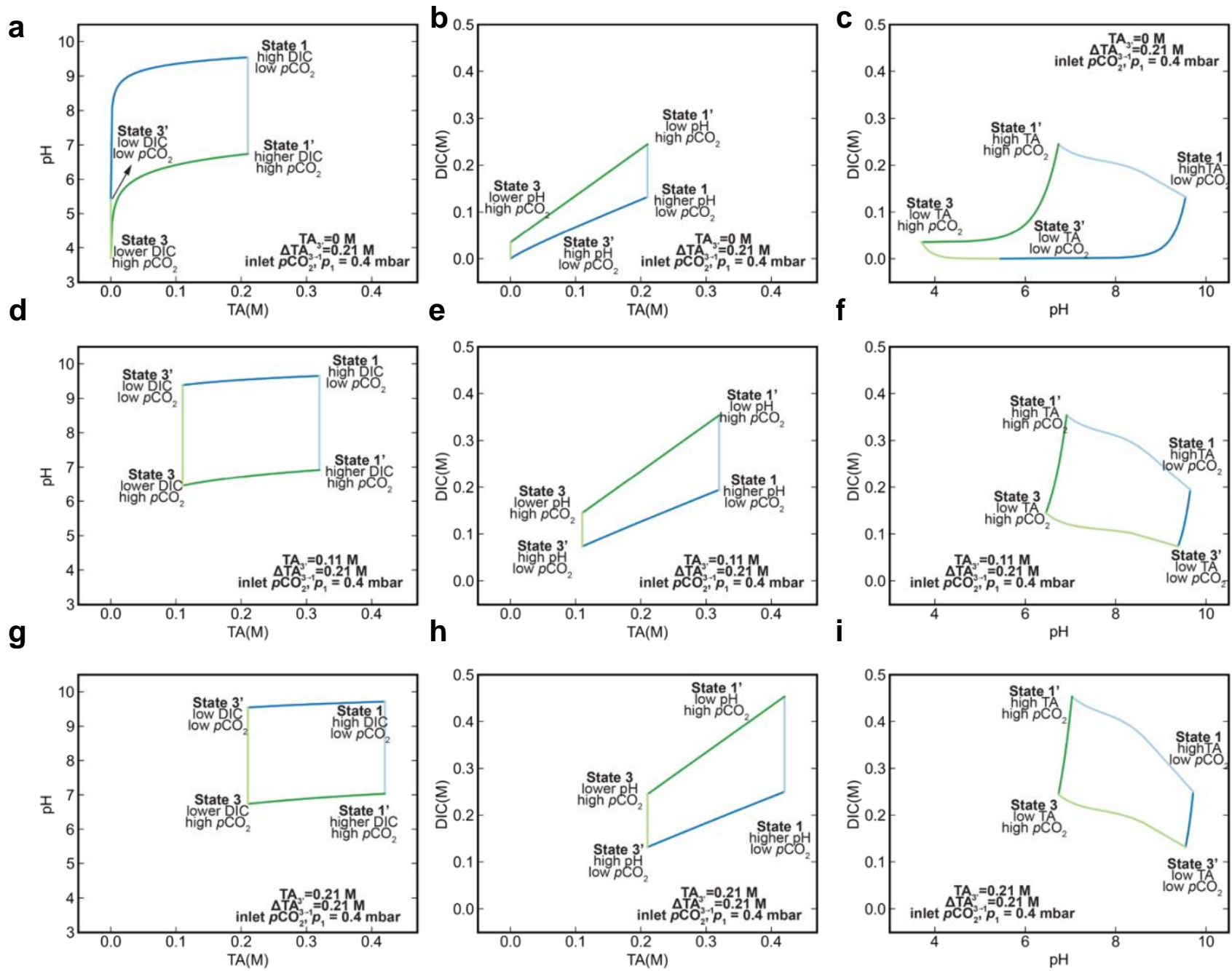

Fig. S 1 Ideal cycles constructed using $p_{1}=0.4 \mathrm{mbar}$ and $p_{3}=1$ bar, $\Delta \mathrm{TA}_{3 \rightarrow 1}=0.21 \mathrm{M}$ and varying $\mathrm{TA}_{3^{\prime}}$. a-c,

$155 \mathrm{TA}_{3^{\prime}}=0.0 \mathrm{M} ; \mathbf{d}-\mathbf{f}, \mathrm{TA}_{3^{\prime}}=0.11 \mathrm{M}$ and $\mathbf{g}-\mathbf{i}, \mathrm{TA}_{3^{\prime}}=0.21 \mathrm{M}$;

156 The area enclosed by the cycles in Fig. $\mathbf{S ~ 1 a , ~} \mathbf{d}$ and $\mathbf{g}$, is proportional to the ideal cycle work for 157 the cycles with fixed $p_{1}=0.4 \mathrm{mbar}, p_{3}=1 \mathrm{bar}, \Delta \mathrm{TA}_{3 \rightarrow 1}=0.21 \mathrm{M}$ and TA${ }_{3}$, being $0.0,0.11$ and 0.21

$158 \mathrm{M}$, respectively. The area roughly stays the same as $\mathrm{TA}_{3}$, increases, but $\Delta \mathrm{DIC}_{\mathrm{TA}-\mathrm{eq}, 3 \rightarrow 1}$ shrinks 159 significantly, as shown in Fig. $\mathbf{S} \mathbf{1 b}$, e and $\mathbf{h}$. As a result, $\bar{w}_{\text {ideal }}$ increases as TA3, increases. With 160 TA3 , being $0.0,0.11$ and $0.21 \mathrm{M}$, the ideal cycle work is $3.58,3.40$ and $3.31 \mathrm{~kJ} \mathrm{~L}^{-1}$, respectively, $161 \Delta \mathrm{DIC}_{\mathrm{TA}-\mathrm{eq}, 3 \rightarrow 1}$ is $0.097,0.049$ and $0.005 \mathrm{M}$, respectively and the resulting $\bar{w}_{\text {ideal }}$ is $37.02,69.31$ 162 and $661.9 \mathrm{~kJ} \mathrm{molcO}^{-1}$, respectively. 
a

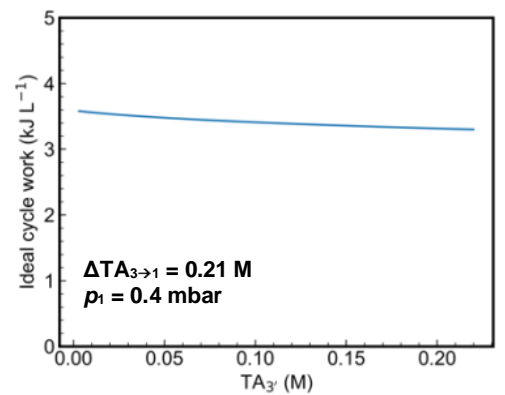

b

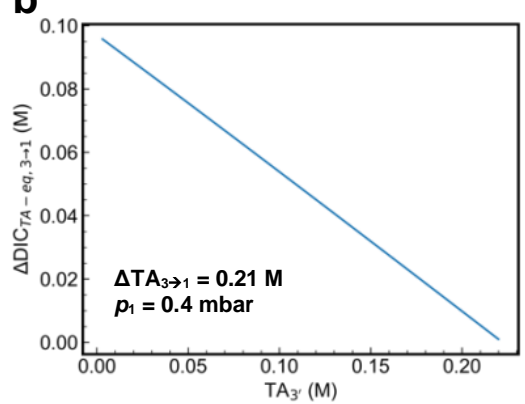

C

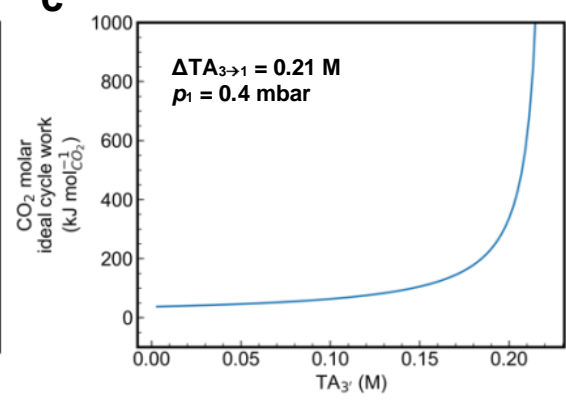

Fig. S 2| Dependence of (a) $w_{\text {cycle,ideal, }}$ (b) $\Delta \mathrm{DIC}_{\mathrm{TA}-\mathrm{pH}, 3 \rightarrow 1}$ (c) and $\bar{w}_{\text {ideal }}$ on $\mathrm{TA}_{3}$, in the ideal cycles with $p_{1}=0.4$ mbar, and $p_{3}=1$ bar, $\Delta \mathrm{TA} 3 \rightarrow 1=0.21 \mathrm{M}$.

Fig. S 2 shows the dependence of $w_{\text {cycle,ideal, }} \Delta \mathrm{DIC}_{\mathrm{TA}-\mathrm{eq}, 3 \rightarrow 1}$ and $\bar{w}_{\text {ideal }}$ on $\mathrm{TA}_{3}$ '. Again, $\bar{w}_{\text {ideal }}$ increases with increasing $\mathrm{TA}_{3}$, because of the linearly decreasing $\Delta \mathrm{DIC}_{\mathrm{TA}-\mathrm{pH}, 3 \rightarrow 1}$ in the denominator of eq. S11.
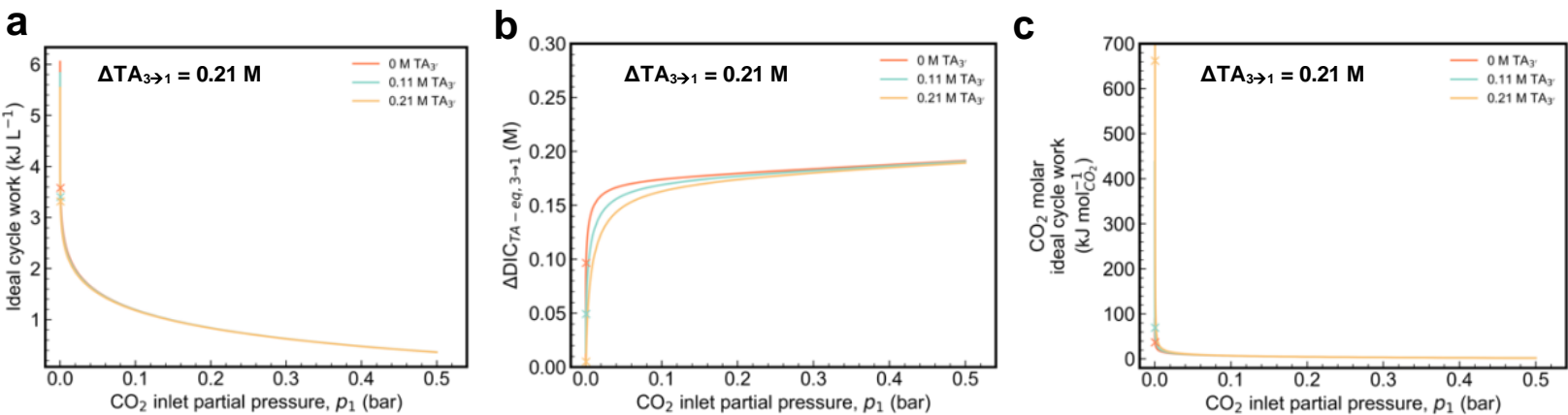

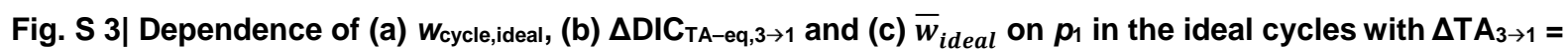
$0.21 \mathrm{M}$ and $\mathrm{TA}_{3}$ ' $=0.0,0.11$ and $0.21 \mathrm{M}$. The ' $x$ ' marks indicate $p_{1}=0.4$ mbar.

Fig. $\mathbf{S} 3$ shows the dependence of $w_{\text {cycle,ideal }}, \Delta \mathrm{DIC}_{\mathrm{TA}-\mathrm{eq}, 3 \rightarrow 1}$ and $\bar{w}_{\text {ideal }}$ on $p_{1} . w_{\text {cycle,ideal }}$ decreases as $p_{1}$ increases because of lower negolyte $\mathrm{pH}$, hence cell potential, during deacidification, but the curves are almost identical for different TA 3 , values. The $\Delta \mathrm{DIC}_{\mathrm{TA}-\mathrm{eq}, 3 \rightarrow 1} \mathrm{vs}$. $p_{1}$ curves for different $\mathrm{TA}_{3}$, are similar for large $p \mathrm{CO}_{2}$ values, but significantly different at low $p_{1}$. Therefore, to keep $\bar{w}_{i d e a l}$ low for any inlet pressure $p_{1}$, high TA3 , should be avoided.

a

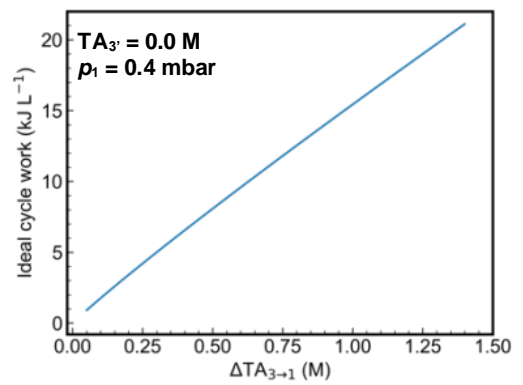

b

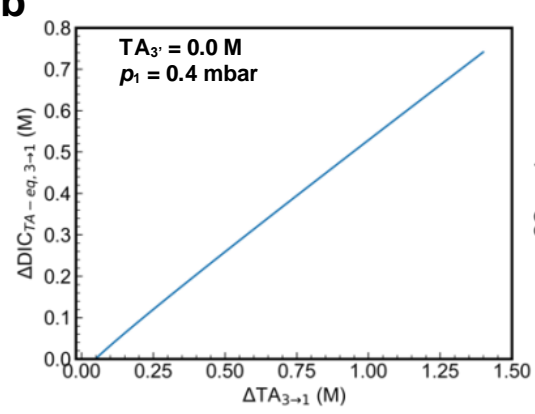

C

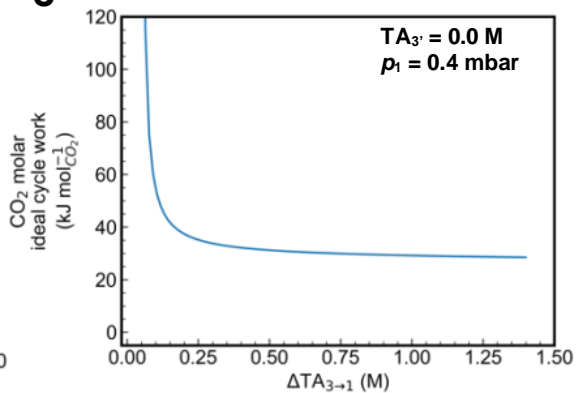

Fig. S 4| Dependence of (a) $w_{\text {cycle,ideal, }}(\mathrm{b}) \Delta \mathrm{DIC} \mathrm{T}_{\mathrm{TA-eq}, 3 \rightarrow 1}$ and (c) and $\bar{w}_{\text {ideal }}$ on $\Delta T A_{3 \rightarrow 1}$ in the ideal cycles with $p_{1}=0.4 \mathrm{mbar}, p_{3}=1 \mathrm{bar}$ and $\mathrm{TA}_{3}=0.0 \mathrm{M}$.

The last parameter that affects $w_{\text {cycle,ideal, }} \Delta \mathrm{DIC}_{\mathrm{TA}-\mathrm{eq}, 3 \rightarrow 1}$ and $\bar{w}_{\text {ideal }}$ is $\Delta \mathrm{TA}_{3 \rightarrow 1}$, which is equivalent to twice the amount of DSPZ concentration. DSPZ has a solubility of $0.7 \mathrm{M}$ in $1 \mathrm{M} \mathrm{KCl}$ or $1 \mathrm{M}$ 
$182 \mathrm{KOH}$ aqueous solution, so the largest $\Delta \mathrm{TA}_{3 \rightarrow 1}$ it can induce is $1.4 \mathrm{M}$. Fig. $\mathbf{S} 4$ shows the 183 dependence of $w_{\text {cycle,ideal, }} \Delta \mathrm{DIC}_{\mathrm{TA}-\mathrm{eq}, 3 \rightarrow 1}$ and $\bar{w}_{\text {ideal }}$ on $\Delta \mathrm{TA}_{3 \rightarrow 1}$ for cycles with $\mathrm{TA}_{3},=0.0 \mathrm{M}, p_{1}=$ 1840.4 mbar and $p_{3}=1$ bar. Not surprisingly, $w_{\text {cycle, ideal }}$ and $\Delta \mathrm{DIC}_{\mathrm{TA}-\mathrm{eq}, 3 \rightarrow 1}$ increase with $\Delta \mathrm{TA} \mathrm{A}_{3 \rightarrow 1}$ but 185 the difference in their increase rate causes $\bar{w}_{\text {ideal }}$ to decrease with larger $\Delta \mathrm{TA} 3 \rightarrow 1$. At $1.4 \mathrm{M}$ $186 \Delta \mathrm{TA}_{3 \rightarrow 1}, \bar{w}_{\text {ideal }}$ is $28.45 \mathrm{~kJ} \mathrm{molcO}^{-1}$, which is $23 \%$ lower than $37.02 \mathrm{~kJ}^{\mathrm{mol} \mathrm{CO}_{2}}{ }^{-1}$ for $0.21 \mathrm{M}$ $187 \Delta \mathrm{TA}_{3 \rightarrow 1}$. Assuming that similar second law efficiency holds for experimental cycles with different $188 \Delta \mathrm{TA}_{3 \rightarrow 1}$ and same $p_{1}, p_{3}$ and $\mathrm{TA}_{3}$, , using higher concentration of DSPZ can further decrease the

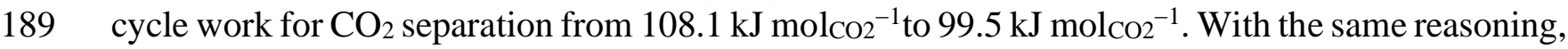
190 if a PCET molecule that undergoes 2- $\mathrm{e}^{-}$transfer and has $10 \mathrm{M}$ solubility is developed, the ideal

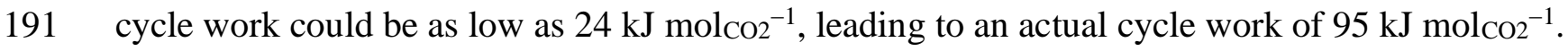


a

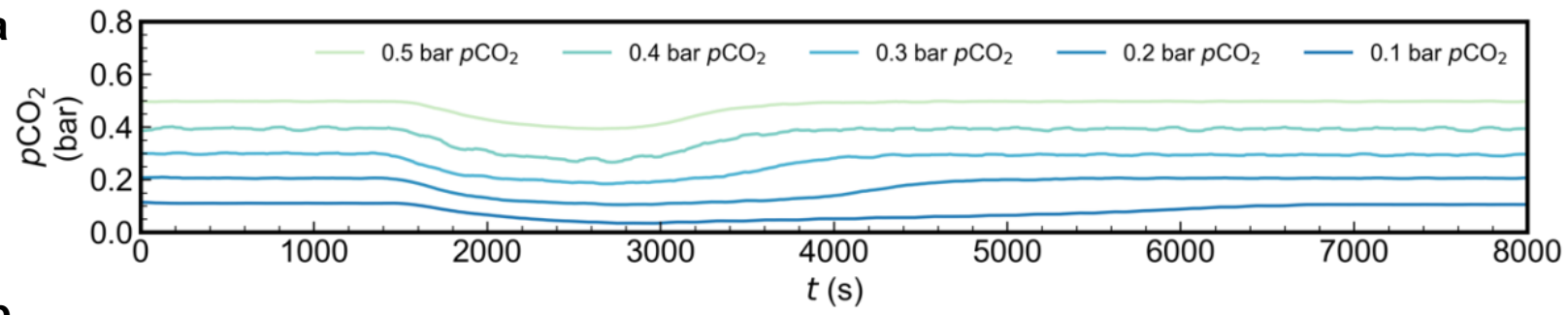

b

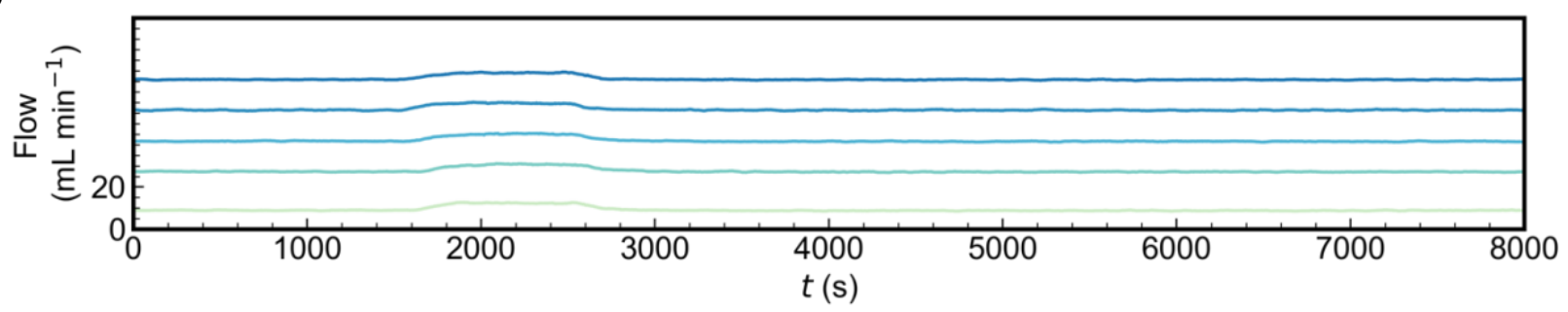

Fig. S 5| Duration of the $\mathrm{CO}_{2}$ capture and release processes in the cycles with $40 \mathrm{~mA} \mathrm{~cm}^{-2}$ current density. a, Downstream $p \mathrm{CO}_{2}$ of one capture half cycle for each of the inlet $p \mathrm{CO}_{2}$ conditions. $\mathbf{b}$, Filtered total gas flow rate of one outgassing half cycle for each of the inlet $p \mathrm{CO}_{2}$ conditions. All the processes look identical because of the same exit condition, so an arbitrary offset is added to differentiate the curves.

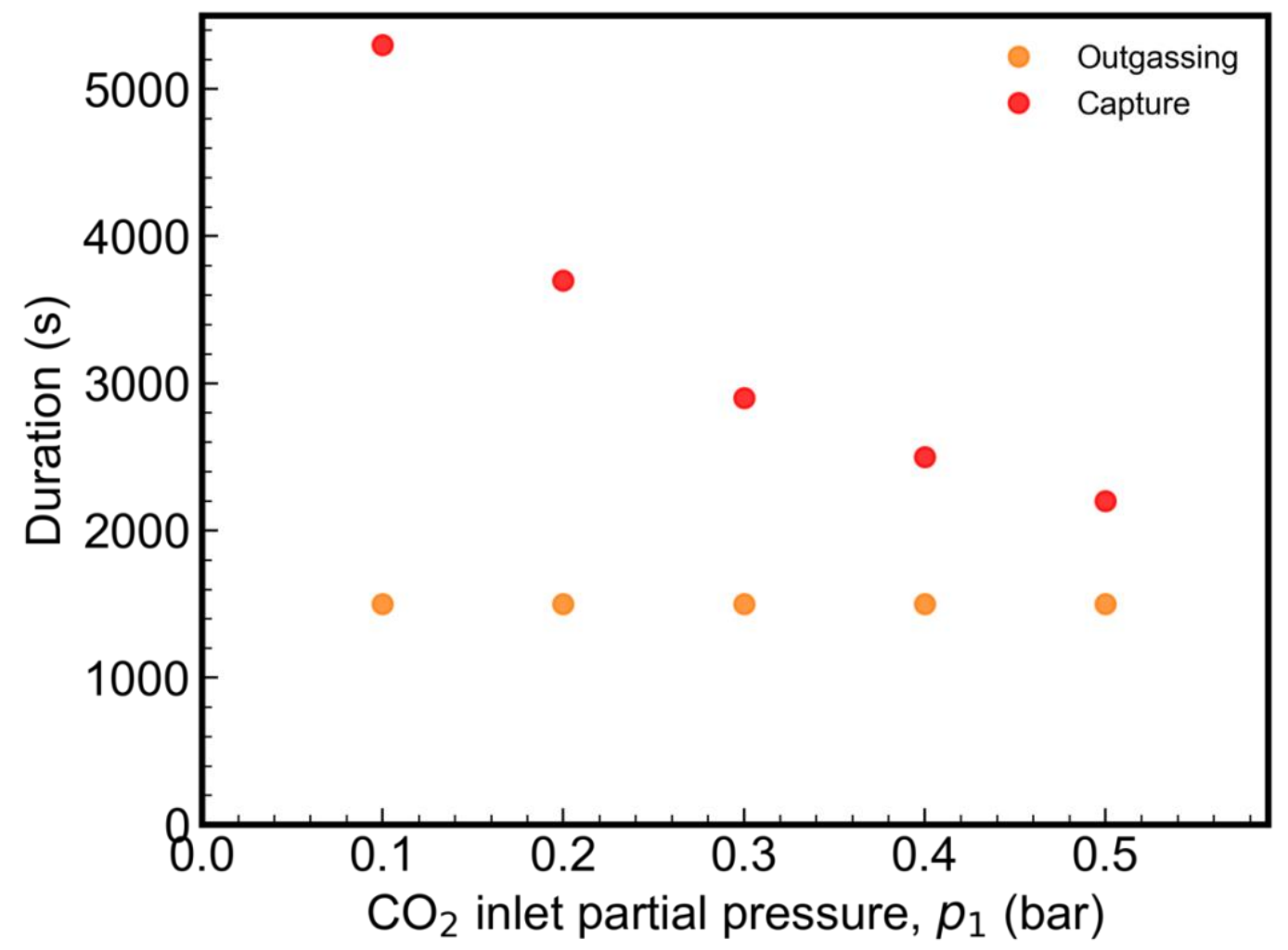

Fig. S 6| Capture and outgassing durations extracted from Fig. S 5 a and b. 
a

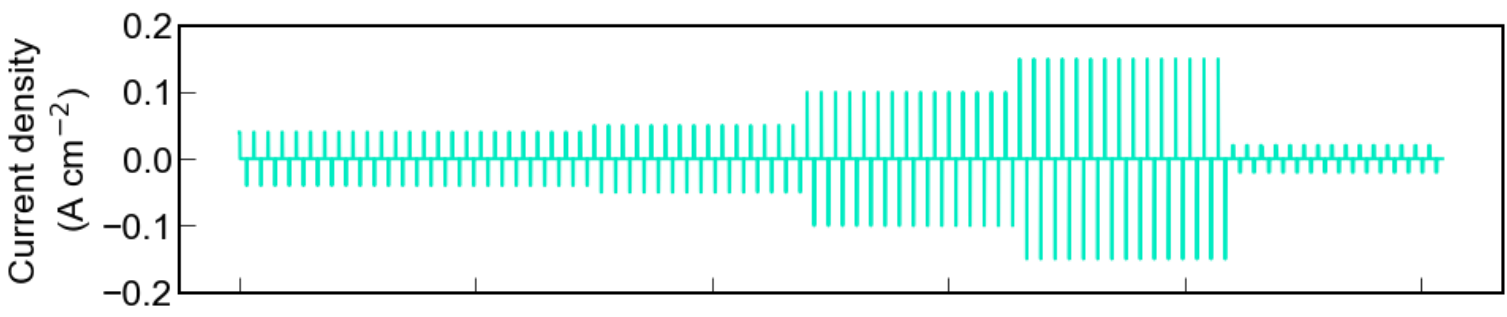

b

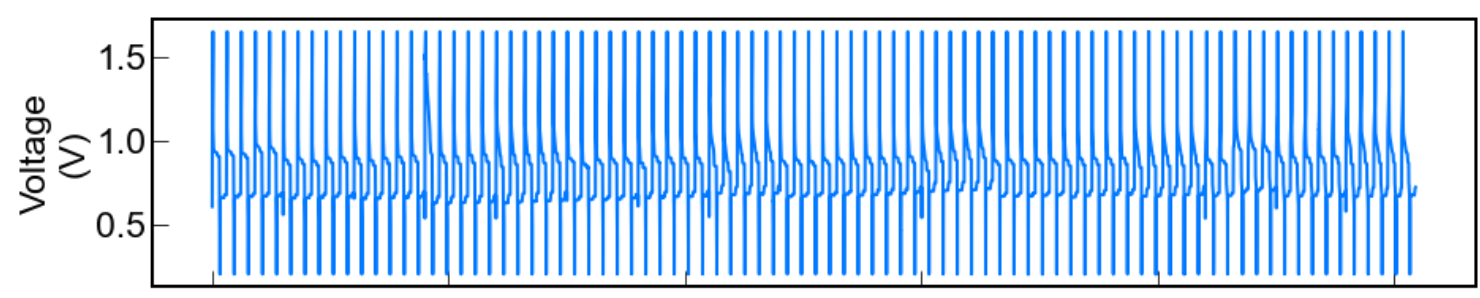

C

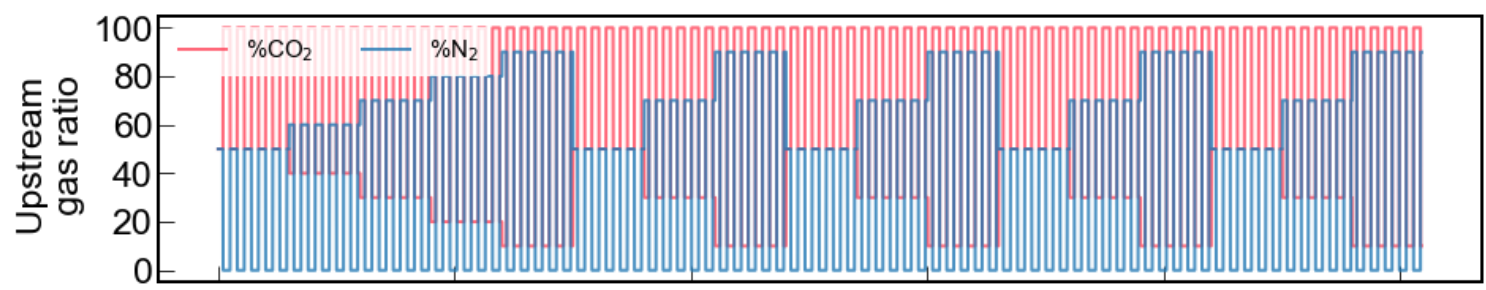

d

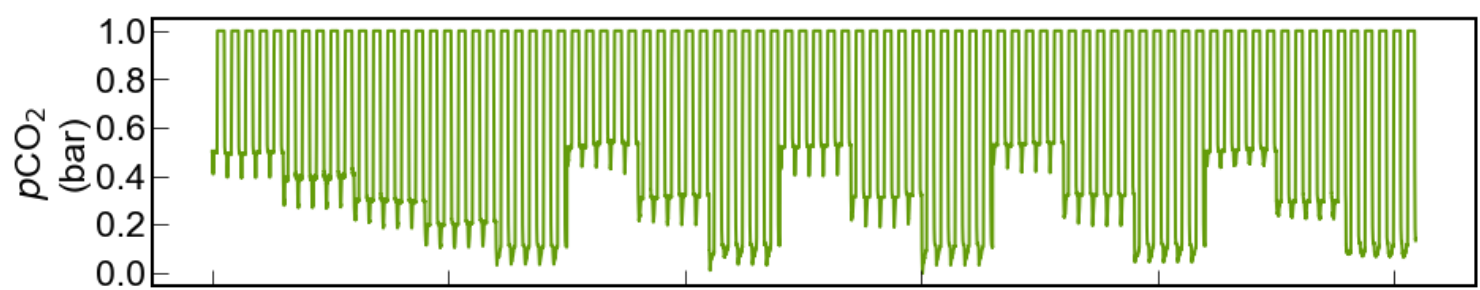

e

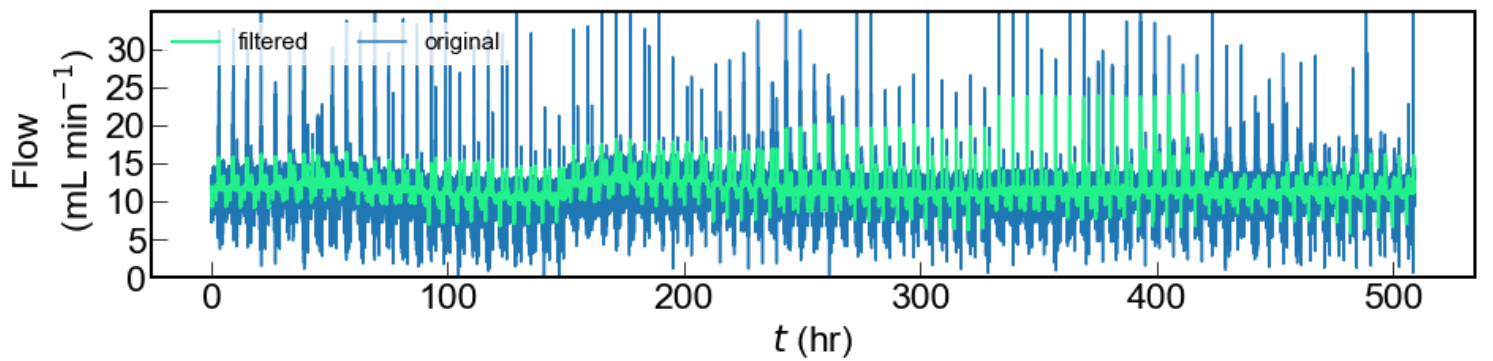

Fig. S 7| Eighty-five $\mathrm{CO}_{2}$ concentrating cycles with varying inlet $p \mathrm{CO}_{2}$ and current densities. These are the raw data for Fig. 5. Same cell was used as in Fig 2. Liquid pumping rate is $50 \mathrm{~mL} \mathrm{~min}^{-1}$ for all the cycles. Note that, the pH measurements for high current densities are inaccurate, as the $\mathrm{pH}$ should never be able to reach $\mathrm{pH}>14$ for $0.11 \mathrm{M}$ DSPZ. a, Current density. b, Voltage. c, $\mathrm{N}_{2}$ and $\mathrm{CO}_{2}$ percentage in the upstream source gas, controlled by mass flow controllers. d, $\mathrm{CO}_{2}$ partial pressure. e, Total gas flow rate. 
a

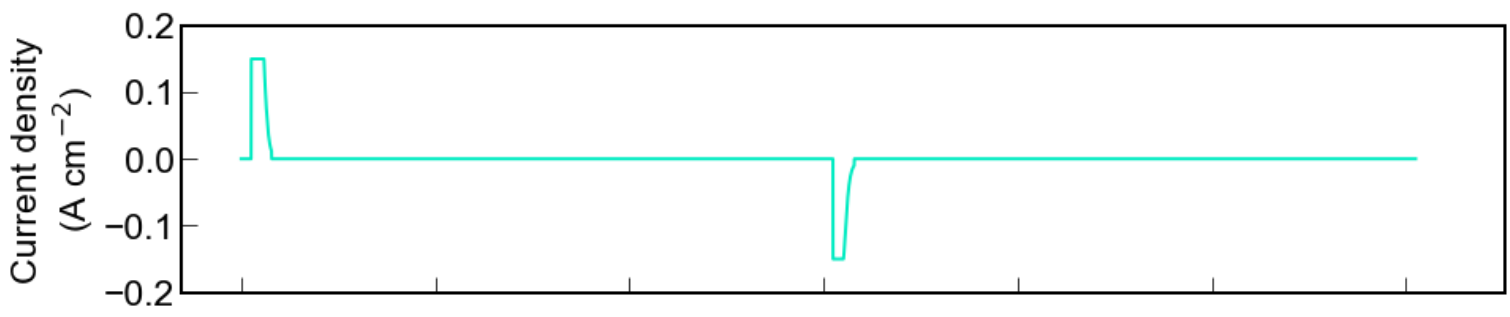

b

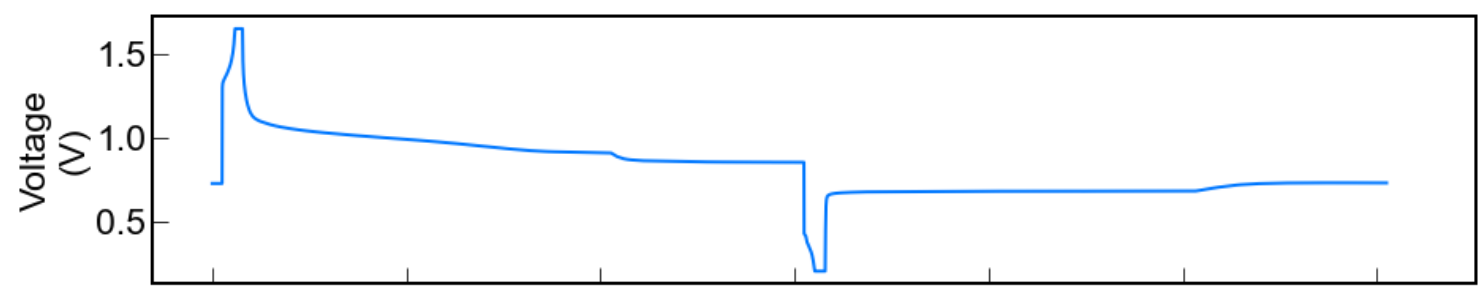

C

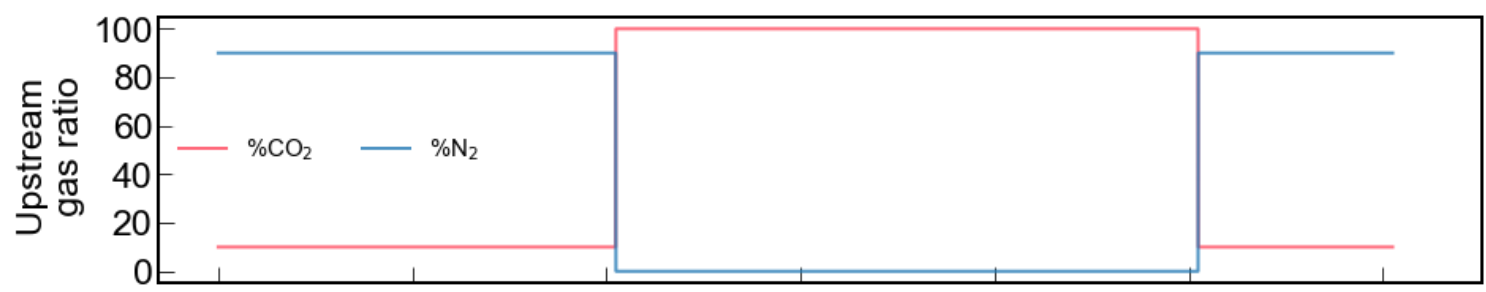

d

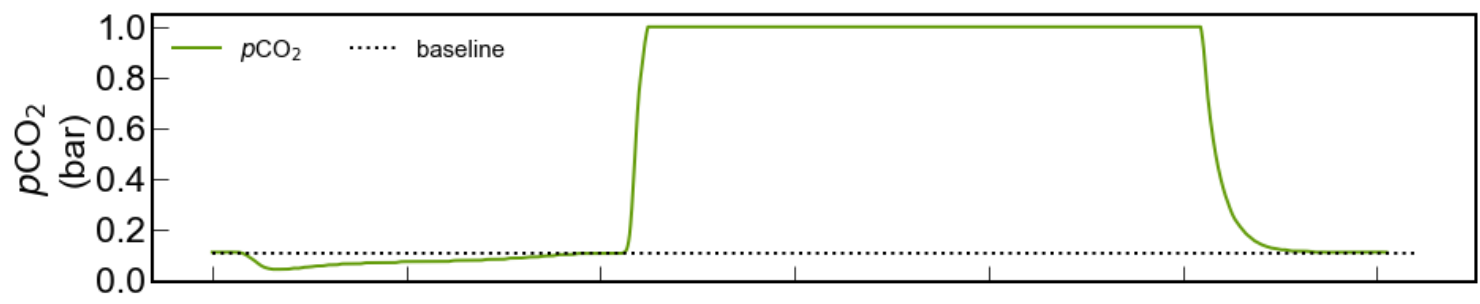

e

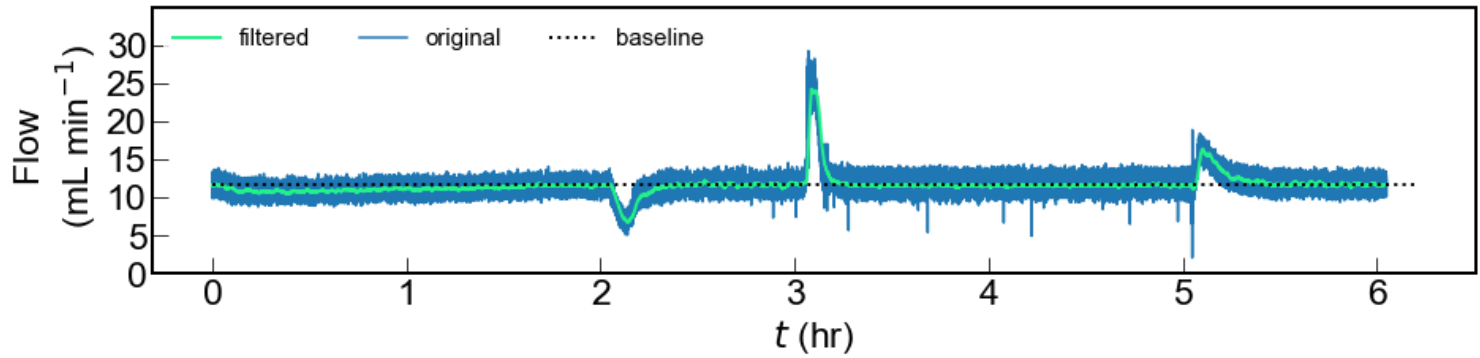

Fig. S 8| One $\mathrm{CO}_{2}$ concentrating cycle from Fig. $\mathrm{S} 7$ with 0.1 bar inlet $p \mathrm{CO}_{2}$ and 1 bar exit $p \mathrm{CO}_{2}$ at $150 \mathrm{~mA} \mathrm{~cm}^{-2}$. Note that, the $\mathrm{pH}$ measurements are not shown because of an inexplicable artifact only present at high current, so it is invalid to extract DIC $\mathrm{TA-pH}_{\mathrm{H}}$ for this condition. However, DIC $\mathrm{TA}_{\mathrm{A} \text { eq }}$ can be extracted because sufficient gas-solution is reached, as demonstrated by fact that the $p \mathrm{CO} 2$ and flow curves return to their baselines after $\mathrm{CO}_{2}$ invasion and outgassing. a, Voltage profile. b, Current density. c, $\mathrm{N}_{2}$ and $\mathrm{CO}_{2}$ percentage in the upstream source gas, controlled by MFC. d, $\mathrm{CO}_{2}$ partial pressure. e, Total gas flow rate. 
a

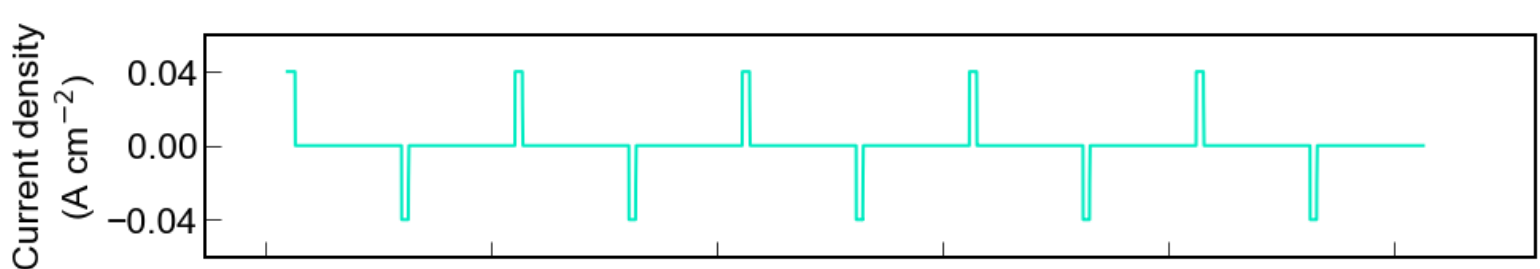

b

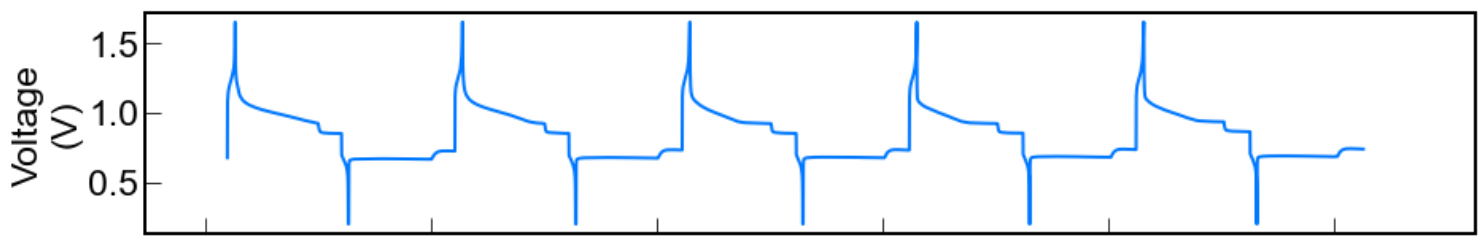

C

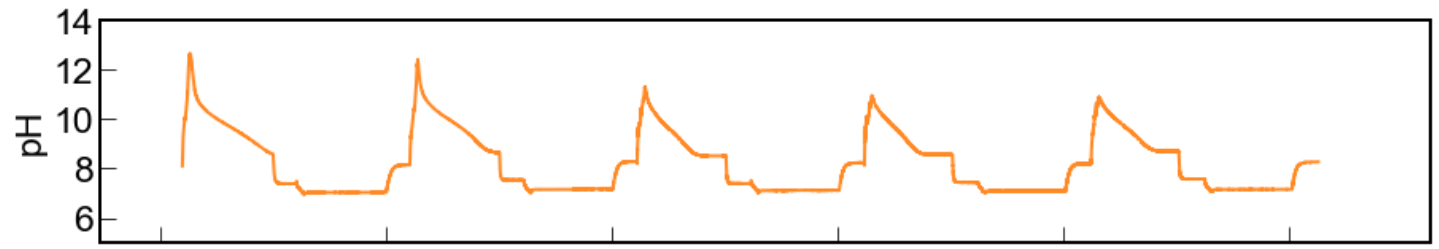

d

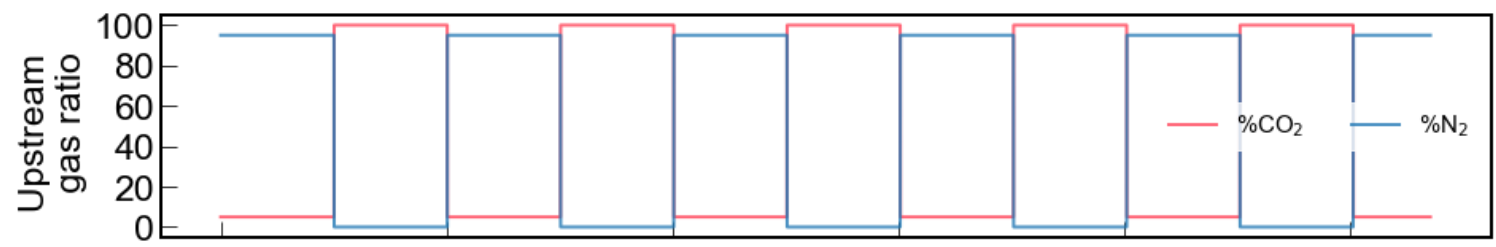

e
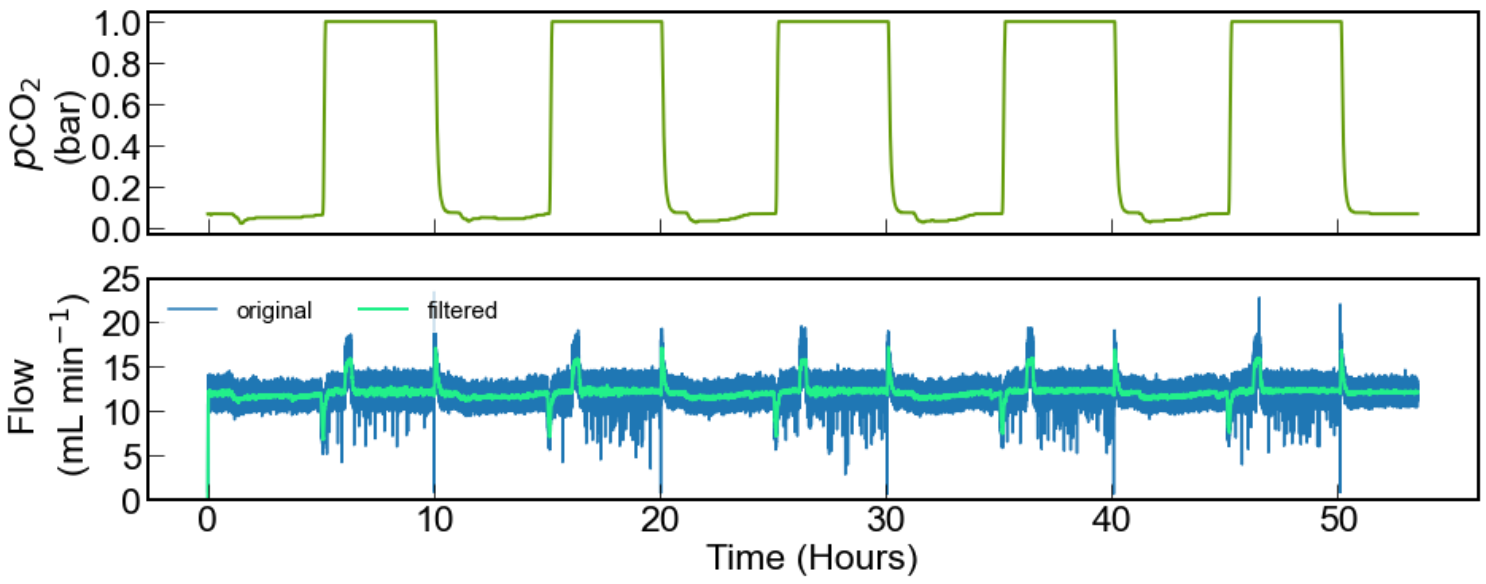

Fig. S 9| Five $\mathrm{CO}_{2}$ concentrating cycles with 0.05 bar inlet $p \mathrm{CO}_{2}$ and 1 bar exit $p \mathrm{CO}_{2}$ at $40 \mathrm{~mA} \mathrm{~cm}-2$. Same cell was used as in Fig. 2. Fresh negolyte and posolyte were used. The liquid pumping rate is $150 \mathrm{~mL} \mathrm{~min}^{-1}$, which is $50 \%$ faster than for capture at higher inlet pressure. a, Voltage profile. b, Current density. c, pH of the negolyte. $\mathbf{d}, \mathrm{N}_{2}$ and $\mathrm{CO}_{2}$ percentage in the upstream source gas, controlled by mass flow controllers. $\mathbf{e}, \mathrm{CO}_{2}$ partial pressure. $\mathbf{f}$, Total gas flow rate. 
a

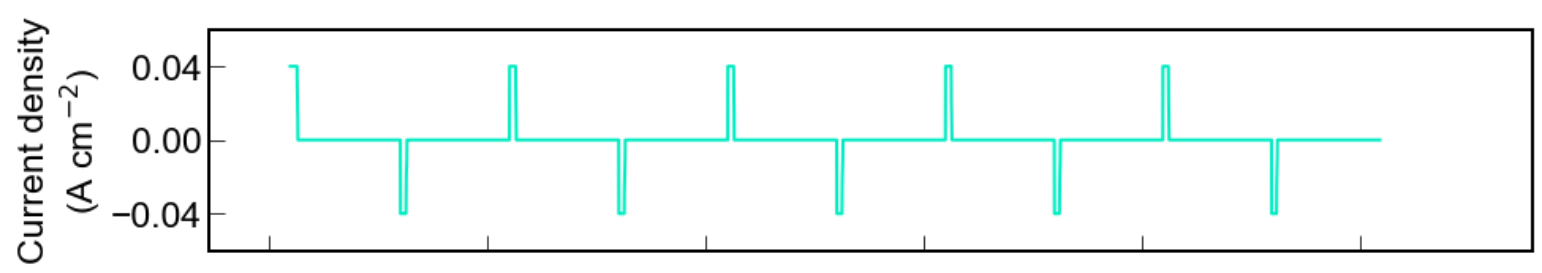

b

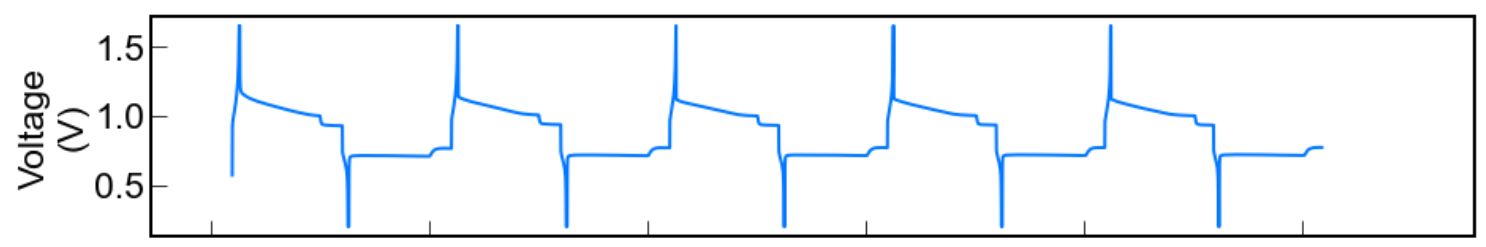

C

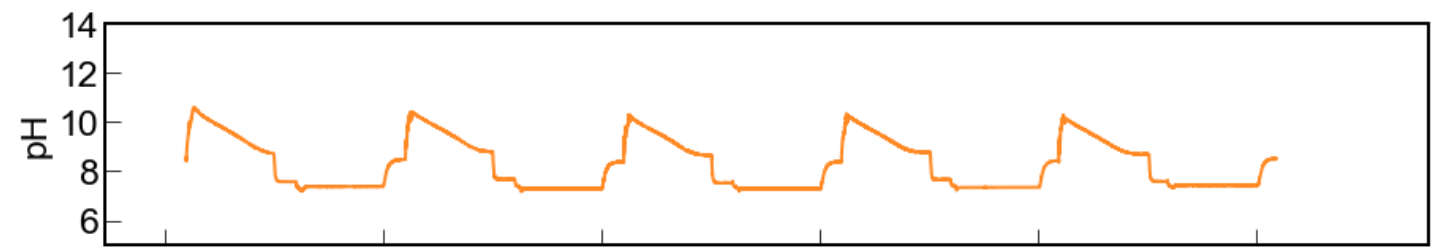

d

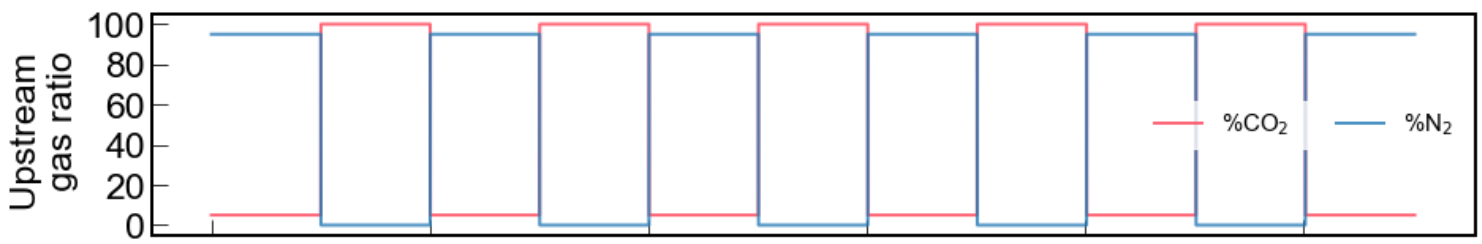

e

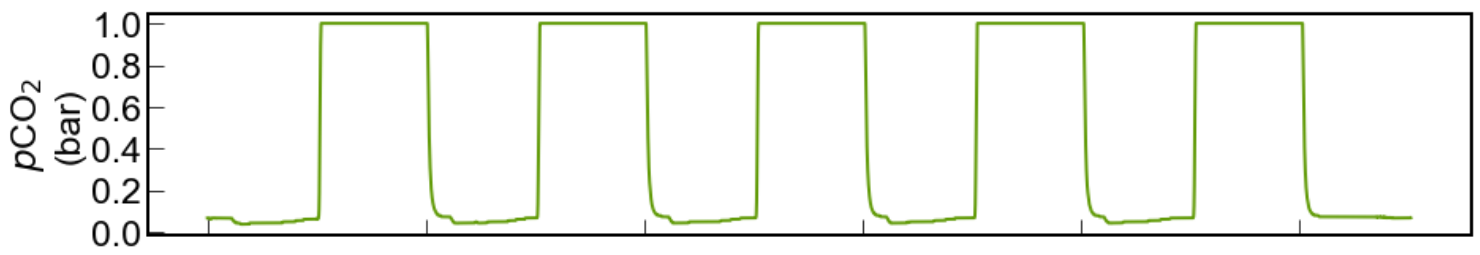

Fig. S 10| Post-electrochemical rebalancing $\mathrm{CO}_{2}$ capture with 0.05 bar inlet $p \mathrm{CO}_{2}$ and 1 bar exit $p \mathrm{CO}_{2}$ at $40 \mathrm{~mA}$

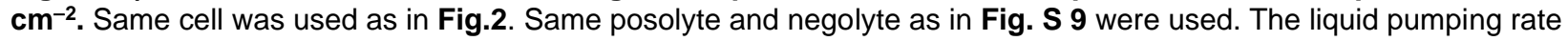
is $150 \mathrm{~mL} \mathrm{~min}{ }^{-1}$. a, Voltage profile. b. Current density. c, pH of the negolyte. d, $\mathrm{N}_{2}$ and $\mathrm{CO}_{2}$ percentage in the upstream source gas, controlled by mass flow controllers. e, $\mathrm{CO}_{2}$ partial pressure. $\mathbf{f}$, Total gas flow rate. The system has the same carbon capture/release capability after the post-electrochemical rebalancing. 
a

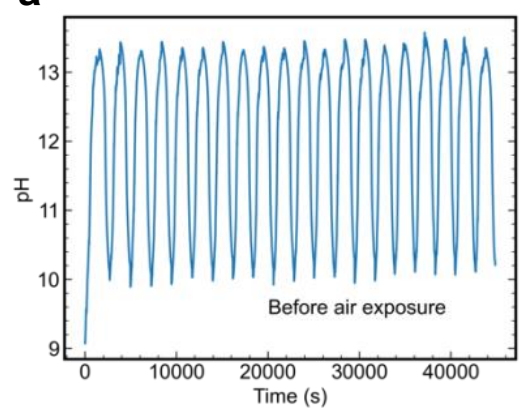

b

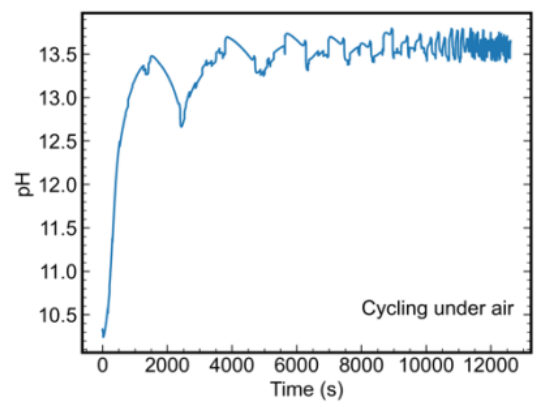

C

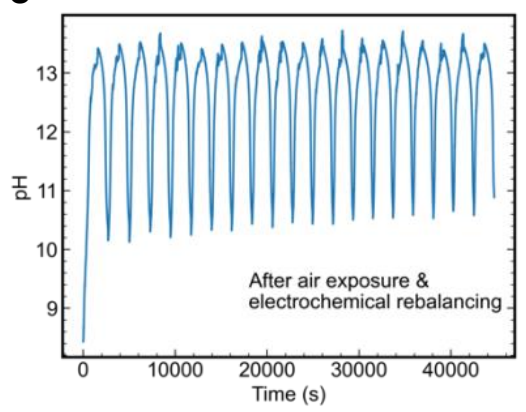

Fig. S 11| pH of the negolyte during cycles before air exposure (a), under air (b) and after electrochemical rebalancing (c), respectively. $\mathrm{pH}$ drifts up because of oxygen presence.

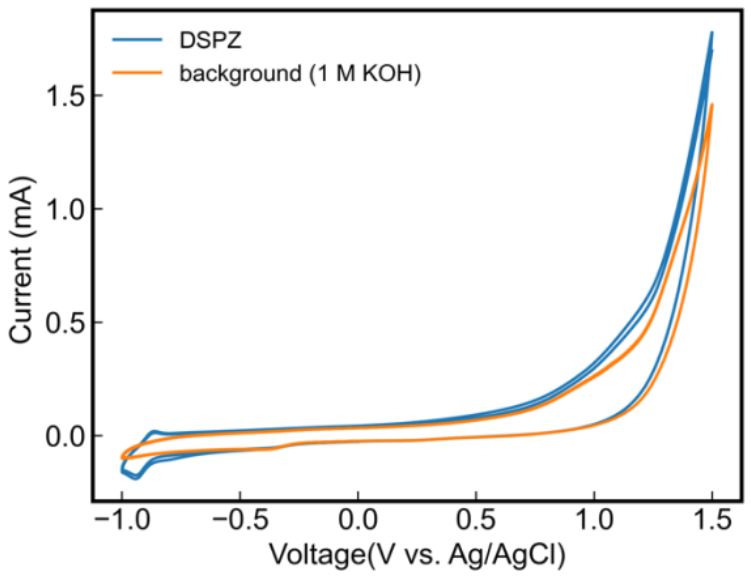

Fig. S 12| Cyclic voltammetry of DSPZ and $1 \mathrm{M} \mathrm{KOH}$ background. No additional peak was observed for DSPZ during the oxidative scan, indicating absence of side reactions.

Fig. 1b lists all the reactions related to carbon capture in our system. When all reactions involving $\mathrm{CO}_{2}$ are removed, the system is the same as an aqueous organic redox flow battery (AORFB). ${ }^{3-5}$ The electrochemical rebalancing method is also applicable to AORFB when there is an oxygen leakage. Fig. 6 demonstrates the application of the electrochemical rebalancing method in an AORFB and carbon capture flow cell, which both are organic PCET systems that have $\mathrm{pH}$ swing ranging from neutral to basic. Here we suggest that the electrochemical rebalancing method also applies to other aqueous based electrochemical systems, including organic and inorganic, PCET or non-PCET, acidic or basic, dissolved or solid redox active materials. If no side reaction is triggered by the oxidative voltage, which is the case for DSPZ as shown in Fig. S 12, the electrochemical rebalancing method can be applied. Here are several examples.

Organic Non-PCET system in neutral aqueous solution: $\mathrm{Fe}(\mathrm{CN})_{6}$ (posolyte) |Viologen (negolyte) Flow Battery

When the viologen-based redox flow battery ${ }^{6-8}$ is charged: oxygen can chemically oxidize the reduced viologen to the oxidized state, accumulating hydroxide in the negolyte, leading to the negolyte to discharged state and the posolyte active species maintaining the oxidized state. Because the redox active core of viologens have two positive charges, we denote their oxidized 
262 form as $\mathrm{Vi}^{2+}$ and the single-electron reduced form as $\mathrm{Vi}^{+}$. The negolyte side is discharged when 263 oxygen is present, i.e. :

Because the electrolyte of a vanadium redox flow battery is strongly acidic, the hydroxide is readily neutralized and forming water. Hence the oxidation reaction is the following:

$$
\frac{1}{2} \mathrm{O}_{2}+2 \mathrm{Vi}^{+}+\mathrm{H}_{2} \mathrm{O} \rightarrow 2 \mathrm{Vi}^{2+}+2 \mathrm{OH}^{-}
$$

The electrochemical rebalancing method can remove the accumulated hydroxide, repelling $\mathrm{O}_{2}$ in the negolyte reservoir:

$$
2 \mathrm{OH}^{-} \rightarrow \frac{1}{2} \mathrm{O}_{2}+\mathrm{H}_{2} \mathrm{O}+2 e^{-}
$$

During the electrochemical rebalancing process, the electrons are transferred to the posolyte side, which has accumulated $\mathrm{Fe}(\mathrm{CN}) 6^{3-}$, and eventually both negolyte and posolyte sides are recover the their initial composition, i.e. $\mathrm{Fe}(\mathrm{CN})_{6}{ }^{4-}$ in posolyte and $\mathrm{Vi}^{2+}$ in negolyte, rebalancing the system.

Inorganic Non-PCET system in strongly acidic aqueous solution: $\mathrm{VO}^{2+} / \mathrm{NO}_{2}{ }^{+}$(posolyte) $\mid \mathrm{V}^{3+} / \mathrm{V}^{2+}$ (negolyte) Flow Battery

When a vanadium redox flow battery ${ }^{9}$ negolyte contains the charged form, i.e. $\mathrm{V}^{2+}$ : if oxygen diffuses into the negolyte, it can chemically oxidize $\mathrm{V}^{2+}$ to $\mathrm{V}^{3+}$, and hydroxide is accumulated in the negolyte,

$$
\frac{1}{2} \mathrm{O}^{2}+2 \mathrm{~V}^{2+}+\mathrm{H}_{2} \mathrm{O} \rightarrow 2 \mathrm{~V}^{3+}+2 \mathrm{OH}^{-}
$$

The electrochemical rebalancing method can remove the accumulated hydroxide, repelling $\mathrm{O}_{2}$ :

$$
2 \mathrm{OH}^{-} \rightarrow \frac{1}{2} \mathrm{O}_{2}+\mathrm{H}_{2} \mathrm{O}+2 e^{-}
$$

$$
\frac{1}{2} \mathrm{O}_{2}+2 \mathrm{~V}^{2+}+2 \mathrm{H}^{+} \rightarrow 2 \mathrm{~V}^{3+}+\mathrm{H}_{2} \mathrm{O}
$$

Therefore, instead of generating two hydroxides in the negolyte, the oxidation by oxygen reaction causes the loss of two protons. And the electrochemical rebalancing method in such scenario is as follows:

$$
\mathrm{H}_{2} \mathrm{O} \rightarrow \frac{1}{2} \mathrm{O}_{2}+2 \mathrm{H}^{+}+2 e^{-}
$$

During the electrochemical rebalancing process, the electrons are transferred to the posolyte side, which has accumulated the oxidized form $\mathrm{VO}^{2+}$, through

$$
2 \mathrm{VO}^{2+}+2 e^{-} \rightarrow 2 \mathrm{VO}_{2}^{+}
$$

, and eventually both negolyte and posolyte sides are fully discharged $\left(\mathrm{VO}_{2}{ }^{+}\right.$in posolyte and $\mathrm{V}^{3+}$ in negolyte), thus rebalancing the system.

Inorganic Non-PCET system in basic aqueous solution: air (posolyte) $\mid S_{4}^{2-} / S_{4}^{4-}$ (negolyte) Battery

When a sulfur-air flow battery ${ }^{10}$ is charged: if oxygen diffuses into polysulfide negolyte, oxygen can chemically oxidize polysulfide, and hydroxide is accumulated in the negolyte, 
304 The electrochemical rebalancing method can remove the accumulated hydroxide, repelling $\mathrm{O}_{2}$ :

$2 \mathrm{OH}^{-} \rightarrow \frac{1}{2} \mathrm{O}_{2}+\mathrm{H}_{2} \mathrm{O}+2 e^{-}$

During the electrochemical rebalancing process, the electrons are transferred to the posolyte side externally, thus rebalancing the system.

Solid polyquinone Non-PCET system for carbon capture: LiFePO4 (cathode) | Polyquinone (anode)

Liu et al. ${ }^{11}$ demonstrated a solid quinone aqueous carbon capture system, where the cathode is $\mathrm{LiFePO}_{4}$ and the anode is polyquinone (PAQ) tethered to a carbon electrode. The authors utilized a 20 molal LiTFSI aqueous solution to ensure that the reduced PAQ are deprotonated, i.e. PAQ ${ }^{2-}$, which then binds with $\mathrm{CO}_{2}$ to form PAQ- $\mathrm{CO}_{2}$ adduct. Although the influence of oxygen in this system is rather small, but side reaction still happens and can cause long term imbalance (accumulation of oxidized cathode material and accumulated $\mathrm{LiOH}$ in the anode side).

When the anode is charged: oxygen can chemically oxidize the air-sensitive anode, and hydroxide is accumulated in the negolyte,

$$
\frac{1}{2} \mathrm{O}_{2}+\mathrm{H}_{2} \mathrm{O}+\mathrm{PAQ}^{2-} \rightarrow \mathrm{PAQ}+2 \mathrm{OH}^{-}
$$

The electrochemical rebalancing method can remove the accumulated hydroxide, repelling $\mathrm{O}_{2}$ :

$$
2 \mathrm{OH}^{-} \rightarrow \frac{1}{2} \mathrm{O}_{2}+\mathrm{H}_{2} \mathrm{O}+2 e^{-}
$$

During the electrochemical rebalancing process, the electrons are transferred to the cathode side externally, eventually both anode and cathode are discharged, rebalancing the system. 


\section{References}

1. Roy, R. N.; Roy, L. N.; Vogel, K. M.; Portermoore, C.; Pearson, T.; Good, C. E.; Millero, F. J.; Campbell, D. M., The Dissociation Constants of Carbonic Acid in Seawater at Salinities 5 to 45 and Temperatures 0 to $45^{\circ} \mathrm{C}$. Mar Chem 1993, 44 (2-4), 249-267.

2. Jin, S.; Wu, M.; Gordon, R. G.; Aziz, M. J.; Kwabi, D. G., pH swing cycle for $\mathrm{CO}_{2}$ capture electrochemically driven through proton-coupled electron transfer. Energy \& Environmental Science 2020, 13 (10), 3706-3722.

3. $\quad$ Hollas, A.; Wei, X. L.; Murugesan, V.; Nie, Z. M.; Li, B.; Reed, D.; Liu, J.; Sprenkle, V.; Wang, W., A biomimetic high-capacity phenazine-based anolyte for aqueous organic redox flow batteries. Nat Energy 2018, 3 (6), 508-514.

4. Jin, S.; Jing, Y.; Kwabi, D. G.; Ji, Y.; Tong, L.; De Porcellinis, D.; Goulet, M. A.; Pollack, D. A.; Gordon, R. G.; Aziz, M. J., A water-miscible quinone flow battery with high volumetric capacity and energy density. ACS Energy Letters 2019, 4 (6), 1342-1348.

5. Ji, Y.; Goulet, M. A.; Pollack, D. A.; Kwabi, D. G.; Jin, S.; Porcellinis, D.; Kerr, E. F.; Gordon, R. G.; Aziz, M. J., A phosphonate-functionalized quinone redox flow battery at near-neutral $\mathrm{pH}$ with record capacity retention rate. Advanced Energy Materials 2019, 9 (12), 1900039.

6. Beh, E. S.; De Porcellinis, D.; Gracia, R. L.; Xia, K. T.; Gordon, R. G.; Aziz, M. J., A Neutral pH Aqueous Organic-Organometallic Redox Flow Battery with Extremely High Capacity Retention. ACS Energy Letters 2017, 2 (3), 639-644. 7. Jin, S.; Fell, E. M.; Vina-Lopez, L.; Jing, Y.; Michalak, P. W.; Gordon, R. G.; Aziz, M. J., Near Neutral pH Redox Flow Battery with Low Permeability and Long-Lifetime Phosphonated Viologen Active Species. Advanced Energy Materials 2020, 10 (20), 2000100. 8. Luo, J.; Hu, B.; Debruler, C.; Bi, Y. J.; Zhao, Y.; Yuan, B.; Hu, M. W.; Wu, W. D.; Liu, T. L., Unprecedented Capacity and Stability of Ammonium Ferrocyanide Catholyte in $\mathrm{pH}$ Neutral Aqueous Redox Flow Batteries. Joule 2019, 3 (1), 149-163.

9. Mena, E.; Lopez-Vizcaino, R.; Millan, M.; Canizares, P.; Lobato, J.; Rodrigo, M. A., Vanadium redox flow batteries for the storage of electricity produced in wind turbines. International Journal of Energy Research 2018, 42 (2), 720-730.

10. Li, Z.; Pan, M. S.; Su, L.; Tsai, P. C.; Badel, A. F.; Valle, J. M.; Eiler, S. L.; Xiang, K.; Brushett, F. R.; Chiang, Y. M., Air-Breathing Aqueous Sulfur Flow Battery for UltralowCost Long-Duration Electrical Storage. Joule 2017, 1 (2), 306-327. 11. Liu, Y.; Ye, H.-Z.; Diederichsen, K. M.; Voorhis, T. V.; Hatton, T. A., Electrochemically mediated carbon dioxide separation with quinone chemistry in saltconcentrated aqueous media. Nature Communications 2020, 11, 2278. 